\title{
WestVirginiaUniversity
}

THE RESEARCH REPOSITORY @ WVU

Graduate Theses, Dissertations, and Problem Reports

2013

\section{Three Essays on Forecasting in Nonlinear Models}

Scott T. Murdoch

West Virginia University

Follow this and additional works at: https://researchrepository.wvu.edu/etd

\section{Recommended Citation}

Murdoch, Scott T., "Three Essays on Forecasting in Nonlinear Models" (2013). Graduate Theses,

Dissertations, and Problem Reports. 531.

https://researchrepository.wvu.edu/etd/531

This Dissertation is protected by copyright and/or related rights. It has been brought to you by the The Research Repository @ WVU with permission from the rights-holder(s). You are free to use this Dissertation in any way that is permitted by the copyright and related rights legislation that applies to your use. For other uses you must obtain permission from the rights-holder(s) directly, unless additional rights are indicated by a Creative Commons license in the record and/ or on the work itself. This Dissertation has been accepted for inclusion in WVU Graduate Theses, Dissertations, and Problem Reports collection by an authorized administrator of The Research Repository @ WVU.

For more information, please contact researchrepository@mail.wvu.edu. 
Three Essays on Forecasting in Nonlinear Models

Scott T. Murdoch

Dissertation submitted to the

College of Business and Economics

West Virginia University

in fulfillment of the requirements

for the degree of

Doctor of Philosophy

in

Economics

Stratford Douglas, Ph.D., Chair

Arabinda Basistha, Ph.D.

Naomi Boyd, Ph.D.

George Hammond, Ph.D.

Feng Yao, Ph.D.

Department of Economics

Morgantown, West Virginia

2012

Keywords: Nonlinear Models; Neural Networks; GARCH; STAR

Copyright 2012 Scott T. Murdoch 


\section{Abstract \\ Three Essays on Forecasting in Nonlinear Models}

Scott T. Murdoch

Nonlinear models have many applications in the economic and financial fields. The following works focus on their use for forecasting. Neural networks, in conjunction with an Affine Term Structure Model, are used to discover possible yield curve arbitrage opportunities. A G/ARCH model is employed to test and forecast the conditional variance of state-level employment growth. A Space-Time Autoregressive (STAR) model is applied to state employment growth to ensure that any measure of volatility in the series is not misdirected as employment movements between neighboring states. 


\section{Contents}

Introduction iv

\begin{tabular}{lll|}
\hline 1 & NN Approach Yield Curve Arbitrage & 1
\end{tabular}

1.1 Review of the Literature . . . . . . . . . . . . . . . . . 2

1.2 Empirical Analysis . . . . . . . . . . . . . . . . . . . . 4

1.2.1 ATSM Architecture . . . . . . . . . . . . . . . . . . 4

1.2 .2 Basic Neural Network . . . . . . . . . . . . . 6

1.2 .3 Neural Network Architecture. . . . . . . . . . . . . . 7

1.3 Empirical Model and Results . . . . . . . . . . . . . . . . . . 11

1.3 .1 Data . . . . . . . . . . . . . . . . . 11

1.3 .2 Empirical Results . . . . . . . . . . . . . . . . . . . . 12

1.4 Conclusion . . . . . . . . . . . . . . . . . . . . . . . . . . 22

1.5 Appendix A: Additional Tables . . . . . . . . . . . . . . . 23

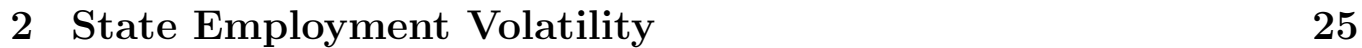

2.1 Review of the Literature . . . . . . . . . . . . . . . . . . . 25

2.2 Empirical Analysis . . . . . . . . . . . . . . . . . . . . 27

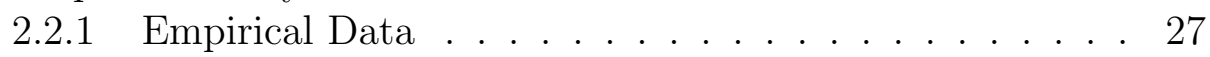

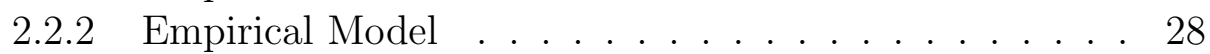

$2.2 .3 \quad$ ARCH Length Specification Algorithm . . . . . . . . . 30

2.3 Results of Empirics . . . . . . . . . . . . . . . . . 33

2.4 Conclusion $\ldots \ldots \ldots \ldots \ldots$. . . . . . . . . . . . . . . . . . . 45

2.5 Appendix A: Additional Tables . . . . . . . . . . . . . . . 46

3 State Spatial Employment Volatility 50

3.1 Review of the Literature . . . . . . . . . . . . . . . . . . 51

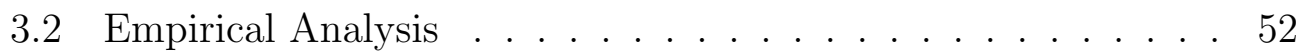

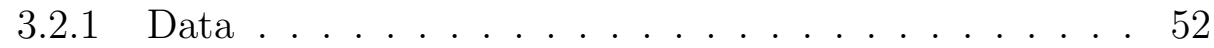

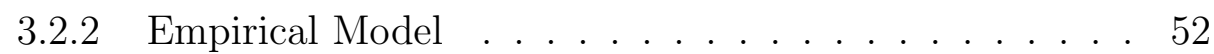

3.3 Results of Empirics . . . . . . . . . . . . . . . . . . . . 54

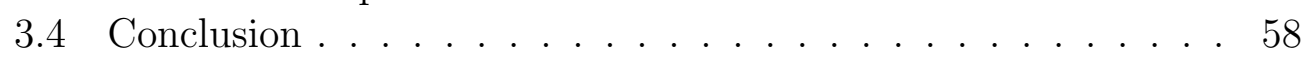




\section{Introduction}

In today's economy, forecasting is both an art and a science. The science side deals with the analytical modeling of economic and financial variables such as employment, personal income, interest rates, and countless others. The art side addresses the deficiencies in the current knowledge in scientific modeling. This is rhythmically seen in the relationship between variables; the structural relationship between variables is often nonlinear. The variables and structure of regression equation(s) used in forecasting are ultimately up to the forecaster.

The essays that follow focus on the scientific side of forecasting; in particular, model methodology. The initial argument for an increased understanding in forecast modeling is to lower the mean squared error (MSE) of the forecast residuals. The argument, while valid, is misleading. The reason for improving a forecast is not for the forecast's sake; it is to have a better and more certain understanding of the future. For example, if one discovers a revolutionary employment forecasting model, the average MSE may be reduced by one half; however, the value added by the revolution is so the individual can make more informed decisions about future employment. Improved decisionmaking is the ultimate goal. Throughout the three subsequent essays the main focus at times may be perceived as MSE reduction, but in fact is just a tool used for the bigger picture.

The first chapter centers around the prediction of yield curve arbitrage opportunities. The point of convergence of these opportunities is the difference between the estimated Affine Term Structure Model and realized yield curve. Affine Term Structure Model (ATSM) generates a yield curve constructed under a no-arbitrage assumption, it assumes markets are efficient. Discovering yield curve arbitrage can be achieved by comparing the yield curve constructed by the ATSM and the realized yield curve. If the curves differ then there are arbitrage opportunities available for exploitation. However, given the speed of global markets, arbitrage opportunities disappear almost instantaneously. Therefore, the most profitable form of arbitrage is to have a landscape of future opportunities. 
Unfortunately, one of the major downfalls of ATSM's is poor out-ofsample forecast performance. The unknown precise relationship between yields to maturity of different terms is undoubtedly one of the largest factors in forecast performance. To address this problem, neural networks will be tested for prediction; one of the key strengths of neural networks is finding relationships among variables when an exact mathematical relationship is unknown. Neural networks are used to forecast both the Affine Term Structure Model curve and the actual yield curve.

The second chapter centers on the structure of state-level employment volatility; assessing whether the conditional variance is anything other than a white noise process. If the assumption of independently and identically distributed errors (iid) is violated, what is the correct structure of the error? The degree of erroneousness in the conditional variance will be tested using methods described in Engle (1982). If the assumption is violated the biased portion of the MSE will be nonzero. The correct specification of the conditional variance would minimize the bias term to zero or at a minimum decrease the magnitude of the term.

The "optimal" volatility structure, if ARCH effects are shown to be present, will be determined by an algorithm described by Figures $2.1 \& 2.2$. The chapter ends by comparing the forecast error, both the Mean Squared Error and Percent Forecast Error, of the volatility structure using the ARCH specification algorithm, a $\operatorname{GARCH}(1,1)$ process, and white noise estimation for each state.

The final chapter serves as an extension of the second. The purpose of this chapter is to examine if the findings of Chapter 2 hold when accounting for spatial spillover effects. If ARCH effects are shown to be present, these effects could be misclassified as changes in employment growth from neighboring states.

Furthermore, the effects of the 'Great Moderation' on the conditional variance for each state are examined. The 'Great Moderation' refers to the reduction in the variance, or volatility, of real U.S. GDP growth due to the Federal Reserve policy changes. The chapter will conclude by comparing the number of the states that display ARCH effects accounting for spatial spillovers and the 'Great Moderation.' 


\section{Chapter 1}

\section{Neural Network Approach to Yield Curve Arbitrage}

Hedge funds and other investment firms seek out arbitrage opportunities to increase their own and their clients' wealth with as little risk as possible. However, it can be seen from the demise of Long Term Capital Management, and more recently, large losses written off by investment banks due to the default subprime lending market. That there is room for improvement in modeling arbitrage opportunities.

Intelligence algorithms are being used more frequently outside of the artificial intelligence field mainly because of their adaptability. Intelligence algorithms attempt to model the human thought process and human logic, and are more flexible than traditional algorithms. This paper focuses on the performance of integrating intelligence algorithms with traditional methods: in particular Affine Term Structure Models (ATSM) of discovering yield curve arbitrage opportunities.

The set of intelligence algorithms discussed in this paper are neural networks. Neural networks (NN) are useful when the relationships between variables are unknown. The criticism of neural networks is that they are a so-called 'Black Box,' meaning it is unknown to the user what exactly the procedure is doing. However, while there is some validity to this criticism, this criticism is also an over-simplification. Neural networks are a nonparametric technique, which differs from regression analysis used in traditional economic and finance studies.

The neural networks illustrated here can be explained in relation to a classical regression setting, refer to Section 1.2.2. These networks will be used for out-of-sample forecasting for both the actual yield curve and the curve estimated by ATSM. Additionally, neural networks with only autoregressive terms and a network with macroeconomic variables in addition to the au- 
toregressive terms will be tested. The design being that the macroeconomic variables should increase the forecast accuracy.

The remainder of this paper is structured as follows. The next section reviews the literature; followed by a characterization of the intelligence algorithms. After the description of the model structure the empirical results are presented.

\subsection{Review of the Literature}

The type of integration between yield curve arbitrage and intelligence algorithms discussed in this paper is not discussed in any great detail in the past literature. There are several articles that aided in the integration between these methods, which can be divided into two subsets; articles that deal with yield curve arbitrage and that deal with intelligence algorithms. There are several articles in the finance literature that use intelligence algorithms with basic finance concepts. In these types of articles neural networks are often used for predicting a variable that has unknown relationship(s) with other variable $(\mathrm{s})$.

One of the most comprehensive articles on arbitrage opportunities is Duarte, Longstaff, and $\mathrm{Yu}$ (2007). It discusses five different forms of fixed income arbitrage and whether these arbitrage methods provide significant excess returns. It finds that yield curve, mortgage, and capital structure arbitrage provide significant excess returns because they require the most 'intellectual capital.' In other words, finding arbitrage opportunities in these three markets requires significant knowledge, which creates a barrier to entry. These three forms of arbitrage produce excess returns even after accounting for transaction costs (including a 2/20 hedge fund fee), and market risk.

Of the three forms of arbitrage that demonstrate excess returns, yield curve arbitrage is the most accessible for this study. The yield curve arbitrage involves comparing the yields from an Affine Term Structure Model with the actual yields and is the form of arbitrage that is focused on in the remainder of this paper. Mortgage arbitrage is relevant given the current state of the market and introduces an interesting dynamic due to the fact that the borrowers (households) can pay loans back before they are due. This has the possibility of disturbing the lenders cash flow, adding uncertainty on the lender's end. Capital structure arbitrage is relatively new form of arbitrage that involves looking at the differences between a company's debt and its assets, such as equity. Yield curve arbitrage was chosen for this study because of the relevant ease of accessibility compared to the other two forms; however, the integration of intelligence algorithm(s) can be applied to any 
form of the arbitrage given the proper methodology and data.

Extending the discussion of yield curve arbitrage, Dai and Singleton (2000) discuss the technique of Affine Term Structure Models (ATSMs) and some goodness-of-fit measures for evaluating ATSMs performance. Affine Term Structure Models are a way of modeling the price of a zero-coupon bond. ATSM's carry the assumption of no arbitrage, or in other words, markets are assumed to be efficient. The ATSM model, in particular Vasicek, is formulated for efficient markets. If the ATSM yield curve does not perfectly fit the actual yield curve then there are arbitrage opportunities available, because the actual yield curve is in a inefficient market structure. This formulation is presented in 1.3.2. The instantaneous interest rates are given by a linear or 'affine' function that is made up of $\mathrm{N}$ unobserved state variables. The state variables are assumed to follow a Brownian motion. A factor in an Affine Term Structure Model is a particular term-to-maturity, for example a 10-year bond.

The number of factors in an ATSM is equal to the number of unobserved state variables. Solving an ATSM requires solving the differential equations of the corresponding unobserved state variable such that the past prices of the state variable are perfectly fitted by the model. The coefficients determined in each of the state variables are used to calculate the prices of other termsto-maturity (TTM) bonds that are not included in the factors. For example, if you have a two factor ATSM that fits the prices of a 6-month and 5year TTM perfectly, you would use the coefficients found in the differential equations of these yields to find prices a of 1-year bond, 2-year bond, etc.

On the intelligence side, Amilon (2003) discuss a neural network approach to pricing options and compares this approach to the traditional BlackScholes method. The results of this paper are that the neural network approach, on the whole, outperform the Black-Scholes method. However, not all of the results were statistically significant at the $5 \%$ level. Anders, Korn, and Schmitt (1998) also show statistically significant results that a neural network approach to pricing options outperforms the traditional Black-Scholes. The interesting point of their study is the variables used in the neural networks. The neural networks, in addition to using the past prices such variables like the stock price over the option strike price, the time to maturity, 30 day standard deviation, Black-Scholes, and DAX volatility index are used as input variables. The data used in this study was call options for 30 of the largest German companies from January 1992 to December 1994. The authors used statistical inference to test performance of the neural networks specification versus the Black-Scholes. All four of the neural network specified in this article outperform the Black-Scholes in terms of RMSE for both in-sample and out-of-sample. 


\subsection{Empirical Analysis}

The empirical analysis is intertwined between estimating a no-arbitrage yield curve and forecasting with neural networks. To illustrate the global model it is best, at the beginning, to separate the analysis into two parts. A detailed description of the ATSM estimation is presented in Section 1.2.1. The architecture of the neural network system is discussed in Section $[1.2 .2$ \& 1.2 .3 .

\subsubsection{ATSM Architecture}

The term structure model chosen for this study is a two factor Vasicek Model, refer to Vasicek (1977). The instantaneous interest rate is given by the Ornstein-Uhlenbeck process:

$$
\begin{array}{r}
d r=\alpha_{i}\left(\gamma_{i}-r\right) d t+\rho_{i} d z \\
a_{i, t}=\gamma_{i}+\left(r(t)-\gamma_{i}\right) e^{-\alpha_{i} \Delta} \\
\sigma_{i, t}^{2}=\frac{\rho_{i}^{2}}{2 \alpha_{i}}\left(1-e^{-2 \alpha_{i} \Delta}\right)
\end{array}
$$

Where Equation $\mathbf{1 . 2} \& \mathbf{1 . 3}$ are the conditional expectation and conditional variance of the Ornstien-Uhlenbaeck process given by equation 1.1. There is a set of the above equations for each factor or yield solved for; and the unknown variables are $\alpha_{i}, \rho_{i}$, and $\gamma_{i}$. In equation 1.1, $\alpha_{i}\left(\gamma_{i}-r\right)$ is the drift term, $\alpha_{i}$ is coined the elastic random walk or speed of reversion (term). $\gamma_{i}$ is often called mean reversion or long-term mean. The instantaneous variance is represented by $\rho_{i}^{2}$. The multi-factor version of equation (1.1) can be demonstrated as follows:

$$
\left(\begin{array}{c}
r_{1, t} \\
r_{10, t}
\end{array}\right)=\left(\begin{array}{cc}
\alpha_{1}\left(\gamma_{1}-r_{1, t}\right) & 0 \\
0 & \alpha_{10}\left(\gamma_{10}-r_{10, t}\right)
\end{array}\right) d t+\left(\begin{array}{cc}
\rho_{1} & 0 \\
0 & \rho_{10}
\end{array}\right)\left(\begin{array}{c}
d z_{1} \\
d z_{10}
\end{array}\right)
$$

In the above example, the ordinary differential equations (ODEs) are for a 1 and 10 year bond. This is an example of a two-factor model because there is two yields being solved. The unknown variables in the ordinary differential equations (ODEs) are solved through a maximum likelihood estimation (MLE). When the estimation is complete and the parameters of the ODEs are known, the ASTM curve should fit the realized yields perfectly for each factor, which in this case is a 1 and 10 year bond. The known parameters are then held constant and used to unravel the ODEs for yields of bonds with different terms to maturity. For example, the six parameters estimated by 
the two-factor model above could be used to construct a no-arbitrage yield curve with terms to maturity such as 3-month, 6-month, 1 year, 2 year, 5 year, and 10 year.

As stated before, the yields for the 1 and 10 year bonds will be the same as the realized yield curve. However, if there are discrepancies between the affine term structure model yield curve and the realized yield curve for some term to maturity (TTM), then there may be arbitrage opportunities that can be exploited. If the estimated ATSM curve is accurate, once the market clears, the yield curve will reach the same point as the ATSM curve. A point on the ATSM curve where the yield is higher than the realized yield curve, one could formulate an arbitrage profit by buying the asset(s) and holding it until the time where the realized yield curve moves up to the ATSM curve. Conversely, if the realized yield curve is higher than the ASTM curve it is possible to make an arbitrage profit by short selling the asset.

While this method for ascertaining yield curve arbitrage is useful, the arbitrage possibilities are given in the current period. Given the computational time for ATSMs and the speed of global markets it is possible that the arbitrage opportunities realized will disappear by the time that they would have been discovered. Therefore, the most constructive use of the Affine Term Structure Model is to forecast it forward. If a forecast of the ATSM yield curve and a forecast of the realized yield curve were available, one would be able to exploit arbitrage opportunities of the future. However while ATSM forecasts traditionally perform well in-sample, they do not perform well outof-sample 1 Since practitioners don't have much use for arbitrage opportunities that have passed, the out-of-sample forecast performance is the most important.

The next step of this empirical model is to forecast both yield curves, actual and ASTM, and then judge the accuracy of the forecast. If the outof-sample performance is established to be satisfactory, then the forecast can be used to predict changes in both the ATSM curve and the expected yield curve. If one knows the direction and magnitude of change in these two curves, one can exploit future arbitrage opportunities before they are realized and/or vanish.

One of the reasons for this poor out-of-sample performance of the ATSMs may be the term structure of interest rates. There are four main theories on the term structure of interest rates, which make different arguments for the curvature of the yield curve. The four main theories of term structure usually

\footnotetext{
${ }^{1}$ Special thanks to Dr. Egorov, while at West Virginia University, for helping with yield curve arbitrage modeling and data. After discussing yield curve arbitrage with him, I found out that Affine Term Structure Models perform well in-sample, but not out-ofsample.
} 
considered are: expectations, liquidity premium, market segmentation, and preferred habitat theory.

Given the fact that none or all of these theories could be true during a given time period; it is rather difficult to model the term structure of interest rates. For example, in the short run the preferred habitat or market segmentation theory may be the best explanation for changes in the yield curve, while the expectations and/or liquidity premium theory may be a better explanation for long-term movements in the yield curve. Incidentally, the distinction between these theories makes it very difficult to choose a single correct model for forecasting the yield curve.

\subsubsection{Basic Neural Network}

There are many different types of neural networks. The optimal network type and structure are dependent on the relationship between the input variables. For example, some neural networks are used primarily for pattern recognition; others are used primarily for model estimation, and some are used for both. Neural networks are used for the purpose of modeling when the mathematical relationship between inputs and the output(s) is unknown or undefined. This is advantageous when forecasting of Affine Term Structure Models since the forward-looking relationship within the yield curve has inconsistent definitions.

One of the most famous neural networks is the backpropagation or feedforward network. The backpropagation neural network is a multiple layer network. Figure 1.1 graphically illustrates a basic network with one hidden layer $2^{2}$ The first layer is the input layer, represented by $x_{1 \ldots n}$. The number of nodes in the input layer is equal to the number of inputs the user believes is necessary to reach the desired output(s). The subsequent layer(s) are hidden layer(s), $z_{1 \ldots p}$, where the connections between different inputs are found through a recursive algorithm. There is a weight associated with each node, or unit, when connecting to a layer. The final layer of the network is the output layer, $y_{1 \ldots m}$. The nodes on the side, represented by $w_{01} \& v_{01}$. are known as the bias. The bias is commonly identified with the intercept in regression analysis; it can be seen as a garbage collector.

The inputs $x_{1 \ldots n}$ are the exogenous variables, similar to the right hand side (RHS) variables of a traditional regression. Each input node represents a single input value. For example, it could be the first autoregressive lag for a 3-month yield during January 1995 (i.e. December 1994). If the second

\footnotetext{
2 Figure 1.1, and Algorithms 1 \& 2 are cited from Fausett $(1993)$. Please refer to Chapter 6 for greater detail on other variations on backpropagation networks.
} 
and third AR lags are included, there would be two more nodes. The target in this case would be the actual 3-month yield for January 1995. The node in the output layer represents the estimated 3-month yield, similar to the $\hat{y}$ of an OLS regression.

The variables and terminology used for the backpropagation training algorithm are defined in Table 1.1. The input vector $x$ will include all independent variables at a specific point in time for each iteration, call it time $r$. The target vector $t$ represents the dependent variable, at time $\mathrm{r}$ per iteration. The output vector represents the final estimates, $\hat{y}$. The weight vectors $v \&$ $w$ are randomly initialized.

Algorithm 1 illustrates the training methodology for backpropagation; Algorithm 2 illustrates the method of inputing new data once the network has been trained. The next section illustrates a time-series variation of the neural network described here.

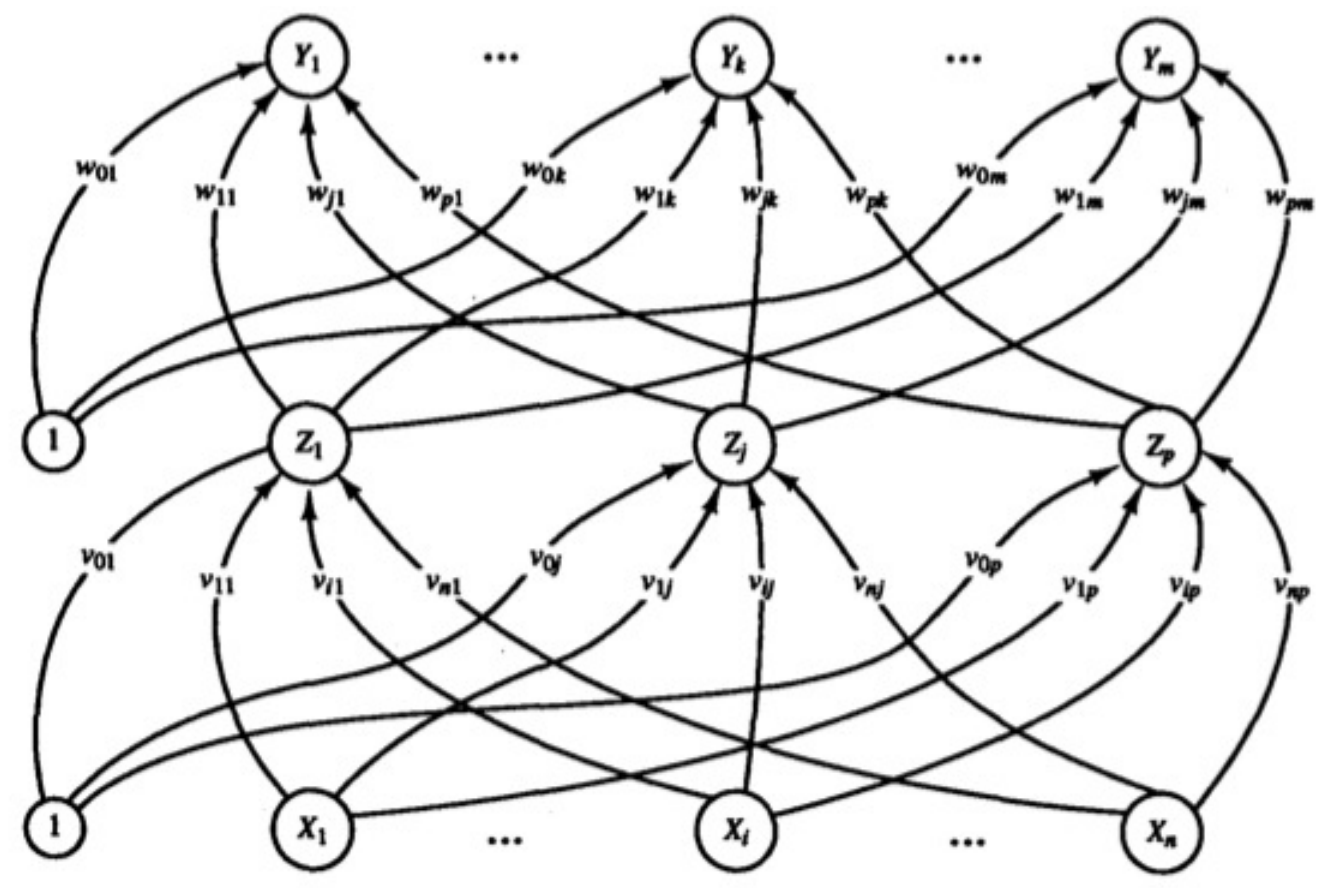

Figure 1.1: Standard Backpropagation Network with 1 Hidden Layer

\subsubsection{Neural Network Architecture}

The two main types of neural networks will enter the discussion here; the nonlinear autoregressive (NAR) and nonlinear autoregressive with exogenous 
Table 1.1: Variables \& Definition for Backpropagation Training Algorithm, with 1 hidden layer ${ }^{2}$

\begin{tabular}{|c|c|}
\hline$x=\left[x_{1}, \ldots, x_{n}\right]$ & Inputs \\
\hline$t=\left[t_{1}, \ldots, t_{m}\right]$ & Targets \\
\hline$z=\left[z_{1}, \ldots, z_{p}\right]$ & Hidden Nodes \\
\hline$v=\left[v_{01}, \ldots, w_{j k}, \ldots, w_{n p}\right]$ & $\begin{array}{l}\text { Weights for hidden layer } \\
\text { from input layer. Note: } v_{01} \\
\text { is the bias for the hidden } \\
\text { layer. }\end{array}$ \\
\hline$w=\left[w_{01}, \ldots, w_{i j}, \ldots, w_{p m}\right]$ & $\begin{array}{l}\text { Weights for output layer } \\
\text { from hidden layer. Note: } \\
w_{01} \text { is the bias for the out- } \\
\text { put layer. }\end{array}$ \\
\hline$\delta$ & $\begin{array}{l}\text { Error: } \delta_{k} \& \delta_{j} \text { denotes the } \\
\text { errors associated with the } \\
\text { weights on output node } k \\
\text { and hidden node } j \text {, respec- } \\
\text { tively. } \delta \text { represents the total } \\
\text { error. }\end{array}$ \\
\hline$y=\left[y_{1}, \ldots, y_{q}\right]$ & Output(s) \\
\hline$\eta$ & $\begin{array}{l}\text { Learning rate, which is the } \\
\text { rate at which weights can be } \\
\text { adapted. }\end{array}$ \\
\hline$f(x)$ & $\begin{array}{l}\text { Activation function for hid- } \\
\text { den layer }\end{array}$ \\
\hline$g(x)$ & $\begin{array}{l}\text { Activation function for out- } \\
\text { put layer. The symbol } \\
\text { primary ' denotes the first } \\
\text { derivative }\end{array}$ \\
\hline$\xi$ & $\begin{array}{l}\text { Error tolerance, as defined } \\
\text { by user }\end{array}$ \\
\hline
\end{tabular}




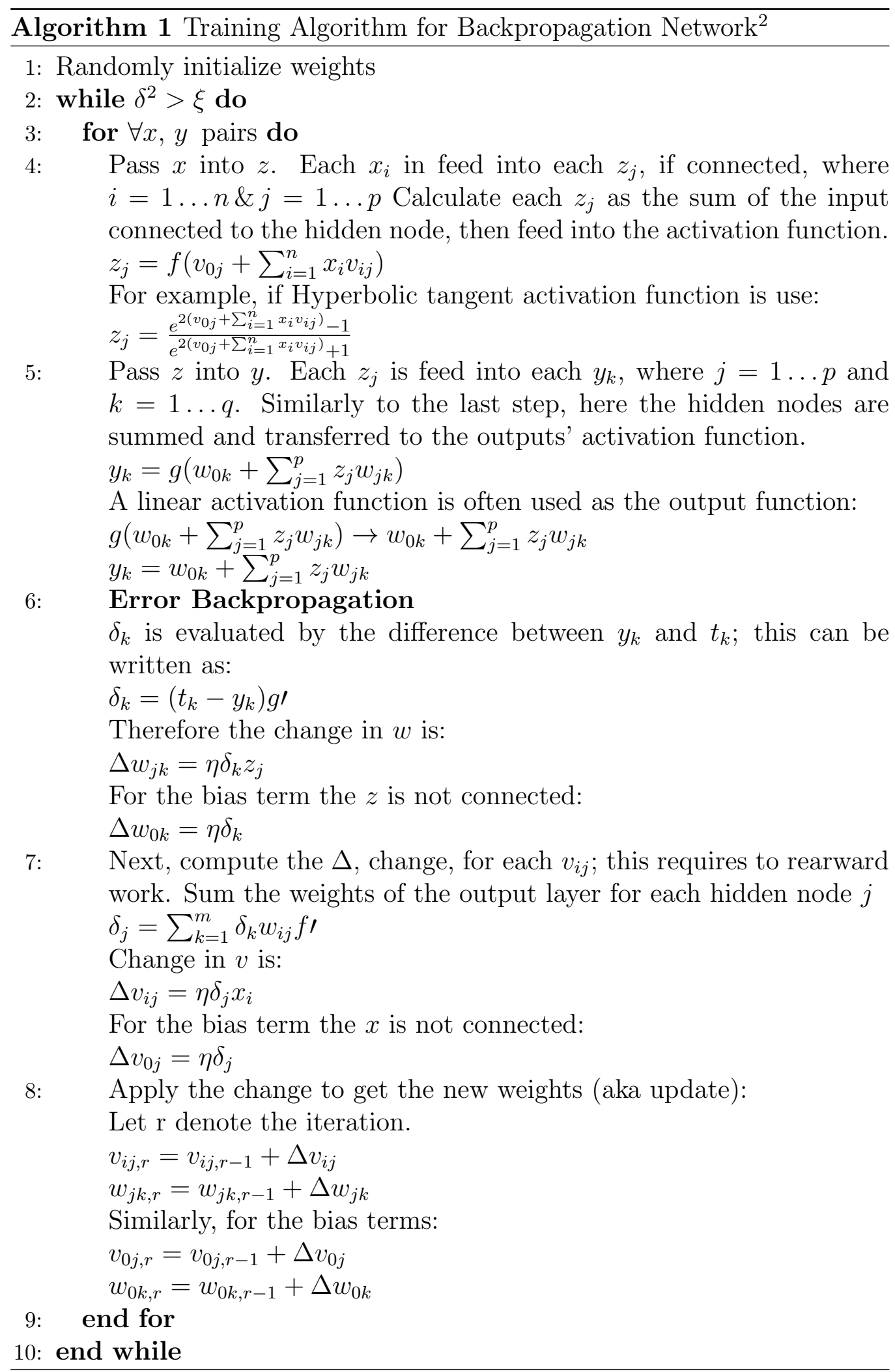




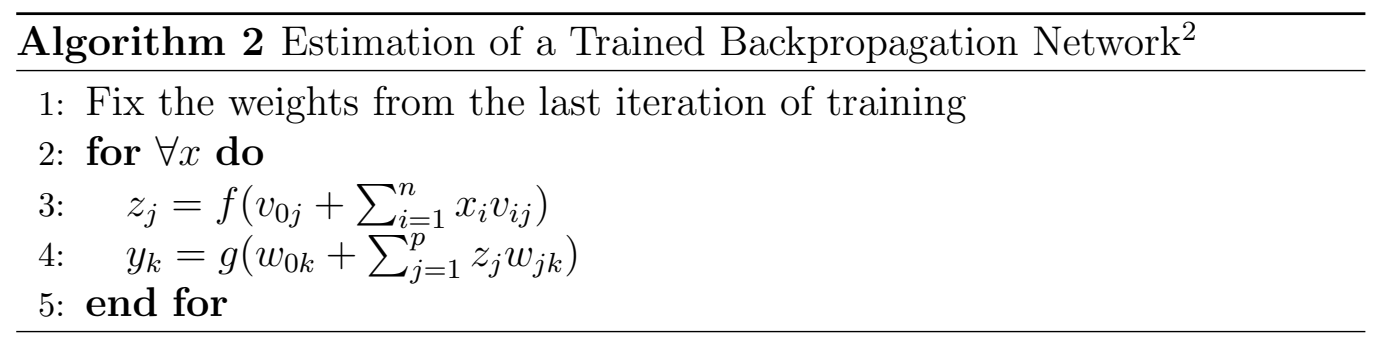

variables (NARX). The NARX network will be used for forecasting that includes macroeconomic variables, while the NAR does not ${ }^{3}$

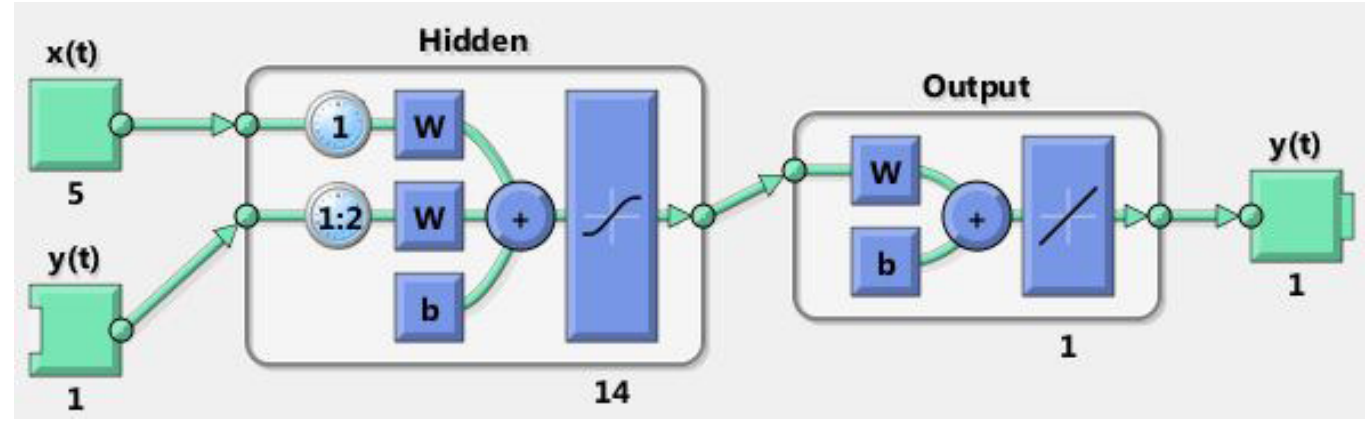

Figure 1.2: Example of a Open NARX Network

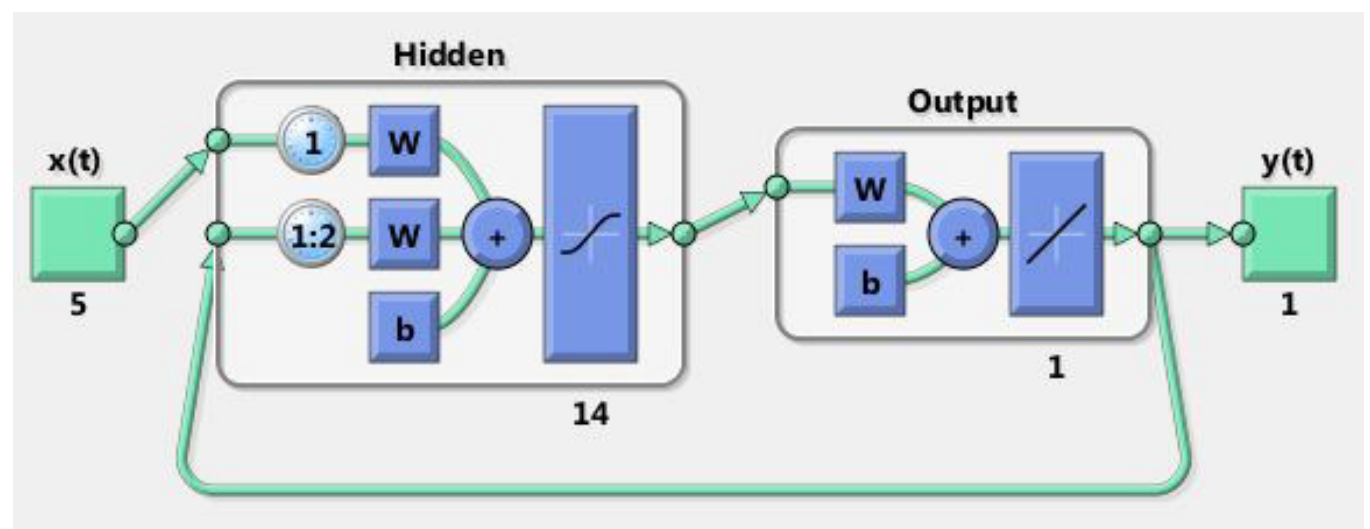

Figure 1.3: Example of a Close (Out-of-Sample) NARX Network

\footnotetext{
${ }^{3}$ It should be noted that all of the neural networks solved in this paper are done using the neural network toolbox in MATLAB. Additionally, the nonlinear autoregressive with exogenous variables network function is NARXNET, while the nonlinear autoregressive network is NARNET.
} 
Figure 1.2 gives a visual representation of a NARX network. This is an 'Open Loop' network, which means the network is being trained. This is analogous to Algorithm 1. The $x(t)$ refers to the exogenous variables, while $y(t)$ refers to the autoregressive terms of output. That is why $y(t)$ is displayed as an input and output. The input layer uses the $1^{\text {st }} \& 2^{\text {nd }}$ lags of the yield being estimated and the $1^{\text {st }}$ lag of the exogenous data. Each yield for both the ASTM and realized curve will be modeled using their own network, univariately.

Figure 1.3 gives a visual of "Close Loop" form. This is an out-of-sample forecast configuration and analogous to Algorithm 2, Notice the feedback loop at the bottom of the diagram. This is to illustrate that the output at time $t$ is used as an autoregressive input during at time $t+1$.

\subsection{Empirical Model and Results}

The data used for modeling and the results of that data using the above methodology are presented.

\subsubsection{Data}

The data is split into two categories, the yield curve and macroeconomic variables. The yield curve data used for the remainder of this chapter is the same data used in Duffee (2002). 4. This data has a long-standing history and wide acceptance, which was the main driver for using it in this study. The data from January 1952 to 1991 is from Mculloch and Kwon (1993). A subset of this dataset, before 1983, was taken from McCulloch (1990) in the Handbook of Monetary Economics. All these datas were gleaned using the methodology of McCulloch (1975) . The methodology uses a cubic spline discount function that is adjusted for tax. The price for a Treasury Bill is given in equation 1.5. where $\mathrm{p}$ is the price, $\mathrm{t}$ is the tax rate, and $\delta(m)$ is the discount function. The discount function, displayed in equation $\mathbf{1 . 6}$, follows a cubic spline.The data used after February 1991 is from Bliss (1997), whom also follows McCulloch (1975).

$$
p=[100(1-t)+t p] \delta(m)
$$

\footnotetext{
${ }^{4}$ This data was provided by Dr. Egorov and was downloaded from Gregory R. Duffee's, Ph.D website. Click here for link.
} 


$$
\delta(m)=1+\sum_{k}^{j=1} a_{j} f_{j}(m)
$$

$$
\text { Each } f_{j}(m) \text { need to satisfy } f_{j}(0)=0
$$

The zero-coupon yield curve estimated cited by Duffee (2002) includes 6 different terms to maturity 3-month, 6-month, 1 year, 2 year, 5 year, and 10 year. Each term includes monthly yields to maturity from January 1952 to December 1998. The zero-coupon curve provides out-of-sample estimates from January 1995 to December 1998. Therefore, this period will also be set aside for analyzing out-of-sample forecast. Additionally, it should be noted that all yields are presented in nominal value, divided by 100 .

Five macroeconomic variables have been chosen to assist forecasting the yield curves. These variables are Debt of Domestic (Non-financial Sector, in $\%$ change, SA), Effective Federal Fund Rate, Housing Starts (New Privately Owned, in \% change, SAAR), Real Personal Consumption Expenditures (in $\%$ change, SAAR), and Civilian Unemployment Rate (in \% change, SA). This data has been gathered from the FRED database at the Federal Reserve Bank of St. Louis. Both Debt of Domestic and Real Personal Consumption Expenditures have the shortest time series of the data series beginning in March 1959. For uniformity, all datas range from March 1959 to December 1994 for the in-sample estimation, or 429 observations.

\subsubsection{Empirical Results}

As stated above, the first step of the empirical model is to calculate a noarbitrage yield curve defined by a two-factor model, where the 1 year and 10 year yields are used as the two factors. The structure of the two-factor and its closed form solution is the $A_{0}(2)$ Model defined by At-Sahalia and Kimmel (2010). Equation 1.7 lays out the $A_{0}(2)$ Model. The state variables, $X_{1, t} \& X_{2, t}$, here are represented by the 1 and 10 -year terms-to-maturity. 5

$$
\left[\begin{array}{l}
X_{1, t} \\
X_{2, t}
\end{array}\right]=\left[\begin{array}{cc}
b_{1,1} & 0 \\
b_{2,1} & b_{2,2}
\end{array}\right]\left[\begin{array}{l}
X_{1, t} \\
X_{2, t}
\end{array}\right] d t+d\left[\begin{array}{l}
W_{1, t}^{p} \\
W_{2, t}^{p}
\end{array}\right]
$$

\footnotetext{
$\sqrt[5]{\text { At-Sahalia and Kimmel }(2010)}$ define the notation of $A_{M}^{N}$ where $N$ is the number of state variables, 'factors,' and $M$ is the number of the linear combinations in the diffusion process for directed at the state variables. So in the case here, there are 2 factors with no linear combinations of the state variables in the diffusion process. Described as $d X_{t}=$ $\left(\tilde{A}+\tilde{B} X_{t}\right) d t+\Sigma \sqrt{S\left(X_{t} ; \alpha, \beta\right) d W_{t}^{Q}}$. Furthermore, M can also be described as rank of $\beta$. Please see At-Sahalia and Kimmel (2010) for more depth.
} 
The Taylor series expansion presented by At-Sahalia and Kimmel (2010) for equation $\mathbf{1 . 7}$ is given in equation 1.8. The coefficients of the Taylor series $C_{x}^{K}$, for $\mathrm{K}=-1 \ldots 2$ are presented beginning at equation $\mathbf{1 . 9}$. The estimates are then listed in Table 1.2, as well in matrix form in equation 1.13. Note here, the notation of 1 and 10 year TTMs have been put in place.

$$
\begin{gathered}
l_{x}^{(K)}\left(\Delta, x \mid x_{0} ; \theta\right)=-\frac{m}{2} \ln (2 \pi \Delta)-D_{v}(x ; \theta)+\frac{C_{x}^{(-1)}\left(x \mid x_{0} ; \theta\right)}{\Delta} \\
+\sum_{k=0}^{K} C_{x}^{(k)}\left(x \mid x_{0} ; \theta\right) \frac{\Delta^{k}}{k !} \\
\text { Where } D_{v}(x ; \theta) \equiv \frac{1}{2} \ln (\operatorname{Det}[v(x ; \theta)]) \\
v(x ; \theta) \equiv \sigma(x ; \theta) \sigma^{T}(x ; \theta) \\
l_{x} \equiv \ln \left(p_{x}\right) \\
c_{X}^{(-1)}\left(x \mid x_{0} ; \theta\right)=-\frac{1}{2}\left(x_{1}-x_{10}\right)^{2}-\frac{1}{2}\left(x_{2}-x_{20}\right)^{2} \\
c_{X}^{(0)}\left(x \mid x_{0} ; \theta\right)=-\frac{1}{2}\left(x_{1}-x_{10}\right)^{2} b_{11}-\left(x_{1}-x_{10}\right) x_{10} b_{11}-\frac{1}{2}\left(x_{1}-x_{10}\right)\left(x_{2}-x_{20}\right) b_{21} \\
-\frac{1}{2}\left(x_{2}-x_{20}\right)^{2} b_{22}+\left(x_{2}-x_{20}\right)\left(-x_{10} b_{21}-x_{20} b_{22}\right) \\
+\frac{1}{6}\left(x_{1}-x_{10}\right) b_{21} b_{22}\left(x_{10} b_{21}+x_{20} b_{22}\right)+\frac{1}{6}\left(x_{2}-x_{20}\right) b_{21}\left(x_{10}\left(b_{11}^{2}+b_{21}^{2}\right)+x_{20} b_{21} b_{22}\right) \\
c_{X}^{(2)}\left(x \mid x_{0} ; \theta\right)=-\frac{1}{12}\left(\left(x_{1}-x_{10}\right)^{2} b_{21}^{2} b_{22}\right)+\frac{1}{12}\left(x_{2}-x_{20} b_{21}^{2} b_{22}\right. \\
c_{X}^{(1)}\left(x \mid x_{0} ; \theta\right)=\frac{1}{24}\left(x_{1}^{2}-x_{10}\right)^{2}\left(-4 b_{11}^{2}-3 b_{21}^{2}\right)-\frac{1}{3}\left(x_{1}-x_{10}\right)\left(x_{2}-x_{20}\right) b_{21} b_{22} \\
\left.+\frac{1}{2}\left(x_{2}-x_{20}\right) b_{22}\left(x_{10} b_{21}+x_{20} b_{22}\right)+\frac{1}{2}\left(x_{1}-x_{10}\right)\left(-x_{10}\left(b_{11}^{2}+b_{21}^{2}\right)\right)-x_{20} b_{21} b_{22}\right) \\
+\frac{1}{24}\left(x_{2}-x_{20}\right)^{2}\left(b_{21}^{2}-4 b_{22}^{2}\right)+\frac{1}{2}\left(b_{11}-x_{10}^{2} b_{11}^{2}+b_{22}-\left(x_{10} b_{21}+x_{20} b_{22}\right)^{2}\right)
\end{gathered}
$$




\section{Table 1.2}

Sample Estimates of Coefficients

\begin{tabular}{lc}
\hline Parameter & Value \\
$b_{11}$ & $2.955 \mathrm{e}-06$ \\
$b_{21}$ & 0 \\
$b_{22}$ & 0.881 \\
\hline
\end{tabular}

\section{Table 1.3}

Ljung-Box test for all terms

Results are at the first lag level.

\begin{tabular}{lcc} 
Term & $\begin{array}{c}\text { 1-lag } \\
\text { Q-stat }\end{array}$ & $\begin{array}{c}\text { 2-lags } \\
\text { Q-stat }\end{array}$ \\
3-month & 1.63 & 0.02 \\
6-month & $4.79^{*}$ & 0.05 \\
1-year & $6.19^{*}$ & 0.07 \\
2-year & $6.50^{*}$ & 0.09 \\
5-year & $2.78^{*}$ & 0.02 \\
10-year & 1.59 & 0.01 \\
\hline * Statistically Significant \\
at the 10\% level. \\
\hline
\end{tabular}

$$
\left[\begin{array}{l}
X_{1, t} \\
X_{10, t}
\end{array}\right]=\left[\begin{array}{cc}
2.955 e-06 & 0 \\
0 & 0.881
\end{array}\right]\left[\begin{array}{c}
X_{1, t} \\
X_{10, t}
\end{array}\right] d t+d\left[\begin{array}{c}
W_{1, t}^{p} \\
W_{10, t}^{p}
\end{array}\right]
$$

The estimated ATSM curve and the actual (zero-coupon) curve will be trained and forecasted through a system of neural networks. First, the proper lag-length of the autoregressive portion of the neural nets needs to be determined. This will be done with the traditional time-series analysis of the autocorrelation function (ACF), and the Ljung-Box Q-statistic. The ACF does not show any major persistence in any of the yields, while the ACF of the shortest term, 3-months, shows minor persistence at the $1^{\text {st }}$ lag. The results of the Ljung-Box test are shown in Table $\mathbf{1 . 3}$.

For concerns of serial correlation, there is no need to go beyond the second lag. This $\mathrm{AR}(2)$ is displayed in regression form in Eq. 1.14. For uniformity, all yields will use two autoregressive terms. 


$$
y_{i t}=\beta_{0}+\beta_{1} y_{i t-1}+\beta_{2} y_{i t-2}
$$

Table 1.4 list the variables to be used in an array of neural networks. For the NAR networks only the own lags will be included. The NARX networks will use all of the variables. The networks are configured as in Figures $\mathbf{1 . 2}$ \& 1.3. The number of nodes in the hidden layer is an additional variant for a neural network. A standard practice is to use between 1.5 to 2 times the number of input nodes, variables, for the number of hidden nodes. For each yield, there will be networks with a different number of nodes in the hidden layers. An algorithm will test a set of networks with the number of hidden nodes in the range between $2 \pm \frac{1}{2}$ of the inputs. The network with the best out-of-sample performance, based on MSE, is chosen for that yield. Furthermore, the training function, how the $\mathrm{NN}$ is updated through each epoch, for all networks is the Levenberg-Marquardt (LM) ${ }^{6}$ The LM training algorithm is described in Equation 1.15.

$$
x_{k+1}=x_{k}-\left[J^{T} J+\mu I\right]^{-1} J^{T} e
$$

Note: $J$ represents the Jacobian, the Hessian is estimated as $J^{T} J$, and the gradient can be defined as $J^{T} e$

Table 1.5 \& 1.6 display the in-sample MSE for the realized (zerocoupon) and ATSM estimated curve, respectively. In Table 1.5, it is shown that when macroeconomic variables are included to the neural network the performance increases, except for the 1-year bond. Table 1.6 demonstrates there are significant gains from incorporating the macroeconomic variables for the 3-month and 6-month terms. The 1-year and 10-year are not displayed in Table 1.6, because these were the two yields, factors, that were used to solve the ATSM curve. Therefore, they will only be forecasted in the realized sample.

In-sample mean squared error is valuable information in some respects, however, the out-of-sample performance is key for model validation. Table

\footnotetext{
${ }^{6}$ This is a traditional training algorithm for backpropagation NN's. The definition provided here is from mat (2011). The "Gradient descent with momentum and adaptive learning rate" training algorithm was also tested. However, initial testing suggested the Levenberg-Marquardt provided better results.
} 


\section{Table 1.4}

List of Variables to be Used in NNs

\begin{tabular}{lcc}
\hline Variables & Format & Seasonal Adj. \\
$1^{s t}$ lag & $/ 100$ & $\mathrm{NA}$ \\
$2^{\text {nd }}$ lag & $/ 100$ & $\mathrm{NA}$ \\
Debt of Domestic (Non-financial Sector) & $\%$ change & $\mathrm{SA}$ \\
Effective Federal Fund Rate & $/ 100$ & $\mathrm{NA}$ \\
Housing Starts: New Privately Owned & $\%$ change & SAAR \\
Real Personal Consumption Expenditures & $\%$ change & $\mathrm{SA}$ \\
Civilian Unemployment Rate & $\%$ change & $\mathrm{SA}$ \\
\hline
\end{tabular}

Table $\mathbf{1 . 5}$

In-sample MSE for Yield Curve

\begin{tabular}{lcccc}
\hline Term & $\begin{array}{c}\text { \# of Nodes } \\
\text { NAR }\end{array}$ & $\begin{array}{c}\text { NAR } \\
\text { w/o Macro vars. }\end{array}$ & $\begin{array}{c}\text { \# of Nodes } \\
\text { NARX }\end{array}$ & $\begin{array}{c}\text { NARX } \\
\text { w Macro vars. }\end{array}$ \\
3-month & 12 & 0.325 & 11 & 0.214 \\
6-month & 10 & 0.258 & 12 & 0.219 \\
1-year & 16 & 0.280 & 14 & 0.332 \\
2-year & 13 & 0.200 & 18 & 0.200 \\
5-year & 11 & 0.149 & 17 & 0.121 \\
10-year & 14 & 0.104 & 13 & 0.097 \\
\hline
\end{tabular}

*MSE is at 1E-04, was multiple for readability

Note: The number of hidden nodes were chosen on the out-of-sample performance. 


\section{Table 1.6}

In-sample MSE for ATSM Curve

\begin{tabular}{lcccc}
\hline Term & $\begin{array}{c}\text { \# of Nodes } \\
\text { NAR }\end{array}$ & $\begin{array}{c}\text { NAR } \\
\text { w/o Macro vars. }\end{array}$ & $\begin{array}{c}\text { \# of Nodes } \\
\text { NAR }\end{array}$ & $\begin{array}{c}\text { NARX } \\
\text { w Macro vars. }\end{array}$ \\
3-month & 11 & 0.474 & 11 & 0.372 \\
6-month & 11 & 0.544 & 11 & 0.313 \\
2-year & 14 & 0.183 & 14 & 0.150 \\
5-year & 12 & 0.115 & 12 & 0.175 \\
\hline *MSE is at 1E-04, was multiple for readability \\
Note: The number of hidden nodes were chosen on the \\
out-of-sample performance.
\end{tabular}

1.7 displays the out-of-sample MSE of each curve. The forecast here is 3months ahead; a 3-month rolling window for 15 different periods is calculated. The MSE displayed in the tables is the mean of those 15 period MSEs.

Each curve displays better performance using only the autoregressive terms in the network for the short terms, while the use of the macroeconomic variables out-performed in the longer terms. The NAR network displays the lowest MSE for 3-month and 6-month terms for the realized yields and again for the 3-month in the ATSM curve. These results are inline with the intuition that shorter terms are more closely based on speculation while longer terms are more heavily based on the macro economy.

As a comparison, a simple random walk forecast is also displayed in Table 1.7. For both curves the short terms, 1-year or less, are significantly out-performed by the use of either neural network structure. The longest term, 10-year, is underperformed with the use of neural networks. The MSE, remember, is based on a rolling 3-month, during this time the YTM on a 10-year zero-coupon bond is not likely to be strongly volatile. Therefore, a random walk will perform well.

Lastly, the difference between the two forecasted curves will be examined. Figure 1.4 exhibits both the realized and ATSM yield curves during the first 1-month forecast for the neural network using macroeconomic variables. As shown, there is a considerable gap, around 100 bases points, in the 3-month and 6-month periods of the curves. The 2-year term demonstrates a similar YTM between the two curves, while the difference reverses and grows for the 5-year bond. The greatest room for financial arbitrage here is seen in the three and six month TTMs. Tables $1.8 \& 1.9$ in Appendix A list the difference between the curves for each yield and forecast time-period. 


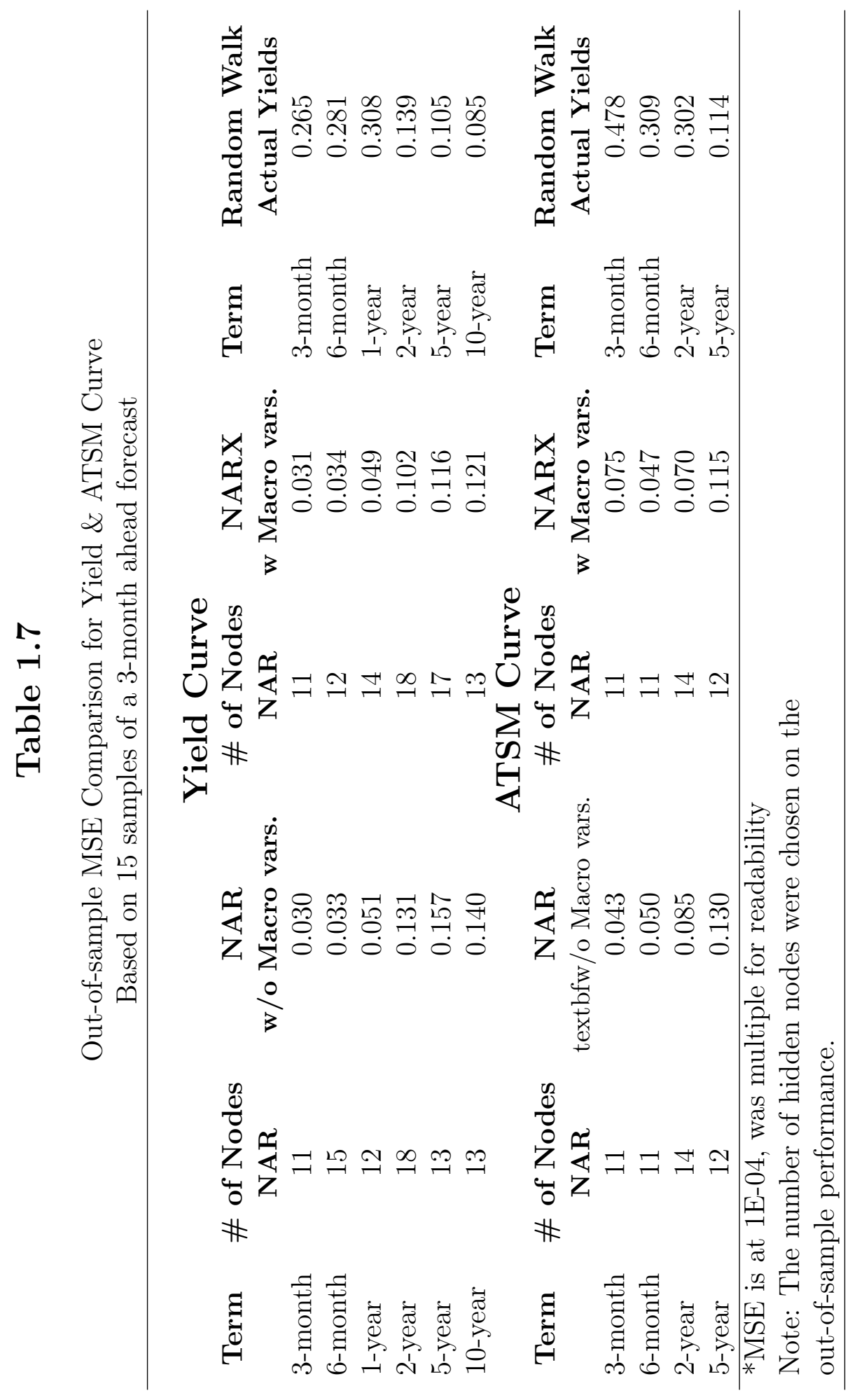




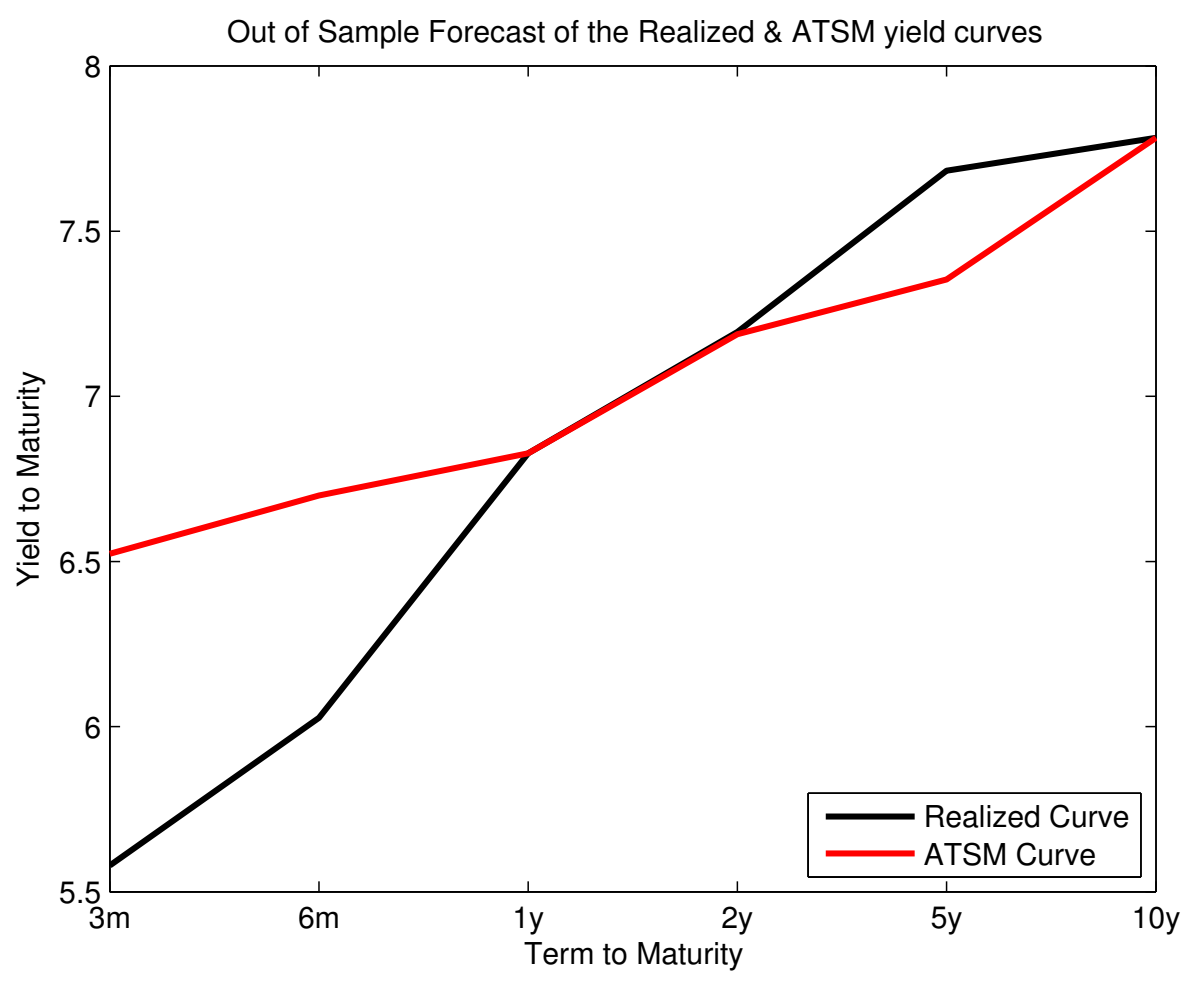

Figure 1.4: First 1-Month Out-of-sample Yield Curve for Actual and ATSM 


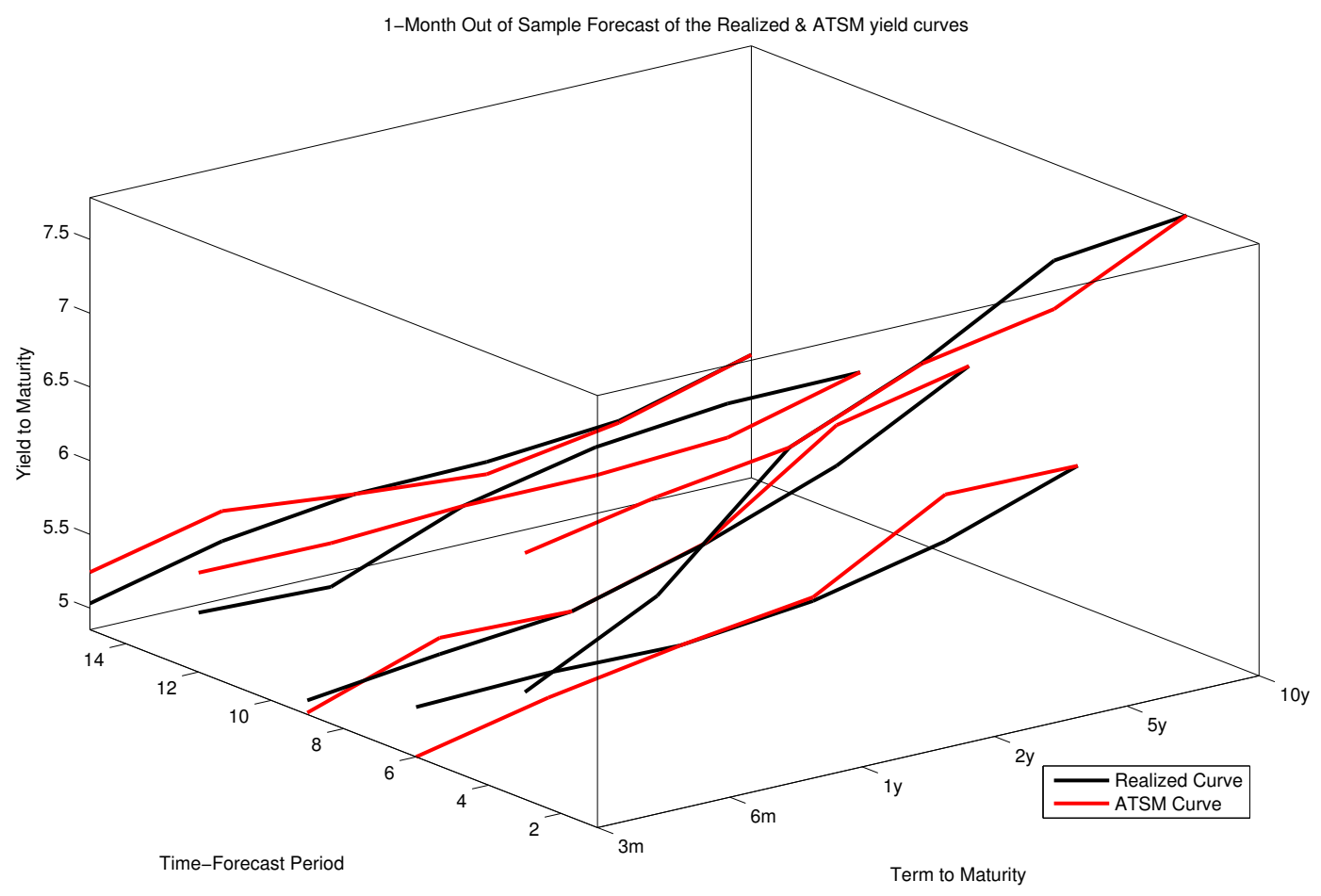

Figure 1.5: Timeseries of 1-Month Out-of-sample Yield Curve for Actual and ATSM 


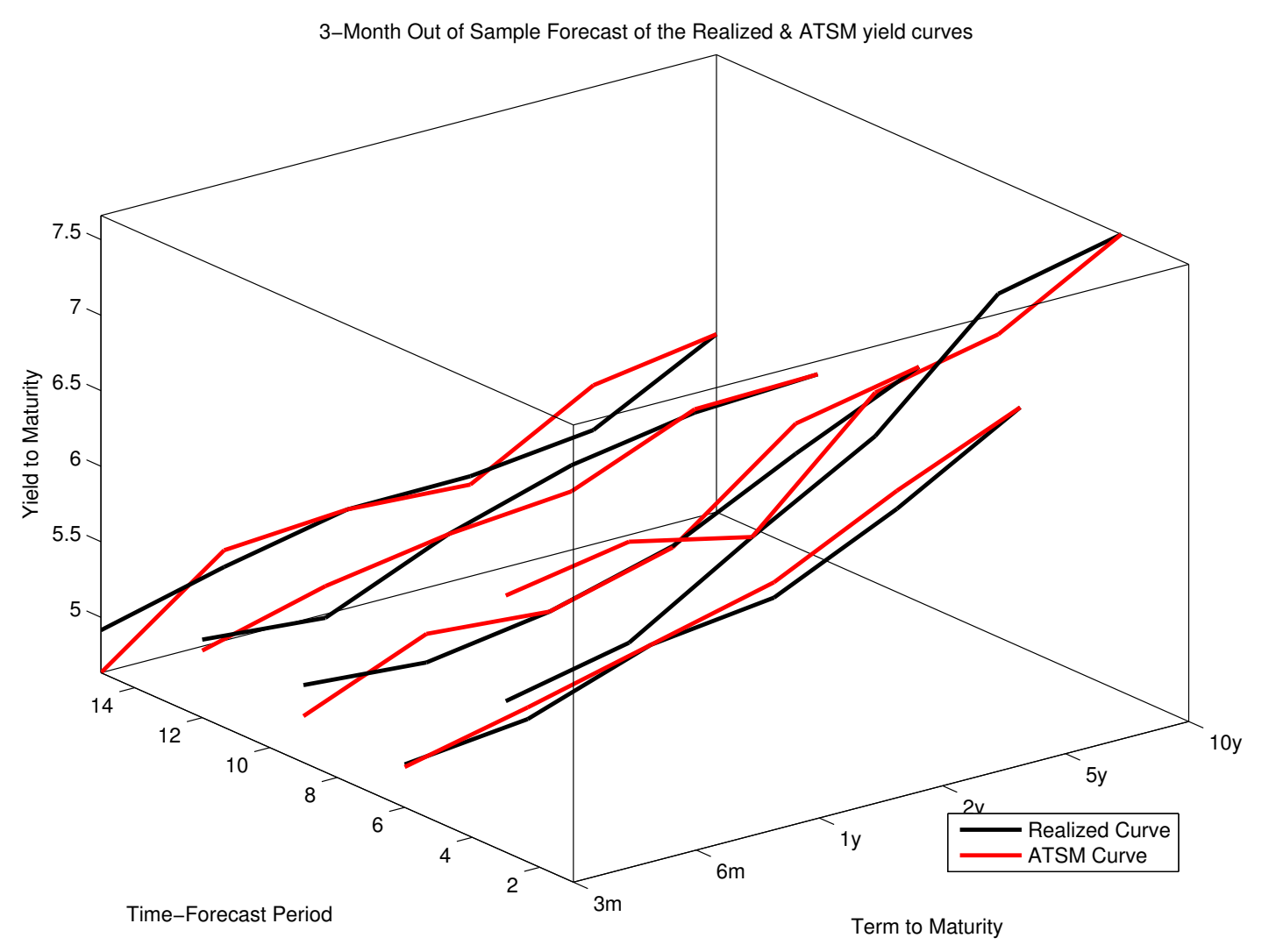

Figure 1.6: Out-of-sample Yield Curve for Actual and ATSM 
Figure $1.5 \& 1.6$ cultivate the visualization of several arbitrage opportunities referenced in Appendix A. The out-of-sample 1-month and 3-month over an expanding forecast is illustrated in figures. Only five of the 15 periods shown in Appendix A have been displayed to keep the graphs legible. Figure 1.5 conveys wider gap between the realized and ATSM curve at the 5 year TTM versus the 3-month or 6-month consistency. Furthermore, Figure 1.6 illustrates a similar pattern.

\subsection{Conclusion}

To conclude here, the estimation and prediction of yield curve arbitrage opportunities are examined. The availability of arbitrage is seen by estimating an Affine Term Structure Model and comparing it to the actual yield curve. Here a two factor Vasicek Model is used to generate the ATSM curve, see Section 1.2.1.

These two curves are then forecasted through a system of neural networks, with and without the use of macroeconomic variables. A nonlinear autoregressive (NAR) and nonlinear autoregressive with exogenous variables (NARX) networks are employed for both the realized and ATSM yield curve. The out-of-sample MSE suggests that only the autoregressive variables are needed for forecasting short-term bonds, 1-year or less. For longer maturities, macroeconomic variables are advantageous for yield prediction.

As a comparison, the 3-month forecast MSE for the neural networks was compared to a random walk forecast. The neural networks outperformed the random walk significantly for TTM 1-year or less. The 10-year term random walk out-preformed the NNs due to the stability of the YTM in a short-range forecast.

Finally, the predicted ATSM and actual yield curve were compared to find possible arbitrage opportunities. The three and six month terms-to-maturity displayed the greatest opportunity. The five-year also illustrated chances for arbitrage.

For future works, it would be compelling to see if other macroeconomic variables increase the predictability for TTMs beyond 1-year. Additionally, analyzing the MSE of longer forecast periods, 6-month or 1-year, would be interesting. Greater foresight will increase the space of arbitrage opportunities. 


\subsection{Appendix A: Additional Tables}

Table 1.8

Results for NARX network, w/ Macro Variables Difference between Forecasted Actual \& ASTM Yields for each 3-month Ahead Forecast for All Periods. (Actual Yield - ASTM Yields) in \%

\begin{tabular}{llcccc}
\hline Forecast & Month & 3-month & $\mathbf{6 - m o n t h}$ & $\mathbf{2}$-year & $\mathbf{5}$-year \\
Period & Ahead & & & & \\
1 & 1 & -0.944 & -0.673 & 0.007 & 0.329 \\
1 & 2 & -0.841 & -0.612 & -0.213 & 0.363 \\
1 & 3 & -0.699 & -0.668 & -0.288 & 0.269 \\
2 & 1 & -0.234 & -0.084 & 0.235 & -0.010 \\
2 & 2 & -0.120 & -0.132 & 0.242 & -0.074 \\
2 & 3 & 0.110 & -0.378 & 0.207 & -0.499 \\
3 & 1 & 0.298 & 0.182 & 0.034 & -0.141 \\
3 & 2 & 0.418 & 0.211 & 0.002 & -0.286 \\
3 & 3 & 0.648 & 0.152 & -0.008 & -0.502 \\
4 & 1 & 0.120 & -0.088 & 0.049 & -0.039 \\
4 & 2 & 0.223 & -0.141 & 0.100 & -0.016 \\
4 & 3 & 0.313 & -0.195 & 0.130 & -0.037 \\
5 & 1 & 0.338 & 0.168 & -0.025 & -0.316 \\
5 & 2 & 0.537 & 0.126 & -0.030 & -0.305 \\
5 & 3 & 0.649 & 0.003 & -0.088 & -0.279 \\
6 & 1 & 0.017 & -0.077 & -0.102 & -0.120 \\
6 & 2 & 0.139 & -0.105 & -0.093 & -0.368 \\
6 & 3 & 0.260 & -0.197 & -0.175 & -0.509 \\
7 & 1 & -0.083 & -0.180 & 0.105 & 0.008 \\
7 & 2 & 0.032 & -0.182 & 0.098 & 0.110 \\
7 & 3 & 0.200 & -0.232 & 0.014 & -0.225 \\
8 & 1 & -0.329 & -0.178 & 0.047 & 0.336 \\
8 & 2 & -0.211 & -0.326 & -0.006 & 0.221 \\
8 & 3 & -0.121 & -0.422 & 0.018 & 0.110 \\
9 & 1 & 0.084 & -0.111 & -0.005 & -0.275 \\
9 & 2 & 0.133 & -0.139 & 0.036 & -0.314 \\
9 & 3 & 0.205 & -0.190 & 0.009 & -0.200 \\
10 & 1 & -0.299 & -0.288 & 0.020 & 0.333 \\
10 & 2 & -0.187 & -0.297 & -0.018 & 0.141 \\
10 & 3 & -0.044 & -0.287 & -0.055 & 0.151 \\
11 & 1 & -0.150 & -0.139 & 0.166 & 0.309 \\
11 & 2 & 0.038 & -0.183 & 0.037 & 0.152 \\
11 & 3 & 0.178 & -0.172 & 0.057 & 0.135 \\
12 & 1 & -0.093 & -0.139 & 0.190 & 0.118 \\
12 & 2 & 0.060 & -0.240 & 0.076 & 0.065 \\
12 & 3 & 0.158 & -0.276 & 0.097 & 0.222 \\
13 & 1 & -0.270 & -0.297 & 0.191 & 0.231 \\
13 & 2 & -0.123 & -0.234 & 0.156 & -0.139 \\
13 & 3 & 0.072 & -0.210 & 0.173 & -0.021 \\
14 & 1 & -0.124 & -0.139 & 0.131 & -0.080 \\
14 & 2 & 0.001 & -0.069 & 0.114 & -0.348 \\
14 & 3 & 0.025 & -0.065 & 0.349 & -0.016 \\
15 & 1 & -0.212 & -0.204 & 0.083 & 0.013 \\
15 & 2 & 0.062 & -0.087 & 0.128 & -0.354 \\
15 & 3 & 0.281 & -0.111 & 0.056 & -0.297 \\
\hline & & & & &
\end{tabular}




\section{Table 1.9}

Results for NAR network, w/o Macro Variables Difference between Forecasted Actual \& ASTM Yields for each 3-month Ahead Forecast for All Periods.

(Actual Yield - ASTM Yields) in \%

\begin{tabular}{|c|c|c|c|c|c|}
\hline Forecast & Month & 3-month & 6-month & 2-year & 5-year \\
\hline Period & Ahead & & & & \\
\hline 1 & 1 & -0.830 & -0.714 & 0.006 & 0.297 \\
\hline 1 & 2 & -0.770 & -0.648 & -0.105 & 0.360 \\
\hline 1 & 3 & -0.695 & -0.499 & -0.200 & 0.410 \\
\hline 2 & 1 & -0.281 & 0.090 & 0.087 & 0.200 \\
\hline 2 & 2 & -0.178 & 0.283 & 0.056 & 0.254 \\
\hline 2 & 3 & -0.090 & 0.487 & 0.022 & 0.310 \\
\hline 3 & 1 & 0.317 & 0.353 & -0.067 & -0.013 \\
\hline 3 & 2 & 0.408 & 0.497 & -0.042 & 0.050 \\
\hline 3 & 3 & 0.471 & 0.641 & -0.019 & 0.125 \\
\hline 4 & 1 & -0.002 & 0.123 & 0.066 & 0.071 \\
\hline 4 & 2 & 0.005 & 0.230 & 0.100 & 0.142 \\
\hline 4 & 3 & 0.016 & 0.338 & 0.133 & 0.220 \\
\hline 5 & 1 & 0.182 & 0.158 & -0.096 & 0.038 \\
\hline 5 & 2 & 0.186 & 0.242 & -0.137 & 0.117 \\
\hline 5 & 3 & 0.180 & 0.322 & -0.175 & 0.195 \\
\hline 6 & 1 & -0.020 & 0.010 & -0.138 & -0.083 \\
\hline 6 & 2 & -0.011 & 0.082 & -0.180 & -0.019 \\
\hline 6 & 3 & 0.010 & 0.154 & -0.203 & 0.056 \\
\hline 7 & 1 & -0.135 & -0.036 & 0.209 & 0.181 \\
\hline 7 & 2 & -0.117 & 0.070 & 0.266 & 0.223 \\
\hline 7 & 3 & -0.102 & 0.177 & 0.326 & 0.267 \\
\hline 8 & 1 & -0.198 & -0.034 & 0.215 & 0.163 \\
\hline 8 & 2 & -0.178 & 0.085 & 0.267 & 0.201 \\
\hline 8 & 3 & -0.159 & 0.202 & 0.318 & 0.242 \\
\hline 9 & 1 & -0.086 & 0.010 & 0.063 & 0.110 \\
\hline 9 & 2 & -0.085 & 0.095 & 0.040 & 0.194 \\
\hline 9 & 3 & -0.075 & 0.175 & 0.009 & 0.281 \\
\hline 10 & 1 & -0.272 & -0.091 & 0.226 & 0.197 \\
\hline 10 & 2 & -0.243 & 0.015 & 0.282 & 0.260 \\
\hline 10 & 3 & -0.213 & 0.118 & 0.344 & 0.326 \\
\hline 11 & 1 & -0.362 & 0.006 & 0.278 & 0.194 \\
\hline 11 & 2 & -0.332 & 0.122 & 0.346 & 0.248 \\
\hline 11 & 3 & -0.295 & 0.232 & 0.412 & 0.306 \\
\hline 12 & 1 & -0.184 & -0.016 & 0.180 & 0.193 \\
\hline 12 & 2 & -0.180 & 0.086 & 0.217 & 0.266 \\
\hline 12 & 3 & -0.166 & 0.187 & 0.270 & 0.345 \\
\hline 13 & 1 & -0.339 & -0.143 & 0.218 & 0.251 \\
\hline 13 & 2 & -0.319 & -0.033 & 0.226 & 0.341 \\
\hline 13 & 3 & -0.288 & 0.080 & 0.245 & 0.432 \\
\hline 14 & 1 & -0.239 & -0.052 & 0.103 & 0.179 \\
\hline 14 & 2 & -0.216 & 0.046 & 0.064 & 0.257 \\
\hline 14 & 3 & -0.192 & 0.144 & 0.033 & 0.336 \\
\hline 15 & 1 & -0.336 & 0.002 & 0.133 & 0.219 \\
\hline 15 & 2 & -0.296 & 0.103 & 0.095 & 0.296 \\
\hline 15 & 3 & -0.259 & 0.200 & 0.056 & 0.373 \\
\hline
\end{tabular}




\section{Chapter 2}

\section{Estimating and Predicting State Employment Volatility}

When forecasting on the regional level there are several dynamic relationships to consider. The prime example is the relationship between the regions in question and the parent economy. The main focus of this study is to consider the structure of the error term in state level employment growth.

The importance of volatility employment is stated in the accuracy of the estimation and prediction of regional employment. Erroneous assumptions about the volatility structure will bias estimation results and ultimately lead to unsatisfactory forecasts.

Unsatisfactory forecast errors are the main motivation for this study. One could have an excellent forecasting model that is backed by sound economic theory. However, if the assumption of white noise in the error term is violated, the forecast is doomed to produce inefficient results. It is important to have an accurate forecast, not for the forecast itself, but for the implications and policies that are based on the findings of the forecast. The user of economic forecasts must be confident in the results; otherwise employers and policy maker will to rely on the current set of information. It will be illustrated that measuring the ARCH effects have improved the forecast accuracy.

The remainder of this paper is structured as follows: Section 2.1 discusses the current state of the literature, Section illustrates the empirical analysis, Section 2.3 reports the empirical results, and Section 2.4 concludes the study.

\subsection{Review of the Literature}

The literature focused on here deals with forecasting state-level employment and the umbrella idea of volatility time variance and clustering. 
The seminal work on measuring a variance conditional on the past is by Engle (1982). The model is coined Autoregressive Conditional Heteroscedasticity $(\mathrm{ARCH})$. The author points to several applications of the model, the first being economic forecasters have notice a clustering of uncertainty over different forecast intervals. Secondly, the ARCH model could be a better approximation for real world complexity is a subject of structural breaks or omitted variables bias. The variance clustering is of particular interest to forecasters since incorrectly modeling the error distribution will lend too less accurate forecasting. This inefficiency can been corrected by ARCH since the volatility clustering of high or low variance periods will be captured by the model, including the forecast. Higher accuracy allows forecasters and users of the forecast to be more confident in the results.

On the state-level, Carlino, DeFina, and Sill (2007) examined the reduction in employment growth volatility. The data used ES202 state employment ranging from 1960 to 2002. State level volatility was measured by regressing employment growth on state and time dummies, then using the absolute value of the error term as volatility. A panel regression with a two fixed effects model that accounts for structural breaks (i.e. the 'Great Moderation'), the manufacturing to total employment share, and the deregulation of each state were used to determine the source of the volatility. The authors concluded that both state and national factors influence state volatility; however, national factors have a greater effect on volatility than state factors. The statistically significant national factors were monetary policy, oil prices, fluctuations in trade as a share of GDP, and fluctuations in inventory as a share of sales. The key state factors were the loosening of banking regulations and the level of manufacturing employment to total employment.

Blanchard and Simon (2001) studied the reduction in GDP volatility for the U.S. The study begins by examining the decline in U.S. output volatility as measured by a rolling standard deviation of twenty quarters beginning in the first quarter of 1952. The authors also looked at the rolling standard deviation of residuals from an $\mathrm{AR}(1)$ process, which also concluded a decline in GDP volatility. In the multivariate case, the authors measured output volatility by using a panel regression, keeping country and time fixed. The regressors in the panel regression were the rolling mean and rolling standard deviations of the inflation rate. The volatility of output was also divided into the components of GDP. The authors concluded that more efficient monetary policy played a role in the reduction of GDP volatility. Blanchard and Simon (2001) also found that developments in financial markets caused investment and consumption volatility to decline.

Morgan, Rime, and Strahan (2004) studied the effects of interstate banking integration on state growth volatility. The authors' main question was 
whether allowing interstate banking softened supply or demand shocks within a state because of diversification. The dataset ranged from 1976 to 1994, except for GDP, which began in 1978. For growth variables the authors looked at employment, real personal income, and real GDP. The volatility of state growth was measured as the magnitude of divergence from the average state growth. Morgan, Rime, and Strahan (2004) used two different measures of banking integration, interstate asset ratio and other state ratio. The first ratio measured the financial assets in a state relative to a holding company that holds assets in at least two states. The second ratio measured the financial assets held by a holding company outside of the state in question compared to all the financial assets within the state. The authors found that allowing for interstate banking has decreased state volatility growth and decreased the divergence between states.

The literature surrounding the decline in employment and GDP volatility here focuses on structural breaks. There is no doubt that changes in banking regulation and monetary policy have played a role in the decline of employment and GDP volatility. However, if one was to forecast these variances without including the presence of $\mathrm{ARCH}$ effects, the accuracy is at-risk as stated in Engle (1982).

\subsection{Empirical Analysis}

\subsubsection{Empirical Data}

As stated previously, the analysis of this study centers around state-level employment volatility. The data series is from the Bureau of Labor Statistics (BLS) Current Employment Statistics (CES). The data is monthly nonseasonally adjusted total non-farm payroll employment for the U.S. 51 states. The time series ranges from January 1939 to December 2009, which 46 among the 51 states demonstrate. The shortest series length is Alaska, which begins in January 1960 to December 2009.

For the analysis to follow, the growth rate of employment is used in place of the levels to ensure issues of stationarity do not arise. The growth rates are calculated by taking the first difference of natural logarithm in the levels. After studying the graphical representation of the states' employment growth, the fluctuation in the growth was significantly wide for several states became apparent. Given this dynamic, the best course of action for a reliable analysis is to use the growth rate from January 1960 to December 2009 for all states, which is 599 observations per state.

\footnotetext{
${ }^{1}$ The analysis below indicates the full time series for those 46 state. Wide fluctuation
} 


\subsubsection{Empirical Model}

At the heart of the empirical model in this study is the structure of the error term because the variable of interest is employment volatility. Focusing solely on state-level employment growth, other factors must be accounted for as to not skew the interpretation of state employment volatility. In the regression the US employment growth rate is added to account for national factors that affect the state level economy. Eleven seasonal dummies are also included to account for seasonal fluctuations in employment. Lastly, state lags are added to ensure that serial correlation is not an issue. The statistic used to test for serial correlation is the Ljung-Box Q-statistic lack-of-fit test defined as follows:

$$
\tilde{Q}(\hat{r})=n(n+2) \sum_{k=1}^{m} \frac{r_{k}^{2}}{n-k}
$$

where

$$
r_{k}=\frac{\sum_{t=k+1}^{n} \epsilon_{t} \epsilon_{t-k}}{\sum_{t=1}^{n} \epsilon_{t}^{2}}
$$

The $H_{o}$ is no serial correlation in the residuals; the $H_{a}$ is serial correlation in the residuals. The statistical testing is comparing the $Q$-statistic with the chi-square distribution; the null is rejected in the case of $Q>\chi_{m-q}^{2}$. Since our interest is in determining the optimal lag structure for the error term, every lag 1 through 12 inclusive, are tested. The dynamics of the autocorrelation and partial autocorrelation functions are also used to judge the possibility of serial correlation. The number of the state lag length will depend on the results of these tests.

The structure of the volatility equation is an ARCH model specification with restricted coefficients to satisfy non-negativity. These constraints are put in place to ensure the forecasts of the conditional variance will remain positive. This set of equations is estimated through a maximum likelihood estimation. The number of ARCH coefficients can range from 2 to 12 . The specific ARCH structure will vary from state to state, and the criteria on which the specification is determine by an algorithm are discussed in the

pre-1960 counted as outliers rather than a separate process; therefore, it was excluded. Because the main purpose of the study is a forecast of the current period, it is reasonable to begin the series where the data follows the process found in today's economy. 
next section. The general form of the model specification is as follows:

$$
\begin{gathered}
y_{i, t}=\beta_{i, 0}+\beta_{i, 1} y_{u s, t-1}+\sum_{m=1}^{\leq 12} \beta_{i, m+1} y_{i, t-m}+\sum_{s=1}^{11} \beta_{i, c+s+1} d u m_{s, t}+\epsilon_{i, t} \\
\sigma_{i, t}^{2}=\omega_{i}+\sum_{n=1}^{q} \alpha_{i, n} \epsilon_{i, t-n}^{2} \\
\omega>0 \\
\alpha_{n} \geq 0 \forall n, \sum_{n=1}^{q} \alpha_{i, n}<1
\end{gathered}
$$

Where $i=\mathrm{i}^{\text {th }}$ State, $q=1 \ldots 12,\left\{\epsilon_{i, t} \mid \mathrm{I}_{i, t-1}\right\} \sim \mathcal{N}\left(0, \sigma_{i, t}^{2}\right)$

Lagrange multiplier test as defined by Engle $(1982)$ is used to judge the statistical significance of the ARCH effect.

It should be addressed at this point the choice for this particular $\mathrm{ARCH}$ model. It is reasonable to place the restrictions on coefficients in the variance to provide a reasonable and stabile forecast. However, there are other, more advanced, configurations of the G/ARCH such as the threshold-GARCH or exponential GARCH. Enders (2010) correctly coins the issue confronted by the use of the TGARCH as the leverage effect. The effect being that moments in variance are more affected when the residual is negative then when it is positive. This is a case often seen with the pricing of securities. However, it is not believe to be the case for the state level employment growth discussed here. Furthermore, exponential-GARCH (EGARCH) has the agreeable feature that the volatility can never go negative. The EGARCH, similarly to TGARCH, has the ability to incorporate leverage effects. Finally, the variance equations for EGARCH are in the log-linear form. Given that the forecast and interpretation of the variance equation is key to this study and leverage effects are not needed, equation 2.3 is a reasonable choice for modeling.

Once the $\beta$ 's and $\alpha$ 's have been estimated and issues of statistical significance have been addressed, the inquiry continues into the usefulness of the predictability in the error structure to decrease the mean squared error (MSE) of the forecast. In other words, does having a better understanding of the error structure lower forecast errors? In theory, the answer is unequivocally yes; however, the analysis will tell us if the empirics match the theory. 


\subsubsection{ARCH Length Specification Algorithm}

As stated above, the degree of the ARCH structure is allowed to change across states. The addition of this feature allows for more flexibility in each state. There is no reason to assume that the employment growth for each individual state will follow the same $\mathrm{ARCH}$ process. However, the criteria and process for which the ARCH structure is chosen for each state should be the same.

A flow chart of the algorithm charged with finding the ARCH process for each state is displayed below. The primary criterion of this search algorithm is the Akaike Information Criterion (AIC). There are many decisions and processes employed throughout the algorithm; however, the basic concept is relatively simple.

The starting ARCH length is 4 lags, then $-1 /+1$ lags are estimated (3 and 5 lags). While 4 is a somewhat arbitrary choice it allows the algorithm to move in either direction, increasing the flexibility of the algorithm. There are two restrictions placed on the number of $\mathrm{ARCH}$ coefficients, a minimum of 1 lags and maximum of 12. The minimum of 1 is to ensure that $\mathrm{ARCH}$ effects are still captured and the maximum of 12 is to ensure overlapping effects from year to year do not occur.

Once the $4-1 /+1$ lags have been estimated and their respective AIC have been calculated, estimates will continue along the path of lowest AIC. For example, assume the ARCH structure of a particular state follows the characteristic $A I C_{A R C H(3)}>A I C_{A R C H(4)}>A I C_{A R C H(5)}$. Since the autoregressive conditional heteroskedasticity model with 5 lags produces the lowest AIC value, a model with 6 lags will be estimated and so on will be calculated as long as the AIC decreases. Once the AIC of a model increases from the last lag, this portion of the algorithm is terminated and the previous lag length is used. The next portion of the algorithm calculates the significance level of the last lag in the length divulged in the previous portion and test to see if it is significant at the $10 \%$ level. If the lag is significant then this lag length is used as the optimal ARCH structure. If the lag is deemed insignificant then the algorithm cuts that lag off and will continue to do so until the last lag in the sequence is significant at the $10 \%$ level. When a lag is insignificant and the minus one process has not already been estimated from the previous step in the algorithm then it will be estimated. There are several different decisions that must be managed when working through this procedure, but these are the basic concepts the algorithm faces.

One could compose an argument for simply calculating all of the possible different ARCH structures and then comparing them. However, the computational time for this endeavor is massive and it is not backed by sound 


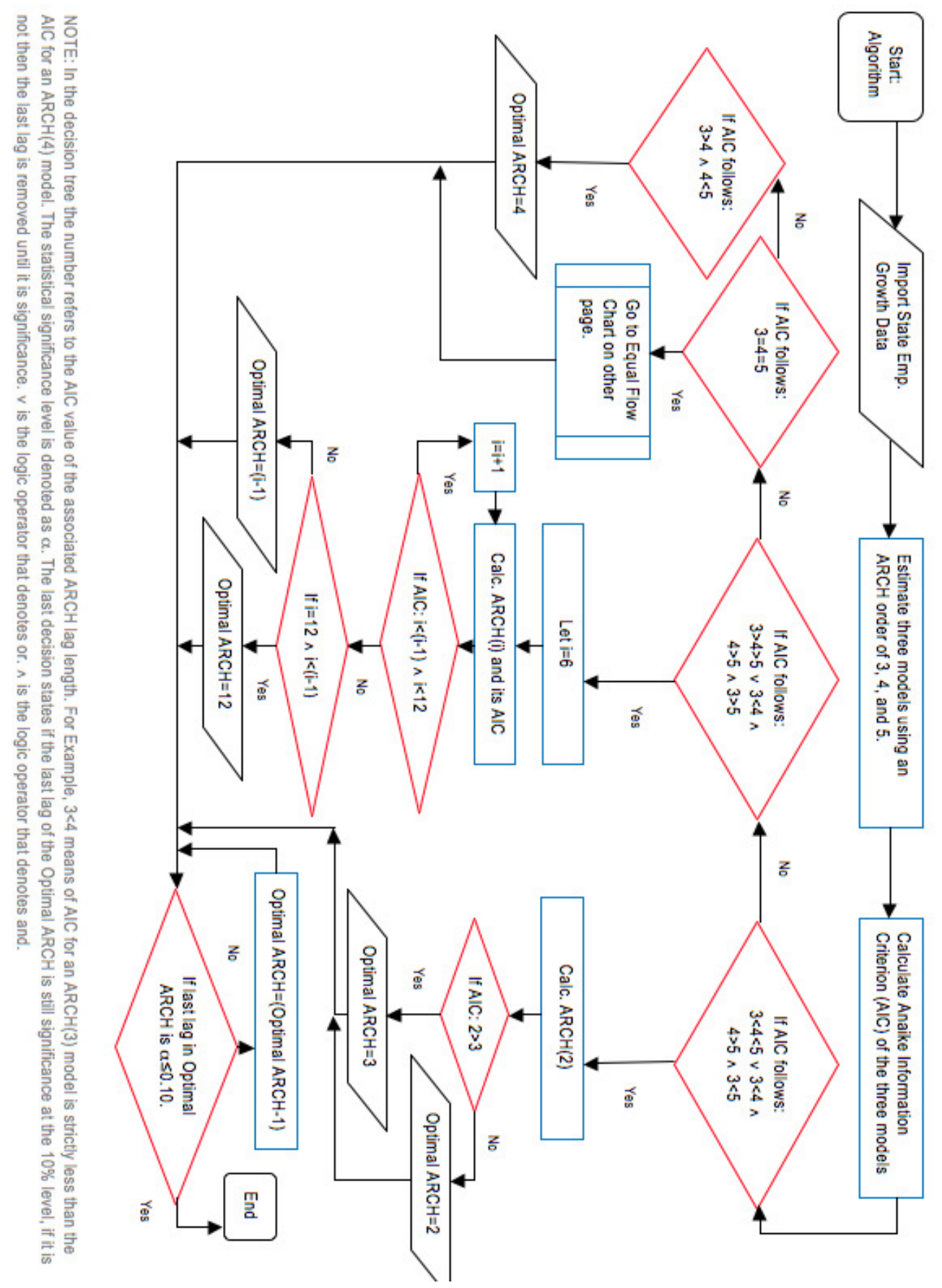

Figure 2.1: Flow Chart of the ARCH Length Specification Algorithm 


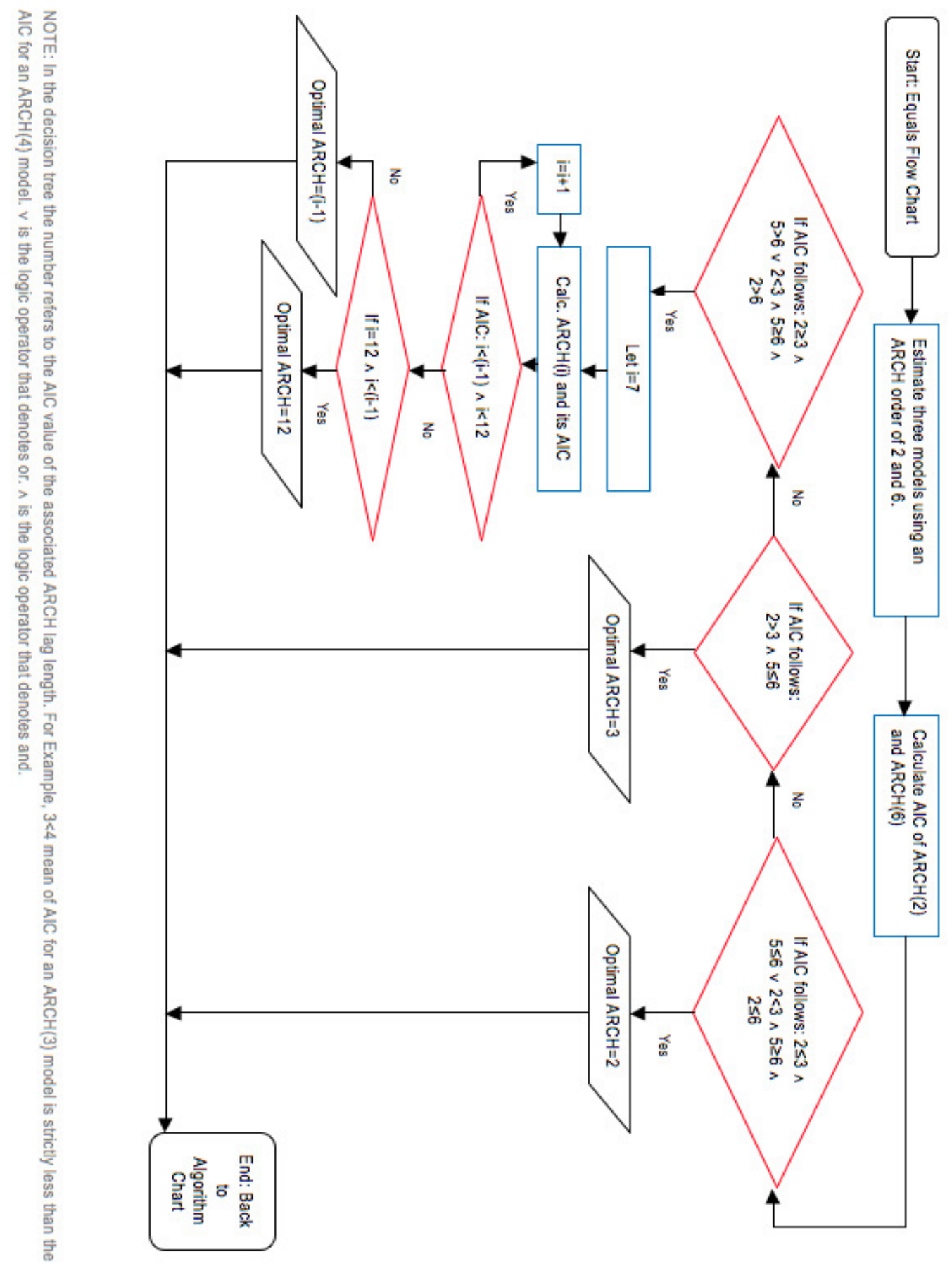

Figure 2.2: Sub-rountine for equals decision in $\mathrm{ARCH}$ algorithm flow chart 
theory. These are the main issues this algorithm aims to address. Now that the theory behind the empirical model has been discussed, the results will be presented.

\subsection{Results of Empirics}

Equation 2.2 was estimated for each state and tested for serial correlation. The evidence of correlation between the errors is mixed when studying the progression of the autocorrelation and partial autocorrelation functions. There is an emphasis placed on the first few lags and primarily the mid-year lags when studying the correlation. The Ljung-Box test does find evidence of serial correlation in the first 12 lags. This evidence is sufficiently reduced when an autoregressive model of order 6 is used for Equation 2.2. Therefore, c in equation 2.2 is equal to 6 for the regression model, yielding:

$$
y_{i, t}=\beta_{i, 0}+\beta_{i, 1} y_{u s, t-1}+\sum_{m=1}^{6} \beta_{i, m+1} y_{i, t-m}+\sum_{s=1}^{11} \beta_{i, c+s+1} d u m_{s, t}+\epsilon_{i, t}
$$

In addition to serial correlation, the stationary of employment growth has also been tested for. Table 2.1 displays the results of Phillips-Perron test for unit root for each state and the US. The results are using the growth rate to be inline with rest of the analysis. Each state and the United States rejected the null hypothesis of unit root. The conclusions are unchanged using Newey-West at 0 or 1 lag. Therefore, concerns of the unit root in the mean regression are no longer an issue.

With corrections made to account for serial correlation, forward progression leads us to the feasibility of ARCH effects in state employment growth. To begin, Engle (1982) Lagrange multiplier is tested for each state at a 12 lag-length and the results are displayed in Table $\mathbf{2 . 2}$ below. If the $\mathrm{ARCH}$ test displays the presence of $\mathrm{ARCH}$ effects at the 12 lag-length, the specification algorithm will refine the model for each state and Engle's ARCH test will be re-implemented at each state specific length.

The results from Table $\mathbf{2 . 2}$ are promising, 47 out of 51 states are statistically significant at the $10 \%$ level for ARCH effects. Additionally, the significant 47 states were also statistically significant at the $1 \%$ level. Given the strong evidence for ARCH effects at the 12 lag-length, the ARCH Length Specification Algorithm is implemented. Table 2.3 displays the optimal ARCH length chosen by the algorithm and the associated Engle (1982) Lagrange multiplier test for that lag. 


\section{Table 2.1}

\begin{tabular}{|c|c|c|c|c|c|}
\hline \multicolumn{6}{|c|}{ Phillips-Perron test for Unit Root } \\
\hline State & $\begin{array}{l}\text { NW 0-lag } \\
\text { PP-statistic }\end{array}$ & $\begin{array}{l}\text { NW 1-lag } \\
\text { PP-statistic }\end{array}$ & State & $\begin{array}{l}\text { NW 0-lag } \\
\text { PP-statistic }\end{array}$ & $\begin{array}{l}\text { NW 1-lag } \\
\text { PP-statistic }\end{array}$ \\
\hline Alabama & $-22.68^{*}$ & $-22.68^{*}$ & Montana & $-15.89^{*}$ & $-15.81^{*}$ \\
\hline Alaska & $-10.16^{*}$ & $-10.66^{*}$ & Nebraska & $-19.84^{*}$ & $-19.91^{*}$ \\
\hline Arizona & $-20.12 *$ & $-20.15^{*}$ & Nevada & $-15.05^{*}$ & $-14.97^{*}$ \\
\hline Arkansas & $-20.51^{*}$ & $-20.53^{*}$ & New Hampshire & $-18.22^{*}$ & $-18.16^{*}$ \\
\hline California & $-25.31^{*}$ & $-25.31^{*}$ & New Jersey & $-20.75 *$ & $-20.78^{*}$ \\
\hline Colorado & $-24.44 *$ & $-24.44 *$ & New Mexico & $-23.28^{*}$ & $-23.28 *$ \\
\hline Connecticut & $-24.27^{*}$ & $-24.27^{*}$ & New York & $-24.80^{*}$ & $-24.80^{*}$ \\
\hline Delaware & $-24.00^{*}$ & $-24.00^{*}$ & North Carolina & $-23.55^{*}$ & $-23.55^{*}$ \\
\hline Washington D.C. & $-25.54^{*}$ & $-25.55^{*}$ & North Dakota & $-16.32^{*}$ & $-16.53^{*}$ \\
\hline Florida & $-18.75^{*}$ & $-18.74^{*}$ & Ohio & $-21.63^{*}$ & $-21.65 *$ \\
\hline Georgia & $-23.68^{*}$ & $-23.68^{*}$ & Oklahoma & $-22.93^{*}$ & $-22.94^{*}$ \\
\hline Hawaii & $-23.24^{*}$ & $-23.24 *$ & Oregon & $-21.29 *$ & $-21.28^{*}$ \\
\hline Idaho & $-17.24^{*}$ & $-17.23^{*}$ & Pennsylvania & $-21.71^{*}$ & $-21.73^{*}$ \\
\hline Illinois & $-22.01 *$ & $-22.02 *$ & Rhode Island & $-23.92^{*}$ & $-23.92 *$ \\
\hline Indiana & $-20.88^{*}$ & $-20.92^{*}$ & South Carolina & $-23.75^{*}$ & $-23.75^{*}$ \\
\hline Iowa & $-20.82^{*}$ & $-20.87^{*}$ & South Dakota & $-17.37^{*}$ & $-17.35^{*}$ \\
\hline Kansas & $-23.81^{*}$ & $-23.81^{*}$ & Tennessee & $-22.28^{*}$ & $-22.29 *$ \\
\hline Kentucky & $-21.80^{*}$ & $-21.82^{*}$ & Texas & $-23.36^{*}$ & $-23.36^{*}$ \\
\hline Louisiana & $-23.25^{*}$ & $-23.25^{*}$ & Utah & $-22.46^{*}$ & $-22.46^{*}$ \\
\hline Maine & $-18.62^{*}$ & $-18.50^{*}$ & Vermont & $-23.02 *$ & $-23.02 *$ \\
\hline Maryland & $-23.19^{*}$ & $-23.20^{*}$ & Virginia & $-21.70^{*}$ & $-21.72^{*}$ \\
\hline Massachusetts & $-24.03^{*}$ & $-24.03 *$ & Washington & $-21.63^{*}$ & $-21.63^{*}$ \\
\hline Michigan & $-23.43^{*}$ & $-23.44^{*}$ & West Virginia & $-21.44^{*}$ & $-21.46^{*}$ \\
\hline Minnesota & $-18.03^{*}$ & $-18.08^{*}$ & Wisconsin & $-19.71^{*}$ & $-19.72^{*}$ \\
\hline Mississippi & $-21.68^{*}$ & $-21.69^{*}$ & Wyoming & $-13.87^{*}$ & $-13.89^{*}$ \\
\hline Missouri & $-21.86^{*}$ & $-21.89^{*}$ & US & $-22.35 *$ & $-22.36^{*}$ \\
\hline
\end{tabular}

As Table 2.3 exhibits the length of the ARCH process ranges widely from state to state, from Maine with 1 lag to Alaska with 9 lags. One of the most notable observations from Table 2.3 is that New Jersey is not included; this is because the model of New Jersey did not converge. Given no-convergence for New Jersey, the state will be excluded from the remainder of the analysis. There are 2 states that chose the minimum lag length of 1 , and Alaska is the only state with 9 lags. Hence, none of the states reached the maximum constraint of 12 lags. The second lengthiest ARCH process is Utah with 8 lags. Additionally, 16 and 7 states have lag lengths of 3 and 2, respectively. Meaning 25 states have a volatility structure of lag length less then or equal toi 3 , or $50 \%$.

The District of Columbia, Idaho, Nebraska, and New Mexico became insignificant at the $10 \%$ level when the $\mathrm{ARCH}$ process was allowed to deviate from a lag length of 12. The higher ARCH-statistic at the 12-lag length for these states versus their respective chosen lags from the algorithm is likely do to residual seasonal overlaps from year to year. Louisiana, Maryland, and Virginia remain statistically insignificant at the $10 \%$ level after the $\mathrm{ARCH}$ process was allowed to fluctuate. However, it is interesting to note these states chose lag lengths relatively small compared to 12. Louisiana and Maryland chose 3 lags and Virginia chose 5 lags. Tennessee is significant 


\section{Table 2.2}

\begin{tabular}{lclc}
\multicolumn{4}{c}{ ARCH LM test ARCH-statistics for all 51 States } \\
\hline State & $\begin{array}{c}\text { 12-Lags } \\
\text { ARCH-statistic }\end{array}$ & State & $\begin{array}{c}\text { 12-Lags } \\
\text { ARCH-statistic }\end{array}$ \\
Alabama & $42.76^{*}$ & Montana & $67.91^{*}$ \\
Alaska & $105.75^{*}$ & Nebraska & $35.87^{*}$ \\
Arizona & $34.59^{*}$ & Nevada & $111.94^{*}$ \\
Arkansas & $101.36^{*}$ & New Hampshire & $323.47^{*}$ \\
California & $63.01^{*}$ & New Jersey & $50.75^{*}$ \\
Colorado & $49.88^{*}$ & New Mexico & $97.11^{*}$ \\
Connecticut & $53.13^{*}$ & New York & $71.04^{*}$ \\
Delaware & $66.73^{*}$ & North Carolina & $67.87^{*}$ \\
Washington D.C. & $122.50^{*}$ & North Dakota & $142.47^{*}$ \\
Florida & $100.46^{*}$ & Ohio & $54.61^{*}$ \\
Georgia & $51.95^{*}$ & Oklahoma & $97.28^{*}$ \\
Hawaii & $204.56^{*}$ & Oregon & $160.96^{*}$ \\
Idaho & $63.64^{*}$ & Pennsylvania & $37.06^{*}$ \\
Illinois & $41.42^{*}$ & Rhode Island & $43.45^{*}$ \\
Indiana & $43.64^{*}$ & South Carolina & $43.57^{*}$ \\
Iowa & $35.49^{*}$ & South Dakota & $52.34^{*}$ \\
Kansas & $118.86^{*}$ & Tennessee & 15.21 \\
Kentucky & $37.67^{*}$ & Texas & $74.03^{*}$ \\
Louisiana & 4.42 & Utah & $83.67^{*}$ \\
Maine & $80.82^{*}$ & Vermont & $256.86^{*}$ \\
Maryland & 4.74 & Virginia & 9.35 \\
Massachusetts & $72.99^{*}$ & Washington & $103.27^{*}$ \\
Michigan & $83.76^{*}$ & West Virginia & $74.28^{*}$ \\
Minnesota & $37.77^{*}$ & Wisconsin & $55.05^{*}$ \\
Mississippi & $34.73^{*}$ & Wyoming & $80.26^{*}$ \\
Missouri & $55.61^{*}$ & & \\
*Statistically Significant at the & 10\% level. & \\
\hline & \multicolumn{4}{c}{} \\
\hline
\end{tabular}

\section{Table 2.3}

Optimal ARCH length as defined by the algorithm and its associated ARCH test statistic

\begin{tabular}{|c|c|c|c|c|c|}
\hline State & Optimal-Lags & ARCH-Statistic & State & Optimal-Lags & ARCH-Statistic \\
\hline Alabama & 4 & $22.35^{*}$ & Missouri & 3 & 5.82 \\
\hline Alaska & 9 & $74.79^{*}$ & Montana & 3 & $22.60^{*}$ \\
\hline Arizona & 3 & $6.81^{*}$ & Nebraska & 4 & 7.21 \\
\hline Arkansas & 6 & $44.63^{*}$ & Nevada & 5 & $51.30^{*}$ \\
\hline California & 6 & $20.44^{*}$ & New Hampshire & 4 & $57.14^{*}$ \\
\hline Colorado & 7 & $25.66^{*}$ & New Mexico & 5 & 7.57 \\
\hline Connecticut & 3 & $8.85^{*}$ & New York & 2 & $13.28^{*}$ \\
\hline Delaware & 5 & $39.56^{*}$ & North Carolina & 3 & $24.02^{*}$ \\
\hline District of Columbia & 4 & 3.62 & North Dakota & 6 & $24.41^{*}$ \\
\hline Florida & 5 & $38.91^{*}$ & Ohio & 6 & $48.14^{*}$ \\
\hline Georgia & 3 & $38.59^{*}$ & Oklahoma & 3 & $23.39^{*}$ \\
\hline Hawaii & 2 & $10.92^{*}$ & Oregon & 5 & $37.05^{*}$ \\
\hline Idaho & 2 & 3.04 & Pennsylvania & 3 & $14.03^{*}$ \\
\hline Illinois & 4 & $23.04^{*}$ & Rhode Island & 1 & $14.43^{*}$ \\
\hline Indiana & 4 & $24.46^{*}$ & South Carolina & 3 & $15.15^{*}$ \\
\hline Iowa & 6 & $27.69^{*}$ & South Dakota & 3 & $10.75^{*}$ \\
\hline Kansas & 2 & $111.29^{*}$ & Tennessee & 2 & $8.04^{*}$ \\
\hline Kentucky & 5 & $22.89^{*}$ & Texas & 6 & $30.79^{*}$ \\
\hline Louisiana & 3 & 4.36 & Utah & 8 & $72.83^{*}$ \\
\hline Maine & 1 & $25.90^{*}$ & Vermont & 2 & $29.90^{*}$ \\
\hline Maryland & 3 & 3.32 & Virginia & 5 & 7.81 \\
\hline Massachusetts & 3 & $19.28^{*}$ & Washington & 6 & $51.06^{*}$ \\
\hline Michigan & 2 & $68.09^{*}$ & West Virginia & 3 & $25.36^{*}$ \\
\hline Minnesota & 3 & $17.05^{*}$ & Wisconsin & 7 & $56.75^{*}$ \\
\hline Mississippi & 3 & $10.53^{*}$ & Wyoming & 4 & $25.87^{*}$ \\
\hline
\end{tabular}


with 2 lags compare to insignificant at 12 .

Table 2.4 displays the results of the volatility regression, Equation 2.3, for each state. As illustrated by Table 2.4 the constraints set on the volatility equation have been satisfied, $\omega>0$ and $\alpha_{n} \geq 0$. The $\omega$ for each state has been scaled by 1E04, which mean's $\omega$ is very small for each state. Neverthe-less, they are greater than zero for each state and statistically significant at the $10 \%$ level. The last lag in the $\mathrm{ARCH}$ process for each state must be significant as part of the conditions set by the algorithm. The only exception to this rule is Michigan; the $1^{\text {st }} \mathrm{ARCH}$ term has a coefficient very close to one. This suggest this second term is in place to satisfy the constraint place on equation 2.3, that sum of $\alpha$ must be less then 1 . While it is impossible for states with other lag lengths to have the final lag insignificant, it is possible for intermediate $\operatorname{lag}(\mathrm{s})$ to be insignificant. The $2^{\text {nd }}$ is the lag that is most often insignificant, 21 out of the 50 states found this lag to be insignificant. However, this results are somewhat skewed given that every state must include this lag. Case in point, Alaska has insignificant lags at 2,5,6, and 7 . In this case, Alaska's volatility model may be improved by ending at the $4^{\text {th }}$ lag, this could be discussed in future research endeavors.

Table 2.11 in the Appendix displays the results from the state employment growth regression, Equation 2.2. The constant term on this regression is insignificant for 6 states. The first lag of the United States employment growth is significant at the $10 \%$ level for 47 out of the 50 states. Every regression coefficient of United States employment growth displayed a positive and correct signs, meaning US employment growth aids in a individual state's employment growth. The insignificant states include the District of Columbia, Washington, and Wyoming. The significance level of the state employment lags are mixed. The $5^{t h}$ lag is the most often to be insignificant of any lag. The first and second quarter lags (the $3^{\text {th }}$ and $6^{\text {th }}$ ) are most often to be significant; 32 out of the 50 states have these lags significant at the $10 \%$ level. While the contribution of each individual lag on the current period varies, the sum of the lagged coefficients does not exceed 1 or -1 . Additionally, no single lagged coefficients exceed 1 or -1 , ensuring the issue of stationarity does not arise. The remaining $\beta$ 's of these regressions are the seasonal dummies. The most noteworthy trend of this set of $\beta$ 's is that the final dummy was statistically significant at the $10 \%$ for all 50 states, suggesting that annual effects play a strong role in the current employment growth rate.

At this juncture the next question to be answered is whether the knowledge of ARCH effects being present allows for greater predictability in volatility. In judging the relevant predictability of the ARCH effects, several forecasts are implemented for comparability. First we examine performance of a 


\section{Table 2.4}

Equation 2.3 estimates, the volatility equation, displayed for AL-MS

\begin{tabular}{|c|c|c|c|c|c|c|c|c|c|c|}
\hline State & $\omega^{\dagger}$ & $\alpha_{1}$ & $\alpha_{2}$ & $\alpha_{3}$ & $\alpha_{4}$ & $\alpha_{5}$ & $\alpha_{6}$ & $\alpha_{7}$ & $\alpha_{8}$ & $\alpha_{9}$ \\
\hline \multirow[t]{2}{*}{ Alabama } & 0.074 & 0.044 & 0.164 & 0.330 & 0.150 & & & & & \\
\hline & $(0.012)^{*}$ & $(0.039)$ & $(0.047)^{*}$ & $(0.083)^{*}$ & $(0.052)^{*}$ & & & & & \\
\hline \multirow[t]{2}{*}{ Alaska } & 0.088 & 0.255 & 0.003 & 0.174 & 0.203 & 0.000 & 0.000 & 0.055 & 0.166 & 0.144 \\
\hline & $(0.032)^{*}$ & $(0.062)^{*}$ & $(0.029)$ & $(0.048)^{*}$ & $(0.059)^{*}$ & $(0.000)$ & $(0.042)$ & $(0.048)$ & $(0.060)^{*}$ & $(0.046)^{*}$ \\
\hline \multirow[t]{2}{*}{ Arizona } & 0.135 & 0.138 & 0.203 & 0.261 & & & & & & \\
\hline & $(0.017)^{*}$ & $(0.045)^{*}$ & $(0.057)^{*}$ & $(0.078)^{*}$ & & & & & & \\
\hline \multirow[t]{2}{*}{ Arkansas } & 0.056 & 0.111 & 0.039 & 0.503 & 0.054 & 0.209 & 0.084 & & & \\
\hline & $(0.015)^{*}$ & $(0.035)^{*}$ & $(0.032)$ & $(0.088)^{*}$ & $(0.038)$ & $(0.045)^{*}$ & $(0.044)^{*}$ & & & \\
\hline \multirow[t]{2}{*}{ California } & 0.042 & 0.216 & 0.051 & 0.074 & 0.149 & 0.043 & 0.200 & & & \\
\hline & $(0.009)^{*}$ & $(0.077)^{*}$ & $(0.052)$ & $(0.060)$ & $(0.055)^{*}$ & $(0.054)$ & $(0.078)^{*}$ & & & \\
\hline \multirow[t]{2}{*}{ Colorado } & 0.033 & 0.300 & 0.000 & 0.068 & 0.050 & 0.156 & 0.259 & 0.111 & & \\
\hline & $(0.009)^{*}$ & $(0.073)^{*}$ & $(0.038)$ & $(0.044)$ & $(0.049)$ & $(0.062)^{*}$ & $(0.071)^{*}$ & $(0.059)^{*}$ & & \\
\hline \multirow[t]{2}{*}{ Connecticut } & 0.105 & 0.089 & 0.000 & 0.267 & & & & & & \\
\hline & $(0.009)^{*}$ & $(0.052)^{*}$ & $(0.046)$ & $(0.076)^{*}$ & & & & & & \\
\hline \multirow[t]{2}{*}{ Delaware } & 0.209 & 0.233 & 0.108 & 0.030 & 0.191 & 0.145 & & & & \\
\hline & $(0.031)^{*}$ & $(0.069)^{*}$ & $(0.045)^{*}$ & $(0.036)$ & $(0.059)^{*}$ & $(0.057)^{*}$ & & & & \\
\hline \multirow[t]{2}{*}{ District of Columbia } & 0.409 & 0.083 & 0.000 & 0.000 & 0.058 & & & & & \\
\hline & $(0.034)^{*}$ & $(0.054)$ & $(0.043)$ & $(0.031)$ & $(0.025)^{*}$ & & & & & \\
\hline \multirow[t]{2}{*}{ Florida } & 0.070 & 0.415 & 0.111 & 0.062 & 0.000 & 0.280 & & & & \\
\hline & $(0.018)^{*}$ & $(0.093)^{*}$ & $(0.061)^{*}$ & $(0.055)$ & $(0.046)$ & $(0.068)^{*}$ & & & & \\
\hline \multirow[t]{2}{*}{ Georgia } & 0.107 & 0.142 & 0.000 & 0.178 & & & & & & \\
\hline & $(0.008)^{*}$ & $(0.037)^{*}$ & $(0.038)$ & $(0.057)^{*}$ & & & & & & \\
\hline \multirow[t]{2}{*}{ Hawaii } & 0.301 & 0.200 & 0.616 & & & & & & & \\
\hline & $(0.033)^{*}$ & $(0.054)^{*}$ & $(0.093)^{*}$ & & & & & & & \\
\hline \multirow[t]{2}{*}{ Idaho } & 0.334 & 0.151 & 0.159 & & & & & & & \\
\hline & $(0.027)^{*}$ & $(0.058)^{*}$ & $(0.060)^{*}$ & & & & & & & \\
\hline \multirow[t]{2}{*}{ Illinois } & 0.072 & 0.219 & 0.122 & 0.100 & 0.163 & & & & & \\
\hline & $(0.009)^{*}$ & $(0.057)^{*}$ & $(0.048)^{*}$ & $(0.045)^{*}$ & $(0.047)^{*}$ & & & & & \\
\hline \multirow[t]{2}{*}{ Indiana } & 0.189 & 0.015 & 0.160 & 0.000 & 0.102 & & & & & \\
\hline & $(0.018)^{*}$ & $(0.042)$ & $(0.056)^{*}$ & $(0.039)$ & $(0.047)^{*}$ & & & & & \\
\hline \multirow[t]{2}{*}{ Iowa } & 0.049 & 0.112 & 0.091 & 0.286 & 0.230 & 0.022 & 0.169 & & & \\
\hline & $(0.010)^{*}$ & $(0.059)^{*}$ & $(0.060)$ & $(0.058)^{*}$ & $(0.062)^{*}$ & $(0.050)$ & $(0.071)^{*}$ & & & \\
\hline \multirow[t]{2}{*}{ Kansas } & 0.171 & 0.132 & 0.369 & & & & & & & \\
\hline & $(0.014)^{*}$ & $(0.053)^{*}$ & $(0.062)^{*}$ & & & & & & & \\
\hline \multirow[t]{2}{*}{ Kentucky } & 0.063 & 0.130 & 0.110 & 0.190 & 0.098 & 0.471 & & & & \\
\hline & $(0.016)^{*}$ & $(0.049)^{*}$ & $(0.024)^{*}$ & $(0.051)^{*}$ & $(0.045)^{*}$ & $(0.090)^{*}$ & & & & \\
\hline Louisiana & 0.121 & 0.081 & 0.021 & 0.898 & & & & & & \\
\hline & $(0.016)^{*}$ & $(0.045)^{*}$ & $(0.036)$ & $(0.125)^{*}$ & & & & & & \\
\hline Maine & 0.343 & 0.132 & & & & & & & & \\
\hline & $(0.020)^{*}$ & $(0.040)^{*}$ & & & & & & & & \\
\hline Maryland & 0.101 & 0.030 & 0.068 & 0.583 & & & & & & \\
\hline & $(0.011)^{*}$ & $(0.024)$ & $(0.039)^{*}$ & $(0.105)^{*}$ & & & & & & \\
\hline Massachusetts & 0.089 & 0.209 & 0.063 & 0.177 & & & & & & \\
\hline & $(0.010)^{*}$ & $(0.060)^{*}$ & $(0.039)$ & $(0.046)^{*}$ & & & & & & \\
\hline Michigan & 0.208 & 0.999 & 0.000 & & & & & & & \\
\hline & $(0.016)^{*}$ & $(0.123)^{*}$ & $(0.027)$ & & & & & & & \\
\hline Minnesota & 0.074 & 0.084 & 0.071 & 0.587 & & & & & & \\
\hline & $(0.008)^{*}$ & $(0.026)^{*}$ & $(0.042)^{*}$ & $(0.104)^{*}$ & & & & & & \\
\hline Mississippi & 0.170 & 0.142 & 0.044 & 0.169 & & & & & & \\
\hline & $(0.018)^{*}$ & $(0.054)^{*}$ & $(0.037)$ & $(0.051)^{*}$ & & & & & & \\
\hline
\end{tabular}




\section{Table 2.4 Continued}

Equation 2.3 estimates, the volatility equation, displayed for MO-WY

\begin{tabular}{|c|c|c|c|c|c|c|c|c|c|c|}
\hline State & $\omega^{\dagger}$ & $\alpha_{1}$ & $\alpha_{2}$ & $\alpha_{3}$ & $\alpha_{4}$ & $\alpha_{5}$ & $\alpha_{6}$ & $\alpha_{7}$ & $\alpha_{8}$ & $\alpha_{9}$ \\
\hline \multirow[t]{2}{*}{ Missouri } & 0.136 & 0.062 & 0.104 & 0.204 & & & & & & \\
\hline & $(0.016)^{*}$ & $(0.052)$ & $(0.038)^{*}$ & $(0.065)^{*}$ & & & & & & \\
\hline \multirow[t]{2}{*}{ Montana } & 0.452 & 0.006 & 0.115 & 0.170 & & & & & & \\
\hline & $(0.045)^{*}$ & $(0.039)$ & $(0.040)^{*}$ & $(0.073)^{*}$ & & & & & & \\
\hline \multirow[t]{2}{*}{ Nebraska } & 0.136 & 0.000 & 0.000 & 0.074 & 0.185 & & & & & \\
\hline & $(0.014)^{*}$ & $(0.039)$ & $(0.033)$ & $(0.043)^{*}$ & $(0.058)^{*}$ & & & & & \\
\hline \multirow[t]{2}{*}{ Nevada } & 0.140 & 0.104 & 0.255 & 0.102 & 0.119 & 0.243 & & & & \\
\hline & $(0.022)^{*}$ & $(0.045)^{*}$ & $(0.060)^{*}$ & $(0.054)^{*}$ & $(0.053)^{*}$ & $(0.062)^{*}$ & & & & \\
\hline \multirow[t]{2}{*}{ New Hampshire } & 0.099 & 0.119 & 0.015 & 0.814 & 0.052 & & & & & \\
\hline & $(0.020)^{*}$ & $(0.044)^{*}$ & $(0.022)$ & $(0.109)^{*}$ & $(0.028)^{*}$ & & & & & \\
\hline \multirow[t]{2}{*}{ New Mexico } & 0.128 & 0.094 & 0.227 & 0.090 & 0.000 & 0.143 & & & & \\
\hline & $(0.020)^{*}$ & $(0.055)^{*}$ & $(0.062)^{*}$ & $(0.056)$ & $(0.042)$ & $(0.051)^{*}$ & & & & \\
\hline \multirow[t]{2}{*}{ New York } & 0.088 & 0.302 & 0.066 & & & & & & & \\
\hline & $(0.007)^{*}$ & $(0.077)^{*}$ & $(0.031)^{*}$ & & & & & & & \\
\hline \multirow[t]{2}{*}{ North Carolina } & 0.110 & 0.141 & 0.077 & 0.182 & & & & & & \\
\hline & $(0.012)^{*}$ & $(0.057)^{*}$ & $(0.059)$ & $(0.069)^{*}$ & & & & & & \\
\hline \multirow[t]{2}{*}{ North Dakota } & 0.201 & 0.301 & 0.000 & 0.054 & 0.000 & 0.081 & 0.063 & & & \\
\hline & $(0.023)^{*}$ & $(0.080)^{*}$ & $(0.051)$ & $(0.036)$ & $(0.039)$ & $(0.035)^{*}$ & $(0.031)^{*}$ & & & \\
\hline \multirow[t]{2}{*}{ Ohio } & 0.051 & 0.135 & 0.112 & 0.000 & 0.040 & 0.040 & 0.403 & & & \\
\hline & $(0.010)^{*}$ & $(0.051)^{*}$ & $(0.041)^{*}$ & $(0.046)$ & $(0.043)$ & $(0.041)$ & $(0.081)^{*}$ & & & \\
\hline \multirow[t]{2}{*}{ Oklahoma } & 0.154 & 0.082 & 0.113 & 0.256 & & & & & & \\
\hline & $(0.014)^{*}$ & $(0.047)^{*}$ & $(0.039)^{*}$ & $(0.055)^{*}$ & & & & & & \\
\hline \multirow[t]{2}{*}{ Oregon } & 0.078 & 0.121 & 0.150 & 0.000 & 0.634 & 0.095 & & & & \\
\hline & $(0.018)^{*}$ & $(0.057)^{*}$ & $(0.052)^{*}$ & $(0.034)$ & $(0.101)^{*}$ & $(0.047)^{*}$ & & & & \\
\hline \multirow[t]{2}{*}{ Pennsylvania } & 0.085 & 0.131 & 0.000 & 0.254 & & & & & & \\
\hline & $(0.009)^{*}$ & $(0.043)^{*}$ & $(0.034)$ & $(0.070)^{*}$ & & & & & & \\
\hline \multirow[t]{2}{*}{ Rhode Island } & 0.253 & 0.259 & & & & & & & & \\
\hline & $(0.018)^{*}$ & $(0.056)^{*}$ & & & & & & & & \\
\hline \multirow[t]{2}{*}{ South Carolina } & 0.162 & 0.157 & 0.089 & 0.103 & & & & & & \\
\hline & $(0.018)^{*}$ & $(0.057)^{*}$ & $(0.042)^{*}$ & $(0.057)^{*}$ & & & & & & \\
\hline \multirow[t]{2}{*}{ South Dakota } & 0.134 & 0.148 & 0.187 & 0.304 & & & & & & \\
\hline & $(0.023)^{*}$ & $(0.052)^{*}$ & $(0.058)^{*}$ & $(0.078)^{*}$ & & & & & & \\
\hline \multirow[t]{2}{*}{ Tennessee } & 0.128 & 0.078 & 0.242 & & & & & & & \\
\hline & $(0.012)^{*}$ & $(0.042)^{*}$ & $(0.051)^{*}$ & & & & & & & \\
\hline \multirow[t]{2}{*}{ Texas } & 0.033 & 0.136 & 0.003 & 0.268 & 0.007 & 0.160 & 0.236 & & & \\
\hline & $(0.006)^{*}$ & $(0.045)^{*}$ & $(0.048)$ & $(0.076)^{*}$ & $(0.040)$ & $(0.061)^{*}$ & $(0.075)^{*}$ & & & \\
\hline Utah & 0.031 & 0.018 & 0.152 & 0.105 & 0.063 & 0.054 & 0.262 & 0.074 & 0.192 & \\
\hline & $(0.010)^{*}$ & $(0.033)$ & $(0.045)^{*}$ & $(0.042)^{*}$ & $(0.045)$ & $(0.052)$ & $(0.073)^{*}$ & $(0.045)^{*}$ & $(0.064)^{*}$ & \\
\hline Vermont & 0.209 & 0.671 & 0.329 & & & & & & & \\
\hline & $(0.032)^{*}$ & $(0.096)^{*}$ & $(0.074)^{*}$ & & & & & & & \\
\hline Virginia & 0.085 & 0.044 & 0.248 & 0.040 & 0.000 & 0.236 & & & & \\
\hline & $(0.011)^{*}$ & $(0.037)$ & $(0.061)^{*}$ & $(0.037)$ & $(0.021)$ & $(0.072)^{*}$ & & & & \\
\hline Washington & 0.082 & 0.351 & 0.151 & 0.041 & 0.005 & 0.010 & 0.234 & & & \\
\hline & $(0.018)^{*}$ & $(0.086)^{*}$ & $(0.060)^{*}$ & $(0.043)$ & $(0.039)$ & $(0.027)$ & $(0.062)^{*}$ & & & \\
\hline West Virginia & 0.248 & 0.107 & 0.052 & 0.841 & & & & & & \\
\hline & $(0.032)^{*}$ & $(0.052)^{*}$ & $(0.020)^{*}$ & $(0.088)^{*}$ & & & & & & \\
\hline Wisconsin & 0.036 & 0.145 & 0.051 & 0.272 & 0.038 & 0.161 & 0.096 & 0.072 & & \\
\hline & $(0.009)^{*}$ & $(0.059)^{*}$ & $(0.051)$ & $(0.075)^{*}$ & $(0.049)$ & $(0.060)^{*}$ & $(0.054)^{*}$ & $(0.043)^{*}$ & & \\
\hline Wyoming & 0.442 & 0.250 & 0.331 & 0.062 & 0.079 & & & & & \\
\hline & $(0.056)^{*}$ & $(0.064)^{*}$ & $(0.083)^{*}$ & $(0.036)^{*}$ & $(0.031)^{*}$ & & & & & \\
\hline
\end{tabular}


1-month, 3-month, 6-month and 12-month (or 1-year) ahead forecasts.

These are out-of-sample; forecast and the initial regressions are calculated using the data through November 2008. Given that 6 own lags are needed for the employment growth rate regression, the data begins in June of 1960 . This leaves 581 obs. per state for the first estimates of the state employment growth regression and the volatility equation. The estimated coefficients of these equations are held constant and forecast estimates are produced until the end of the data series is reached. As an example, in the estimation of this first volatility equation, a 1-month, 2-month, 3-month, and so on through 12-month ahead forecast will be produced. Through this forecast structure in total 12 1-month, 10 3-month, 7 6-month,and 1 12-month ahead forecast will be produced for each state. This means the 1-Months MSE will have higher robustness than the other forecast because of the higher number of the forecast observations. Table 2.5 through Table 2.10 display the resulting mean square errors (MSE) of these forecasts. The first displayed is the MSE adjusted for the number of forecast, Equation 2.5. The mean square errors have been scaled by 1E10 to make them user friendly. Also displayed, is the forecast error in terms of percentage, Equation 2.6.

$$
\begin{aligned}
& M S E=\frac{\sum_{k=1}^{n}\left(\sigma_{i, t+k}^{2}-\sigma_{i, t+k}^{2 \hat{}}\right)^{2}}{n} \\
& \text { Error } \%=\left(\frac{\sigma_{i, t+k}^{2}-\sigma_{i, t+k}^{2}}{\sigma_{i, t+k}^{2}}\right) \frac{100}{n}
\end{aligned}
$$

Table $2.5 \& 2.6$ displays the results from forecast models based on the ARCH length specification algorithm.

As a comparison model, Tables $2.7 \& 2.8$ display the results from forecast using a GARCH $(1,1)$. There are many choices in the selection of a comparison model; the $\operatorname{GARCH}(1,1)$ is chosen for a few strategic reason. Enders (2010) refers to Bollerslev (1986) seminal paper as a juxtaposition between an ARCH model, a traditional AR model, and this new GARCH. Bollerslev (1986) position the GARCH model as a natural extend to the $\mathrm{ARCH}$, it allows for the past conditional variance(s) to effect the current. The author further states the $\operatorname{GARCH}(1,1)$ is a simple but effective model.

This is demonstrated by an empirical example comparing the works of Engle and Karft (1983), an analysis of an ARCH framework on the growth rate of U.S. implicit GNP deflator from 1948Q2 to 1980Q3. Bollerslev (1986) changes the $\mathrm{ARCH}(8)$ specification suggested by Engle and Karft (1983) to GARCH formulation. The $\operatorname{GARCH}(1,2) / \operatorname{GARCH}(2,1)$ forms are insignificant according to the LM test. The $\operatorname{GARCH}(1,1)$ is used as the comparison 
model. The author demonstrates the $\operatorname{GARCH}(1,1)$ provides a better model fit and lag structure then the $\mathrm{ARCH}(8)$.

For the specification of $\operatorname{GARCH}(1,1)$, the focus here is on the presence of autoregressive conditional heteroskedastic models and their use in predicting state level employment growth. The addition of 1 generalized autoregressive and restricting the autoregressive term to 1, demonstrates the persistence of autoregressive error. Similar to an ARMA process for a mean equation fitted while with a long series of AR terms, the addition of a MA term can help reduce the persistence autoregressive terms. Therefore, the use of GARCH $(1,1)$ comparison can demonstrate value of the generalized volatility for those states with high ARCH lag length. For instance, if a comparison of a $\operatorname{GARCH}(1,0)$ was use it would not be readily apparent that the benefit of the addition of the generalized moment to the autoregressive in the difference of the forecast error.

In this model, the state employment growth regression is the same, however, the volatility equation is specified as follows:

$$
\sigma_{i, t}^{2}=\omega_{i}+\vartheta_{i, 1} \sigma_{i, t-1}^{2}+\alpha_{i, 1} \epsilon_{i, t-1}^{2}
$$

Lastly, Tables $2.9 \& 2.10$ displays results from a forecast comparison using a white noise process. The advocacy of this theory stems from the phenomenon that a perfectly theoretically sound regression produces unbiased and efficient estimators, which means the error term should follow a white noise process. To test this hypothesis, an error term is generated using a random number generator with mean 0 and a standard deviation equal to the state employment regression residual standard deviation.

$$
\hat{\varepsilon}_{581+q} \sim \mathcal{N}\left(0, \sigma_{\varepsilon_{1 \ldots 580+q}}^{2}\right)
$$

Tables 2.5 \& 2.6 illustrates the forecast based on ARCH length specification algorithm performed well overall. The mean of the 6 -month ahead forecast is slightly higher than the mean of the 12-month. However, this is due solely to the outlying error of Nevada. The state average of a 6-month ahead forecast drops to $-8.35 \%$, out-performing the 12 -month forecast, when Nevada is excluded from the mean. It is noteworthy to point out that all of the state means in Table 2.5 are negative, indicating this model has a trend to under-predict the volatility of state employment growth. Also displayed in Table 2.6 is the mean of the absolute percentage change, ABS Mean. At each step-ahead forecast the absolute percentage change is greater than the percentage change, suggesting there is some cancellation between positive and negative changes. The 12-step ahead showed the largest difference between these two values, jumping to $19.56 \%$ for the absolute percentage 
Table 2.5: ${ }^{\dagger}$

\begin{tabular}{|c|c|c|c|c|c|c|c|c|c|}
\hline State & 1-Month & 3-Month & 6-Month & 12-Month & State & 1-Month & 3-Month & 6-Month & 12-Month \\
\hline Alabama & 0.0122 & 0.0087 & 0.0202 & 0.0145 & Missouri & 0.0010 & 0.0014 & 0.0012 & 0.0015 \\
\hline Alaska & 0.1256 & 1.1162 & 3.1887 & 0.0267 & Montana & 0.0768 & 0.0528 & 0.2991 & 0.3712 \\
\hline Arizona & 0.0507 & 0.0292 & 0.1348 & 0.1854 & Nebraska & 0.0007 & 0.0012 & 0.0163 & 0.0000 \\
\hline Arkansas & 0.1010 & 0.3856 & 0.6218 & 0.0005 & Nevada & 0.1417 & 0.8998 & 36.1431 & 1.2489 \\
\hline California & 0.0045 & 0.0088 & 0.0696 & 0.1672 & New Hampshire & 0.0171 & 0.0293 & 0.4384 & 0.1206 \\
\hline Colorado & 0.0141 & 0.0291 & 0.1164 & 0.5145 & New Mexico & 0.0126 & 0.0373 & 0.2935 & 0.0032 \\
\hline Connecticut & 0.0002 & 0.0021 & 0.0143 & 0.0154 & New York & 0.0049 & 0.0325 & 0.1666 & 0.0022 \\
\hline Delaware & 0.2036 & 0.3058 & 0.3808 & 0.3178 & North Carolina & 0.0008 & 0.0087 & 0.1078 & 0.0560 \\
\hline District of Columbia & 0.0014 & 0.0228 & 0.1528 & 0.0337 & North Dakota & 0.0193 & 0.2149 & 0.5984 & 0.0754 \\
\hline Florida & 0.0273 & 2.5413 & 1.8000 & 1.3656 & Ohio & 0.0055 & 0.0179 & 0.0614 & 0.1125 \\
\hline Georgia & 0.0021 & 0.0071 & 0.0226 & 0.0586 & Oklahoma & 0.0009 & 0.0043 & 0.0165 & 0.0057 \\
\hline Hawaii & 0.0394 & 0.2896 & 1.7139 & 6.2214 & Oregon & 1.0214 & 1.4549 & 1.8963 & 10.4299 \\
\hline Idaho & 0.0359 & 0.2454 & 0.5589 & 0.0176 & Pennsylvania & 0.0002 & 0.0005 & 0.0024 & 0.0048 \\
\hline Illinois & 0.0012 & 0.0040 & 0.0180 & 0.1073 & Rhode Island & 0.0020 & 0.1146 & 0.2752 & 0.2584 \\
\hline Indiana & 0.0008 & 0.0012 & 0.0653 & 0.0604 & South Carolina & 0.0005 & 0.0027 & 0.0089 & 0.0247 \\
\hline Iowa & 0.0363 & 0.0490 & 0.0404 & 0.2409 & South Dakota & 0.0046 & 0.0100 & 0.0663 & 0.0014 \\
\hline Kansas & 0.0072 & 0.0495 & 0.2573 & 0.4724 & Tennessee & 0.0010 & 0.0073 & 0.0472 & 0.0004 \\
\hline Kentucky & 0.1128 & 0.0998 & 0.2499 & 0.9221 & Texas & 0.0056 & 0.0056 & 0.0230 & 0.0331 \\
\hline Louisiana & 9.0004 & 0.1662 & 2.8956 & 17.0499 & Utah & 0.0045 & 0.0123 & 0.2674 & 1.0959 \\
\hline Maine & 0.0011 & 0.0035 & 0.0098 & 0.0002 & Vermont & 0.0698 & 0.0962 & 1.0592 & 0.1506 \\
\hline Maryland & 0.0043 & 0.0027 & 0.0987 & 0.0071 & Virginia & 0.4279 & 0.5304 & 0.3470 & 0.0098 \\
\hline Massachusetts & 0.0046 & 0.0040 & 0.0094 & 0.0023 & Washington & 0.0172 & 0.0716 & 0.4802 & 0.8588 \\
\hline Michigan & 0.2825 & 2.1449 & 0.9658 & 9.2416 & West Virginia & 0.0240 & 0.0809 & 5.6357 & 0.0054 \\
\hline Minnesota & 0.0010 & 0.0013 & 0.0137 & 0.6648 & Wisconsin & 0.0048 & 0.0135 & 0.0186 & 0.2461 \\
\hline Mississippi & 0.0063 & 0.0213 & 0.0214 & 0.0504 & Wyoming & 0.0648 & 3.5373 & 28.0114 & 8.9208 \\
\hline Mean MSE & 0.2401 & 0.2955 & 1.7944 & 1.2359 & & & & & \\
\hline
\end{tabular}

change. However, the 12-step ahead MSE is only based on one forecast obs., which makes it less robust than the other steps. The smallest forecast MSE is demonstrated by the 12-month forecast for Nebraska, followed by the 1month forecast for Connecticut. The largest forecast MSE was displayed by the 6-month forecast for Nevada.

The results of the $\operatorname{GARCH}(1,1)$ also performed very well. In fact, the average state forecast MSE and percent error out-performed the forecast based on the ARCH length specification algorithm for each step. This evidence suggests that using the first lag of the volatility itself for estimating the current volatility is a very powerful tool. The mean of the forecast MSE once again follows the correct progression of increasing over the forecast horizon, except for the 12-month ahead has a lower MSE than the 3-month and 6-month.

As Tables 2.7 \& 2.8 shows, the mean of the forecast percent error does increase over the forecast horizon. The absolute percentage change in the forecast error was once again higher on all counts, suggesting some cancellation between the errors. The forecast error absolute percentage change is still lower for the GARCH $(1,1)$ then for the algorithm based model. The lowest forecast MSE is held by the 12-month ahead forecast for Louisiana, followed closely by the 1-step ahead forecast for Minnesota. The highest MSE for the 


\section{Table 2.6}

1-Month, 3-Month, 6-Month, \& 12-Month Ahead Percent Forecast Error for the Algorithm Specified ARCH Model

\begin{tabular}{|c|c|c|c|c|c|c|c|c|c|}
\hline State & 1-Month & 3-Month & 6-Month & 12-Month & State & 1-Month & 3-Month & 6-Month & 12-Month \\
\hline Alabama & -0.65 & -2.19 & -4.30 & 10.15 & Missouri & -1.54 & -2.07 & -0.22 & -2.56 \\
\hline Alaska & -2.53 & -10.34 & -23.28 & 2.31 & Montana & 2.75 & 1.18 & -3.67 & 9.23 \\
\hline Arizona & -1.42 & -3.06 & -7.58 & -14.65 & Nebraska & 0.11 & 0.34 & -1.90 & -0.27 \\
\hline Arkansas & -8.36 & -15.79 & -30.16 & -1.59 & Nevada & -6.94 & -16.63 & -110.27 & -21.32 \\
\hline California & -2.62 & -5.51 & -19.89 & -37.70 & New Hampshire & -2.69 & -4.79 & 0.11 & 24.56 \\
\hline Colorado & -6.66 & -8.56 & -18.54 & -73.66 & New Mexico & -1.82 & -4.37 & -13.07 & 3.22 \\
\hline Connecticut & -0.55 & -2.45 & -6.52 & -7.39 & New York & -0.37 & -3.22 & -5.58 & -5.06 \\
\hline Delaware & -5.55 & -5.30 & -6.83 & -22.85 & North Carolina & -0.30 & -2.88 & -12.33 & -14.12 \\
\hline District of Columbia & -0.21 & -1.22 & -3.75 & -4.34 & North Dakota & 0.09 & -1.33 & -0.87 & -7.04 \\
\hline Florida & -0.08 & -3.14 & 1.85 & 14.22 & Ohio & -0.36 & -3.43 & -12.76 & -28.71 \\
\hline Georgia & -0.37 & -0.86 & -3.87 & -17.21 & Oklahoma & -0.71 & -1.95 & -3.58 & -3.96 \\
\hline Hawaii & -1.55 & -4.90 & 0.32 & 30.31 & Oregon & -5.31 & -1.68 & -15.42 & 30.35 \\
\hline Idaho & -2.08 & -5.59 & -7.93 & -3.84 & Pennsylvania & -0.35 & -0.79 & -2.30 & 6.15 \\
\hline Illinois & -0.82 & -4.30 & -9.81 & -30.88 & Rhode Island & -0.15 & -2.34 & -3.72 & -14.25 \\
\hline Indiana & 0.07 & -1.05 & -4.77 & -7.39 & South Carolina & -0.80 & -2.50 & -4.35 & -8.74 \\
\hline Iowa & -1.95 & -2.83 & -5.77 & 44.46 & South Dakota & 1.45 & -1.03 & -3.48 & 1.90 \\
\hline Kansas & 0.64 & -2.16 & -4.63 & -16.98 & Tennessee & -0.34 & -1.70 & -6.82 & -1.50 \\
\hline Kentucky & -5.67 & -7.30 & -10.63 & -33.26 & Texas & 0.67 & -0.22 & -3.62 & 25.86 \\
\hline Louisiana & 6.96 & -2.62 & -6.99 & -71.12 & Utah & -3.13 & -4.34 & -19.06 & -64.31 \\
\hline Maine & -0.83 & -1.37 & -0.59 & -0.34 & Vermont & -2.69 & -5.47 & -19.39 & -15.15 \\
\hline Maryland & -1.53 & -1.96 & -13.34 & -8.12 & Virginia & -4.57 & -6.58 & -24.48 & -6.41 \\
\hline Massachusetts & -0.46 & -2.21 & -3.77 & 3.97 & Washington & -1.07 & -3.51 & -18.30 & -48.87 \\
\hline Michigan & -0.60 & -25.19 & -18.40 & -111.56 & West Virginia & -2.21 & -0.13 & 10.73 & -2.78 \\
\hline Minnesota & -0.14 & 0.02 & 2.48 & 12.81 & Wisconsin & -0.14 & -0.36 & 1.83 & -15.26 \\
\hline Mississippi & 0.23 & -1.15 & 0.60 & -5.70 & Wyoming & -0.49 & -13.64 & -40.63 & 29.83 \\
\hline Mean & -1.35 & -4.09 & -10.39 & -9.59 & ABS Mean & 3.53 & 6.50 & 14.98 & 19.56 \\
\hline
\end{tabular}

Table 2.7: ${ }^{\dagger}$

1-Month, 3-Month, 6-Month, \& 12-Month Ahead Forecast MSE for the GARCH(1,1) Specified Model

\begin{tabular}{|c|c|c|c|c|c|c|c|c|c|}
\hline State & 1-Month & 3-Month & 6-Month & 12-Month & State & 1-Month & 3-Month & 6-Month & 12-Month \\
\hline Alabama & 0.0041 & 0.0053 & 0.0062 & 0.0006 & Missouri & 0.0012 & 0.0016 & 0.0020 & 0.0042 \\
\hline Alaska & 0.0295 & 0.1222 & 0.3544 & 0.0088 & Montana & 0.0143 & 0.0068 & 0.0037 & 0.1229 \\
\hline Arizona & 0.0089 & 0.0129 & 0.0184 & 0.0209 & Nebraska & 0.0008 & 0.0004 & 0.0034 & 0.0084 \\
\hline Arkansas & 0.0002 & 0.0011 & 0.0042 & 0.0005 & Nevada & 0.0133 & 0.0975 & 2.1822 & 4.0063 \\
\hline California & 0.0007 & 0.0011 & 0.0069 & 0.0380 & New Hampshire & 0.0039 & 0.0154 & 0.0207 & 0.0146 \\
\hline Colorado & 0.0017 & 0.0044 & 0.0218 & 0.0626 & New Mexico & 0.0004 & 0.0024 & 0.0206 & 0.0194 \\
\hline Connecticut & 0.0002 & 0.0011 & 0.0052 & 0.0204 & New York & 0.0005 & 0.0008 & 0.0032 & 0.0198 \\
\hline Delaware & 0.1415 & 0.1494 & 0.2395 & 0.5334 & North Carolina & 0.0007 & 0.0066 & 0.0571 & 0.0829 \\
\hline District of Columbia & 0.0012 & 0.0028 & 0.0405 & 0.1718 & North Dakota & 0.0116 & 0.0163 & 0.0374 & 0.0211 \\
\hline Florida & 0.0188 & 0.0810 & 0.1894 & 0.0325 & Ohio & 0.0004 & 0.0022 & 0.0253 & 0.0658 \\
\hline Georgia & 0.0011 & 0.0034 & 0.0143 & 0.0160 & Oklahoma & 0.0004 & 0.0014 & 0.0070 & 0.0077 \\
\hline Hawaii & 0.0391 & 0.0583 & 0.0857 & 0.0097 & Oregon & 0.0056 & 0.0137 & 0.0909 & 0.0430 \\
\hline Idaho & 0.0085 & 0.0164 & 0.0340 & 0.0129 & Pennsylvania & 0.0003 & 0.0006 & 0.0011 & 0.0005 \\
\hline Illinois & 0.0005 & 0.0009 & 0.0030 & 0.0151 & Rhode Island & 0.0012 & 0.0039 & 0.0097 & 0.0421 \\
\hline Indiana & 0.0031 & 0.0041 & 0.0175 & 0.0475 & South Carolina & 0.0005 & 0.0026 & 0.0079 & 0.0206 \\
\hline Iowa & 0.0005 & 0.0004 & 0.0001 & 0.0017 & South Dakota & 0.0011 & 0.0004 & 0.0016 & 0.0046 \\
\hline Kansas & 0.0012 & 0.0019 & 0.0087 & 0.0013 & Tennessee & 0.0276 & 0.0789 & 0.0371 & 0.0029 \\
\hline Kentucky & 0.0053 & 0.0105 & 0.0279 & 0.0998 & Texas & 0.0004 & 0.0002 & 0.0041 & 0.0070 \\
\hline Louisiana & 0.0002 & 0.0035 & 0.0119 & 0.0000 & Utah & 0.0012 & 0.0071 & 0.1430 & 0.1717 \\
\hline Maine & 0.0126 & 0.0172 & 0.0300 & 0.0375 & Vermont & 0.1168 & 0.1384 & 0.2840 & 0.5499 \\
\hline Maryland & 0.0003 & 0.0007 & 0.0031 & 0.0121 & Virginia & 0.0003 & 0.0007 & 0.0016 & 0.0005 \\
\hline Massachusetts & 0.0072 & 0.0059 & 0.0076 & 0.0051 & Washington & 0.0040 & 0.0074 & 0.0416 & 0.2083 \\
\hline Michigan & 0.0057 & 0.0038 & 0.0034 & 0.0360 & West Virginia & 0.0285 & 14.4433 & 31.5146 & 0.0045 \\
\hline Minnesota & 0.0001 & 0.0004 & 0.0043 & 0.0151 & Wisconsin & 0.0002 & 0.0030 & 0.0080 & 0.0089 \\
\hline Mississippi & 0.0019 & 0.0133 & 0.0213 & 0.0418 & Wyoming & 0.0390 & 0.0381 & 0.8568 & 0.2743 \\
\hline Mean MSE & 0.0114 & 0.3082 & 0.7305 & 0.1391 & & & & & \\
\hline
\end{tabular}




\section{Table 2.8}

1-Month, 3-Month, 6-Month, \& 12-Month Ahead Percent Forecast Error for the GARCH(1,1) Specified Model

\begin{tabular}{|c|c|c|c|c|c|c|c|c|c|}
\hline State & 1-Month & 3-Month & 6-Month & 12-Month & State & 1-Month & 3-Month & 6-Month & 12-Month \\
\hline Alabama & -2.85 & -3.70 & -4.01 & -1.69 & Missouri & -2.63 & -3.34 & -4.01 & -6.03 \\
\hline Alaska & -2.95 & -5.38 & -11.36 & 1.86 & Montana & 3.67 & 2.39 & 1.02 & 10.02 \\
\hline Arizona & -0.98 & -2.30 & -3.94 & 5.06 & Nebraska & 2.04 & 0.19 & -1.75 & -6.68 \\
\hline Arkansas & -1.00 & -2.04 & -4.05 & -1.93 & Nevada & -2.97 & -8.71 & -45.79 & -57.93 \\
\hline California & -2.13 & -3.50 & -9.68 & -22.01 & New Hampshire & -2.16 & -4.81 & -6.56 & 6.11 \\
\hline Colorado & -3.91 & -5.94 & -11.69 & -27.59 & New Mexico & -1.08 & -2.90 & -8.39 & -8.79 \\
\hline Connecticut & -1.44 & -3.25 & -7.05 & -15.26 & New York & 0.81 & -0.44 & -2.61 & -10.88 \\
\hline Delaware & -11.35 & -13.44 & -18.97 & -33.08 & North Carolina & -0.85 & -2.82 & -9.39 & -14.28 \\
\hline District of Columbia & -0.20 & -0.85 & -3.35 & -9.24 & North Dakota & -2.03 & -2.63 & -2.87 & -3.29 \\
\hline Florida & -1.74 & -2.56 & -0.16 & -2.53 & Ohio & 0.90 & -1.92 & -11.24 & -20.88 \\
\hline Georgia & -0.14 & -1.35 & -4.34 & 8.14 & Oklahoma & -0.91 & -2.24 & -4.11 & -5.51 \\
\hline Hawaii & -2.81 & -3.65 & -5.08 & -1.67 & Oregon & -3.31 & -5.04 & -12.43 & -8.85 \\
\hline Idaho & -2.85 & -4.23 & -6.73 & -4.09 & Pennsylvania & -1.79 & -2.60 & -3.59 & -2.33 \\
\hline Illinois & -1.89 & -3.12 & -5.92 & -14.43 & Rhode Island & -1.03 & -1.73 & -3.35 & -8.77 \\
\hline Indiana & -1.86 & -2.53 & -5.36 & -9.65 & South Carolina & -0.66 & -2.40 & -4.11 & -8.16 \\
\hline Iowa & 1.25 & 0.39 & -0.64 & 3.58 & South Dakota & 1.70 & 0.48 & -1.10 & -4.40 \\
\hline Kansas & 1.55 & 0.92 & 0.46 & -1.56 & Tennessee & 1.93 & 2.03 & -2.60 & -3.80 \\
\hline Kentucky & -2.99 & -4.39 & -6.49 & -14.31 & Texas & 1.30 & 0.54 & -3.60 & 5.95 \\
\hline Louisiana & -0.36 & -1.39 & -3.01 & 0.01 & Utah & -2.10 & -4.75 & -18.92 & -28.40 \\
\hline Maine & -8.38 & -11.18 & -15.49 & -17.19 & Vermont & -11.38 & -13.94 & -21.82 & -32.06 \\
\hline Maryland & -1.17 & -2.06 & -4.52 & -9.55 & Virginia & -1.46 & -2.16 & -3.37 & -2.16 \\
\hline Massachusetts & -3.82 & -4.39 & -5.06 & -5.89 & Washington & -1.74 & -2.58 & -5.50 & -14.15 \\
\hline Michigan & 2.84 & 1.60 & -0.96 & -6.91 & West Virginia & -0.97 & 6.07 & -6.45 & 1.71 \\
\hline Minnesota & 0.32 & -0.13 & -0.25 & 6.20 & Wisconsin & 0.13 & -0.20 & 1.76 & -4.41 \\
\hline Mississippi & 0.19 & -1.72 & 0.20 & -8.88 & Wyoming & 6.36 & -1.45 & -24.64 & -12.14 \\
\hline Mean MSE & -1.34 & -2.70 & -6.86 & -8.45 & ABS Mean & 2.58 & 4.26 & 8.54 & 10.40 \\
\hline
\end{tabular}

\section{Table 2.9: ${ }^{\dagger}$}

1-Month, 3-Month, 6-Month, \& 12-Month White Noise Process Forecast MSE

\begin{tabular}{|c|c|c|c|c|c|c|c|c|c|}
\hline State & 1-Month & 3-Month & 6-Month & 12-Month & State & 1-Month & 3-Month & 6-Month & 12-Month \\
\hline Alabama & 8.2219 & 11.7834 & 12.3633 & 1.9799 & Missouri & 4.8739 & 9.6795 & 5.7987 & 0.0028 \\
\hline Alaska & 268.4360 & 42.2698 & 943.3265 & 0.0786 & Montana & 182.2295 & 17.9328 & 63.0195 & 43.0603 \\
\hline Arizona & 73.9078 & 9.5004 & 6.8604 & 8.3784 & Nebraska & 3.1217 & 4.8689 & 8.7968 & 0.7098 \\
\hline Arkansas & 23.1969 & 2.1730 & 50.6233 & 1.7126 & Nevada & 14.2164 & 25.5968 & 62.3315 & 7.5469 \\
\hline California & 16.4316 & 4.0893 & 10.5261 & 0.1707 & New Hampshire & 43.5609 & 239.5309 & 88.5697 & 3.3501 \\
\hline Colorado & 5.2305 & 6.2011 & 30.4681 & 0.6301 & New Mexico & 16.2836 & 2.5454 & 18.3348 & 3.1220 \\
\hline Connecticut & 3.1863 & 9.8658 & 3.8473 & 1.9729 & New York & 6.8060 & 3.0857 & 2.3301 & 0.7612 \\
\hline Delaware & 19.4312 & 44.7284 & 66.0319 & 947.5934 & North Carolina & 2.7646 & 7.1811 & 3.9912 & 1.1559 \\
\hline District of Columbia & 14.8130 & 37.7972 & 108.8174 & 17.6396 & North Dakota & 32.1408 & 23.6519 & 11.5053 & 10.5565 \\
\hline Florida & 33.4324 & 27.3232 & 42.0500 & 20.6800 & Ohio & 5.4891 & 14.5968 & 1.4617 & 0.5076 \\
\hline Georgia & 3.8916 & 3.8590 & 2.3906 & 0.5966 & Oklahoma & 9.2177 & 3.5918 & 8.0098 & 0.9436 \\
\hline Hawaii & 73.6731 & 66.2649 & 135.0967 & 50.7524 & Oregon & 37.4819 & 314.9361 & 130.7312 & 110.4641 \\
\hline Idaho & 16.8459 & 35.5788 & 55.2799 & 255.2506 & Pennsylvania & 2.9463 & 1.5035 & 1.6705 & 1.0057 \\
\hline Illinois & 1.6905 & 6.2790 & 3.2411 & 0.8796 & Rhode Island & 13.8014 & 5.4828 & 27.2803 & 12.7185 \\
\hline Indiana & 21.6205 & 120.1084 & 5.5448 & 11.0537 & South Carolina & 6.4346 & 23.8473 & 3.2133 & 1.8402 \\
\hline Iowa & 2.3645 & 52.5359 & 4.3578 & 0.8825 & South Dakota & 7.4803 & 10.7488 & 9.0898 & 3.2748 \\
\hline Kansas & 18.0717 & 14.7262 & 6.4631 & 11.5081 & Tennessee & 9.8356 & 9.5833 & 19.0329 & 1.4889 \\
\hline Kentucky & 64.2997 & 45.3653 & 12.9329 & 1.8602 & Texas & 1.7718 & 15.1218 & 1.0768 & 0.4934 \\
\hline Louisiana & 32.1043 & 69.3320 & 71.5334 & 33.4044 & Utah & 3.9940 & 20.9371 & 11.4376 & 0.8297 \\
\hline Maine & 7.6018 & 7.9137 & 9.0293 & 6.2197 & Vermont & 413.5752 & 55.0391 & 150.5772 & 832.6872 \\
\hline Maryland & 6.0321 & 16.1595 & 2.0660 & 0.3970 & Virginia & 7.9841 & 1.4229 & 0.9122 & 0.2011 \\
\hline Massachusetts & 6.2731 & 15.8457 & 0.6681 & 1.4209 & Washington & 9.5452 & 35.1210 & 51.8624 & 0.9063 \\
\hline Michigan & 90.5795 & 51.3749 & 111.4256 & 3.8160 & West Virginia & 558.4355 & 286.0652 & 621.9184 & 27.2076 \\
\hline Minnesota & 6.5433 & 15.3731 & 5.9778 & 39.6160 & Wisconsin & 4.4943 & 5.7581 & 5.6213 & 4.1582 \\
\hline Mississippi & 4.1236 & 8.4343 & 7.9908 & 0.5947 & Wyoming & 167.8514 & 200.2519 & 62.3286 & 71.1594 \\
\hline Mean MSE & 47.7668 & 41.2593 & 61.5963 & 51.1848 & & & & & \\
\hline
\end{tabular}

Hence, there is 11 one-step ahead forecast instead of 12 and 9 three-step ahead instead of 10 


\section{Table 2.10}

\begin{tabular}{|c|c|c|c|c|c|c|c|c|c|}
\hline State & 1-Month & 3-Month & 6-Month & 12-Month & State & 1-Month & 3-Month & 6-Month & 12-Month \\
\hline Alabama & -30.22 & -83.63 & -64.34 & -118.56 & Missouri & -19.45 & -66.41 & -50.16 & 3.44 \\
\hline Alaska & -59.82 & 16.68 & -242.01 & 3.97 & Montana & -118.06 & 27.67 & -8.70 & 99.46 \\
\hline Arizona & -150.19 & 8.12 & 52.72 & 98.50 & Nebraska & 35.95 & 2.24 & -50.50 & -43.55 \\
\hline Arkansas & -166.23 & 27.27 & -228.51 & 89.01 & Nevada & 14.21 & -10.62 & -26.72 & 52.40 \\
\hline California & -91.10 & -32.35 & -151.82 & -38.08 & New Hampshire & -101.76 & -254.56 & -113.48 & -129.43 \\
\hline Colorado & -33.84 & -16.19 & -162.71 & 81.51 & New Mexico & -1.86 & 3.96 & -9.00 & 100.00 \\
\hline Connecticut & -7.08 & -61.71 & -7.78 & 83.62 & New York & -41.34 & 3.93 & 33.15 & 93.45 \\
\hline Delaware & -11.19 & -65.88 & -120.80 & -1247.56 & North Carolina & 55.53 & -10.99 & 4.84 & 64.15 \\
\hline District of Columbia & 65.39 & 12.16 & -70.24 & 99.45 & North Dakota & -14.56 & -10.79 & -26.89 & 83.31 \\
\hline Florida & 23.04 & 59.55 & 74.56 & 55.33 & Ohio & 25.11 & -65.00 & 60.12 & -60.98 \\
\hline Georgia & -8.49 & 27.16 & -20.13 & 54.92 & Oklahoma & -62.90 & 51.10 & 38.77 & -50.80 \\
\hline Hawaii & 16.84 & -1.75 & 14.73 & 86.58 & Oregon & -17.85 & -191.94 & -76.63 & 98.79 \\
\hline Idaho & 18.46 & 6.07 & -89.23 & -463.32 & Pennsylvania & 6.03 & 12.56 & 15.11 & -88.58 \\
\hline Illinois & 5.99 & -24.34 & -2.98 & 88.39 & Rhode Island & 10.05 & 10.74 & 16.10 & -99.99 \\
\hline Indiana & -43.78 & -128.03 & 81.94 & 100.00 & South Carolina & -33.35 & -152.08 & -15.41 & 75.43 \\
\hline Iowa & 37.79 & -255.54 & 18.58 & 85.10 & South Dakota & 13.25 & -14.53 & 86.33 & 90.57 \\
\hline Kansas & 18.81 & 17.53 & 39.66 & -83.82 & Tennessee & -91.49 & -43.30 & -99.97 & 92.04 \\
\hline Kentucky & -136.94 & -68.62 & -8.37 & 47.24 & Texas & 33.34 & -107.27 & 27.75 & 99.78 \\
\hline Louisiana & 10.82 & -35.44 & -109.87 & 99.55 & Utah & 22.19 & -87.05 & -69.83 & 55.96 \\
\hline Maine & 41.59 & 72.26 & 40.95 & 69.29 & Vermont & -362.92 & -90.38 & -45.99 & -1126.80 \\
\hline Maryland & -40.79 & -74.27 & 5.95 & 60.72 & Virginia & -6.03 & 34.89 & 37.33 & 29.09 \\
\hline Massachusetts & 4.04 & -131.02 & 37.45 & 98.88 & Washington & 38.87 & -27.05 & -32.42 & -50.20 \\
\hline Michigan & 2.55 & -46.36 & -210.25 & 71.69 & West Virginia & -139.62 & -262.88 & -209.61 & -197.58 \\
\hline Minnesota & 24.22 & -63.60 & 31.31 & 98.89 & Wisconsin & 42.97 & 80.70 & 80.82 & 62.74 \\
\hline Mississippi & 57.16 & 15.04 & 94.02 & -19.57 & Wyoming & -13.25 & -26.55 & 56.12 & 84.26 \\
\hline Mean MSE & -23.60 & -40.41 & -27.52 & -23.23 & ABS Mean & 115.85 & 130.33 & 123.63 & 129.53 \\
\hline
\end{tabular}

GARCH(1,1) model is held by the 3 month and 6 month forecast for West Virginia.

The mean percent error in Tables $2.6 \& 2.8$ is particularly interesting since it speaks to the bias of the forecast. As stated before, the trend of the forecast error is correct across the horizon. However, it should be noted that each of the mean percent error under both the algorithm specified ARCH and $\operatorname{GARCH}(1,1)$ are negative at each forecast horizon. This implies that the forecasts of state-level employment growth that use these methods are biased downward. Therefore, forecasts will on average understate the magnitude of employment fluctuation. Seeing that the magnitude of the mean percent error is smaller under the $\operatorname{GARCH}(1,1)$, the bias is reduced under this model specification.

Finally, both of the volatility models are compared to the results of a randomly generated white noise process displayed in Tables $2.9 \& 2.10$. The results illustrate the use of a ARCH or GARCH model in defining volatility increases the predictability of state employment growth greatly. The algorithm generated $\mathrm{ARCH}$ model and the $\operatorname{GARCH}(1,1)$ outperform the white noise. The state average forecast MSEs are significantly higher than the volatility models, as well as the forecast percentage error and absolute forecast percentage error. 


\subsection{Conclusion}

The question addressed in this essay is whether state-level employment growth volatility follows an autoregressive conditional heteroskedastic (ARCH) process. An ARCH length specification algorithm was developed to determine the optimal lag length based on AIC and significance level. Forecasts were produced of this model and for two comparison models. The first comparison model was a standard $\operatorname{GARCH}(1,1)$ model to compare the feasibility of the algorithm's criteria and the addition of a generalized autoregressive moment. The second comparison is a randomly generated white noise process to analyze the performance of the volatility models.

The results demonstrated the $\operatorname{GARCH}(1,1)$ model outperformed the $\mathrm{ARCH}$ algorithm model, suggesting the generalized autoregressive term increases the predictability of state employment growth volatility. Second, the results state that both volatility models significantly over-performed the white noise. Given the information found in this study, when studying the effect of the state-level employment growth rate it is advantageous to also study its variance for greater forecast accuracy.

In concluding this article, it is interesting to consider some additional research. In the future, it would be beneficial to study the effects of including spatial spillover to the conditional mean regression. Second, it would be interesting to implement this study on other variables, such as state-level per capita personal income growth. 


\subsection{Appendix A: Additional Tables}

Table 2.11

Equation 2.2 estimates, displayed for AL-MS $\beta_{0}-\beta_{7}$

\begin{tabular}{|c|c|c|c|c|c|c|c|c|}
\hline \multirow[b]{2}{*}{ State } & \multirow[b]{2}{*}{$\beta_{0}$} & \multirow[b]{2}{*}{$\beta_{1}$} & \multicolumn{6}{|c|}{ AR Lags } \\
\hline & & & $\beta_{2}$ & $\beta_{3}$ & $\beta_{4}$ & $\beta_{5}$ & $\beta_{6}$ & $\beta_{7}$ \\
\hline \multirow[t]{2}{*}{ Alabama } & 0.011 & 0.437 & -0.081 & 0.092 & 0.118 & -0.066 & -0.020 & 0.177 \\
\hline & $(0.002)^{*}$ & $(0.077)^{*}$ & $(0.052)$ & $(0.044)^{*}$ & $(0.042)^{*}$ & $(0.043)$ & $(0.043)$ & $(0.034)^{*}$ \\
\hline \multirow[t]{2}{*}{ Alaska } & 0.014 & -0.242 & 0.200 & 0.002 & -0.019 & -0.131 & -0.154 & -0.213 \\
\hline & $(0.004)^{*}$ & $(0.134)^{*}$ & $(0.043)^{*}$ & $(0.037)$ & $(0.042)$ & $(0.044)^{*}$ & $(0.039)^{*}$ & $(0.036)^{*}$ \\
\hline \multirow[t]{2}{*}{ Arizona } & 0.018 & 0.458 & 0.023 & -0.027 & 0.154 & -0.080 & 0.137 & 0.308 \\
\hline & $(0.002)^{*}$ & $(0.077)^{*}$ & $(0.046)$ & $(0.043)$ & $(0.039)^{*}$ & $(0.037)^{*}$ & $(0.032)^{*}$ & $(0.035)^{*}$ \\
\hline \multirow[t]{2}{*}{ Arkansas } & 0.019 & 0.333 & 0.169 & 0.052 & 0.009 & -0.033 & -0.046 & 0.022 \\
\hline & $(0.002)^{*}$ & $(0.061)^{*}$ & $(0.044)^{*}$ & $(0.042)$ & $(0.048)$ & $(0.038)$ & $(0.041)$ & $(0.030)$ \\
\hline \multirow[t]{2}{*}{ California } & 0.013 & 0.419 & -0.013 & 0.088 & 0.318 & 0.013 & -0.069 & -0.003 \\
\hline & $(0.002)^{*}$ & $(0.079)^{*}$ & $(0.055)$ & $(0.044)^{*}$ & $(0.047)^{*}$ & $(0.046)$ & $(0.042)$ & $(0.047)$ \\
\hline \multirow[t]{2}{*}{ Colorado } & 0.011 & 0.376 & 0.000 & 0.131 & 0.264 & -0.105 & -0.049 & 0.172 \\
\hline & $(0.002)^{*}$ & $(0.081)^{*}$ & $(0.051)$ & $(0.037)^{*}$ & $(0.041)^{*}$ & $(0.043)^{*}$ & $(0.042)$ & $(0.043)^{*}$ \\
\hline \multirow[t]{2}{*}{ Connecticut } & -0.001 & 0.389 & -0.227 & 0.070 & 0.142 & 0.166 & 0.130 & 0.063 \\
\hline & $(0.002)$ & $(0.064)^{*}$ & $(0.050)^{*}$ & $(0.044)$ & $(0.049)^{*}$ & $(0.047)^{*}$ & $(0.041)^{*}$ & $(0.040)$ \\
\hline \multirow[t]{2}{*}{ Delaware } & 0.000 & 0.600 & -0.348 & -0.063 & 0.109 & -0.037 & 0.016 & 0.049 \\
\hline & $(0.003)$ & $(0.120)^{*}$ & $(0.050)^{*}$ & $(0.050)$ & $(0.044)^{*}$ & $(0.043)$ & $(0.046)$ & $(0.033)$ \\
\hline \multirow[t]{2}{*}{ District of Columbia } & 0.003 & 0.003 & -0.162 & -0.180 & 0.003 & -0.087 & 0.038 & 0.055 \\
\hline & $(0.003)$ & $(0.104)$ & $(0.049)^{*}$ & $(0.050)^{*}$ & $(0.046)$ & $(0.053)$ & $(0.052)$ & $(0.047)$ \\
\hline \multirow[t]{2}{*}{ Florida } & 0.013 & 0.200 & 0.237 & 0.122 & 0.194 & -0.133 & -0.063 & 0.071 \\
\hline & $(0.002)^{*}$ & $(0.075)^{*}$ & $(0.049)^{*}$ & $(0.041)^{*}$ & $(0.042)^{*}$ & $(0.041)^{*}$ & $(0.042)$ & $(0.040)^{*}$ \\
\hline \multirow[t]{2}{*}{ Georgia } & 0.006 & 0.321 & -0.098 & 0.045 & 0.191 & 0.065 & 0.079 & 0.189 \\
\hline & $(0.002)^{*}$ & $(0.071)^{*}$ & $(0.057)^{*}$ & $(0.039)$ & $(0.047)^{*}$ & $(0.040)$ & $(0.039)^{*}$ & $(0.041)^{*}$ \\
\hline \multirow[t]{2}{*}{ Hawaii } & 0.022 & 0.354 & 0.080 & -0.083 & -0.072 & -0.187 & -0.018 & 0.093 \\
\hline & $(0.003)^{*}$ & $(0.105)^{*}$ & $(0.040)^{*}$ & $(0.048)^{*}$ & $(0.035)^{*}$ & $(0.042)^{*}$ & $(0.034)$ & $(0.035)^{*}$ \\
\hline \multirow[t]{2}{*}{ Idaho } & 0.027 & 0.759 & 0.125 & -0.099 & 0.094 & -0.074 & -0.090 & -0.200 \\
\hline & $(0.003)^{*}$ & $(0.106)^{*}$ & $(0.052)^{*}$ & $(0.050)^{*}$ & $(0.042)^{*}$ & $(0.040)^{*}$ & $(0.040)^{*}$ & $(0.037)^{*}$ \\
\hline \multirow[t]{2}{*}{ Illinois } & 0.005 & 0.524 & -0.264 & 0.046 & 0.056 & 0.002 & 0.103 & 0.269 \\
\hline & $(0.002)^{*}$ & $(0.060)^{*}$ & $(0.059)^{*}$ & $(0.045)$ & $(0.041)$ & $(0.047)$ & $(0.038)^{*}$ & $(0.034)^{*}$ \\
\hline \multirow[t]{2}{*}{ Indiana } & 0.013 & 0.461 & 0.065 & 0.174 & -0.040 & -0.128 & 0.039 & 0.141 \\
\hline & $(0.002)^{*}$ & $(0.096)^{*}$ & $(0.052)$ & $(0.047)^{*}$ & $(0.044)$ & $(0.047)^{*}$ & $(0.039)$ & $(0.037)^{*}$ \\
\hline Iowa & 0.012 & 0.531 & -0.030 & 0.103 & -0.100 & -0.018 & 0.141 & 0.080 \\
\hline & $(0.002)^{*}$ & $(0.062)^{*}$ & $(0.046)$ & $(0.039)^{*}$ & $(0.046)^{*}$ & $(0.038)$ & $(0.035)^{*}$ & $(0.044)^{*}$ \\
\hline Kansas & 0.013 & 0.572 & -0.131 & -0.064 & -0.015 & -0.046 & 0.033 & 0.079 \\
\hline & $(0.002)^{*}$ & $(0.071)^{*}$ & $(0.048)^{*}$ & $(0.051)$ & $(0.041)$ & $(0.037)$ & $(0.035)$ & $(0.029)^{*}$ \\
\hline Kentucky & 0.005 & 0.368 & -0.131 & -0.049 & 0.034 & 0.133 & 0.092 & 0.090 \\
\hline & $(0.002)^{*}$ & $(0.072)^{*}$ & $(0.041)^{*}$ & $(0.041)$ & $(0.041)$ & $(0.023)^{*}$ & $(0.041)^{*}$ & $(0.034)^{*}$ \\
\hline Louisiana & 0.005 & 0.107 & -0.013 & 0.136 & 0.150 & -0.004 & 0.066 & 0.081 \\
\hline & $(0.002)^{*}$ & $(0.063)^{*}$ & $(0.045)$ & $(0.038)^{*}$ & $(0.052)^{*}$ & $(0.041)$ & $(0.039)^{*}$ & $(0.036)^{*}$ \\
\hline Maine & 0.017 & 0.864 & -0.018 & -0.115 & -0.217 & -0.192 & 0.066 & 0.036 \\
\hline & $(0.003)^{*}$ & $(0.096)^{*}$ & $(0.050)$ & $(0.040)^{*}$ & $(0.046)^{*}$ & $(0.043)^{*}$ & $(0.040)^{*}$ & $(0.047)$ \\
\hline Maryland & 0.002 & 0.318 & -0.204 & 0.003 & 0.241 & 0.137 & 0.030 & 0.137 \\
\hline & $(0.002)$ & $(0.066)^{*}$ & $(0.046)^{*}$ & $(0.040)$ & $(0.047)^{*}$ & $(0.036)^{*}$ & $(0.039)$ & $(0.035)^{*}$ \\
\hline Massachusetts & 0.005 & 0.284 & -0.091 & 0.046 & 0.190 & 0.121 & -0.013 & 0.100 \\
\hline & $(0.002)^{*}$ & $(0.067)^{*}$ & $(0.052)^{*}$ & $(0.045)$ & $(0.051)^{*}$ & $(0.040)^{*}$ & $(0.039)$ & $(0.035)^{*}$ \\
\hline Michigan & 0.003 & 0.548 & -0.230 & 0.002 & 0.136 & 0.071 & 0.194 & 0.140 \\
\hline & $(0.002)$ & $(0.095)^{*}$ & $(0.039)^{*}$ & $(0.033)$ & $(0.036)^{*}$ & $(0.033)^{*}$ & $(0.024)^{*}$ & $(0.029)^{*}$ \\
\hline Minnesota & 0.016 & 0.596 & 0.054 & 0.105 & -0.100 & -0.060 & -0.057 & 0.015 \\
\hline & $(0.001)^{*}$ & $(0.056)^{*}$ & $(0.045)$ & $(0.039)^{*}$ & $(0.047)^{*}$ & $(0.037)$ & $(0.032)^{*}$ & $(0.031)$ \\
\hline Mississippi & 0.009 & 0.383 & -0.081 & 0.141 & 0.076 & 0.003 & 0.043 & 0.053 \\
\hline & $(0.002)^{*}$ & $(0.083)^{*}$ & $(0.054)$ & $(0.044)^{*}$ & $(0.049)$ & $(0.047)$ & $(0.041)$ & $(0.045)$ \\
\hline
\end{tabular}




\section{Table 2.11 Continued}

Equation 2.2 estimates, displayed for AL-MS $\beta_{8}-\beta_{18}$

\begin{tabular}{|c|c|c|c|c|c|c|c|c|c|c|c|}
\hline \multirow[b]{2}{*}{ State } & \multicolumn{11}{|c|}{ Seasonal Dummies } \\
\hline & $\beta_{8}$ & $\beta_{9}$ & $\beta_{10}$ & $\beta_{11}$ & $\beta_{12}$ & $\beta_{13}$ & $\beta_{14}$ & $\beta_{15}$ & $\beta_{16}$ & $\beta_{17}$ & $\beta_{18}$ \\
\hline \multirow{2}{*}{ Alabama } & -0.005 & -0.005 & -0.013 & -0.013 & -0.016 & -0.007 & -0.008 & -0.013 & -0.012 & -0.011 & -0.029 \\
\hline & $(0.002)^{*}$ & $(0.002)^{*}$ & $(0.002)^{*}$ & $(0.002)^{*}$ & $(0.002)^{*}$ & $(0.001)^{*}$ & $(0.002)^{*}$ & $(0.002)^{*}$ & $(0.002)^{*}$ & $(0.002)^{*}$ & $(0.002)^{*}$ \\
\hline \multirow[t]{2}{*}{ Alaska } & -0.021 & -0.014 & 0.012 & 0.014 & 0.003 & -0.012 & -0.025 & -0.038 & -0.017 & -0.008 & -0.038 \\
\hline & $(0.005)^{*}$ & $(0.005)^{*}$ & $(0.005)^{*}$ & $(0.005)^{*}$ & $(0.005)$ & $(0.004)^{*}$ & $(0.005)^{*}$ & $(0.005)^{*}$ & $(0.005)^{*}$ & $(0.004)^{*}$ & $(0.004)^{*}$ \\
\hline \multirow[t]{2}{*}{ Arizona } & -0.020 & -0.015 & -0.028 & -0.031 & -0.027 & -0.011 & -0.002 & -0.011 & -0.012 & -0.009 & -0.037 \\
\hline & $(0.003)^{*}$ & $(0.002)^{*}$ & $(0.003)^{*}$ & $(0.002)^{*}$ & $(0.003)^{*}$ & $(0.002)^{*}$ & $(0.003)$ & $(0.003)^{*}$ & $(0.003)^{*}$ & $(0.003)^{*}$ & $(0.002)^{*}$ \\
\hline \multirow[t]{2}{*}{ Arkansas } & -0.012 & -0.015 & -0.018 & -0.022 & -0.032 & -0.007 & -0.008 & -0.023 & -0.024 & -0.021 & -0.041 \\
\hline & $(0.002)^{*}$ & $(0.002)^{*}$ & $(0.002)^{*}$ & $(0.002)^{*}$ & $(0.002)^{*}$ & $(0.001)^{*}$ & $(0.002)^{*}$ & $(0.002)^{*}$ & $(0.002)^{*}$ & $(0.002)^{*}$ & $(0.002)^{*}$ \\
\hline \multirow[t]{2}{*}{ California } & -0.007 & -0.007 & -0.012 & -0.014 & -0.026 & -0.009 & -0.007 & -0.010 & -0.012 & -0.013 & -0.035 \\
\hline & $(0.002)^{*}$ & $(0.002)^{*}$ & $(0.003)^{*}$ & $(0.002)^{*}$ & $(0.002)^{*}$ & $(0.001)^{*}$ & $(0.002)^{*}$ & $(0.002)^{*}$ & $(0.002)^{*}$ & $(0.002)^{*}$ & $(0.002)^{*}$ \\
\hline \multirow[t]{2}{*}{ Colorado } & -0.004 & -0.002 & -0.015 & -0.004 & -0.015 & -0.007 & -0.014 & -0.011 & -0.012 & -0.007 & -0.035 \\
\hline & $(0.003)$ & $(0.003)$ & $(0.003)^{*}$ & $(0.003)^{*}$ & $(0.003)^{*}$ & $(0.001)^{*}$ & $(0.002)^{*}$ & $(0.003)^{*}$ & $(0.003)^{*}$ & $(0.002)^{*}$ & $(0.002)^{*}$ \\
\hline \multirow[t]{2}{*}{ Connecticut } & 0.006 & 0.012 & 0.011 & 0.011 & -0.016 & -0.005 & 0.010 & 0.004 & 0.006 & 0.006 & -0.027 \\
\hline & $(0.002)^{*}$ & $(0.003)^{*}$ & $(0.003)^{*}$ & $(0.003)^{*}$ & $(0.003)^{*}$ & $(0.001)^{*}$ & $(0.002)^{*}$ & $(0.003)^{*}$ & $(0.002)^{*}$ & $(0.002)^{*}$ & $(0.002)^{*}$ \\
\hline \multirow[t]{2}{*}{ Delaware } & 0.008 & 0.016 & 0.011 & 0.013 & -0.005 & 0.003 & -0.002 & -0.006 & -0.001 & 0.003 & -0.031 \\
\hline & $(0.004)^{*}$ & $(0.004)^{*}$ & $(0.004)^{*}$ & $(0.004)^{*}$ & $(0.004)$ & $(0.002)$ & $(0.003)$ & $(0.004)$ & $(0.003)$ & $(0.003)$ & $(0.003)^{*}$ \\
\hline \multirow[t]{2}{*}{ District of Columbia } & 0.002 & 0.003 & -0.001 & 0.007 & 0.015 & -0.007 & -0.013 & -0.007 & -0.002 & 0.000 & -0.023 \\
\hline & $(0.004)$ & $(0.004)$ & $(0.004)$ & $(0.004)^{*}$ & $(0.004)^{*}$ & $(0.003)^{*}$ & $(0.003)^{*}$ & $(0.004)^{*}$ & $(0.004)$ & $(0.004)$ & $(0.003)^{*}$ \\
\hline \multirow[t]{2}{*}{ Florida } & -0.007 & -0.016 & -0.019 & -0.018 & -0.028 & -0.005 & 0.000 & -0.007 & -0.009 & -0.008 & -0.026 \\
\hline & $(0.002)^{*}$ & $(0.003)^{*}$ & $(0.003)^{*}$ & $(0.003)^{*}$ & $(0.003)^{*}$ & $(0.002)^{*}$ & $(0.002)$ & $(0.003)^{*}$ & $(0.003)^{*}$ & $(0.003)^{*}$ & $(0.002)^{*}$ \\
\hline \multirow[t]{2}{*}{ Georgia } & 0.000 & 0.003 & -0.004 & -0.004 & -0.012 & 0.000 & -0.004 & -0.008 & -0.006 & -0.003 & -0.027 \\
\hline & $(0.002)$ & $(0.003)$ & $(0.003)$ & $(0.002)$ & $(0.002)^{*}$ & $(0.001)$ & $(0.002)^{*}$ & $(0.002)^{*}$ & $(0.002)^{*}$ & $(0.002)^{*}$ & $(0.002)^{*}$ \\
\hline \multirow[t]{2}{*}{ Hawaii } & -0.015 & -0.029 & -0.024 & -0.018 & -0.024 & -0.020 & -0.039 & -0.013 & -0.017 & -0.016 & -0.045 \\
\hline & $(0.004)^{*}$ & $(0.003)^{*}$ & $(0.003)^{*}$ & $(0.003)^{*}$ & $(0.004)^{*}$ & $(0.003)^{*}$ & $(0.003)^{*}$ & $(0.004)^{*}$ & $(0.004)^{*}$ & $(0.003)^{*}$ & $(0.003)^{*}$ \\
\hline \multirow[t]{2}{*}{ Idaho } & -0.020 & -0.017 & -0.023 & -0.018 & -0.042 & -0.008 & -0.014 & -0.032 & -0.032 & -0.031 & -0.058 \\
\hline & $(0.004)^{*}$ & $(0.004)^{*}$ & $(0.004)^{*}$ & $(0.004)^{*}$ & $(0.004)^{*}$ & $(0.002)^{*}$ & $(0.003)^{*}$ & $(0.003)^{*}$ & $(0.003)^{*}$ & $(0.003)^{*}$ & $(0.003)^{*}$ \\
\hline \multirow[t]{2}{*}{ Illinois } & 0.002 & 0.004 & 0.001 & 0.003 & -0.005 & -0.002 & -0.006 & -0.010 & -0.008 & -0.007 & -0.032 \\
\hline & $(0.003)$ & $(0.003)$ & (0.003) & $(0.003)$ & $(0.003)^{*}$ & $(0.002)$ & $(0.002)^{*}$ & $(0.002)^{*}$ & $(0.002)^{*}$ & $(0.002)^{*}$ & $(0.002)^{*}$ \\
\hline \multirow[t]{2}{*}{ Indiana } & -0.003 & -0.005 & -0.012 & -0.015 & -0.023 & -0.001 & 0.001 & -0.023 & -0.020 & -0.012 & -0.036 \\
\hline & $(0.003)$ & $(0.003)$ & $(0.003)^{*}$ & $(0.003)^{*}$ & $(0.003)^{*}$ & $(0.002)$ & $(0.002)$ & $(0.003)^{*}$ & $(0.002)^{*}$ & $(0.002)^{*}$ & $(0.003)^{*}$ \\
\hline Iowa & -0.004 & -0.003 & -0.006 & -0.007 & -0.029 & -0.006 & 0.001 & -0.016 & -0.015 & -0.011 & -0.040 \\
\hline & $(0.002)$ & $(0.003)$ & $(0.003)^{*}$ & $(0.003)^{*}$ & $(0.003)^{*}$ & $(0.001)^{*}$ & $(0.002)$ & $(0.002)^{*}$ & $(0.002)^{*}$ & $(0.002)^{*}$ & $(0.002)^{*}$ \\
\hline Kansas & -0.008 & -0.005 & -0.012 & -0.012 & -0.033 & -0.010 & 0.002 & -0.014 & -0.013 & -0.012 & -0.036 \\
\hline & $(0.003)^{*}$ & $(0.003)^{*}$ & $(0.003)^{*}$ & $(0.003)^{*}$ & $(0.003)^{*}$ & $(0.001)^{*}$ & $(0.002)$ & $(0.003)^{*}$ & $(0.003)^{*}$ & $(0.003)^{*}$ & $(0.002)^{*}$ \\
\hline Kentucky & 0.000 & 0.007 & 0.005 & -0.002 & -0.016 & 0.000 & -0.001 & -0.007 & -0.004 & -0.003 & -0.033 \\
\hline & $(0.002)$ & $(0.002)^{*}$ & $(0.002)^{*}$ & $(0.003)$ & $(0.003)^{*}$ & $(0.001)$ & $(0.002)$ & $(0.002)^{*}$ & $(0.002)^{*}$ & $(0.002)$ & $(0.002)^{*}$ \\
\hline Louisiana & 0.004 & 0.003 & -0.002 & 0.001 & -0.012 & -0.004 & 0.002 & -0.002 & -0.005 & -0.003 & -0.028 \\
\hline & $(0.002)^{*}$ & $(0.002)$ & $(0.002)$ & $(0.002)$ & $(0.002)^{*}$ & $(0.001)^{*}$ & $(0.002)$ & $(0.002)$ & $(0.002)^{*}$ & $(0.002)^{*}$ & $(0.002)^{*}$ \\
\hline Maine & -0.021 & -0.014 & -0.009 & 0.010 & -0.019 & 0.010 & -0.018 & -0.024 & -0.030 & -0.022 & -0.057 \\
\hline & $(0.004)^{*}$ & $(0.004)^{*}$ & $(0.004)^{*}$ & $(0.004)^{*}$ & $(0.004)^{*}$ & $(0.003)^{*}$ & $(0.004)^{*}$ & $(0.004)^{*}$ & $(0.003)^{*}$ & $(0.003)^{*}$ & $(0.003)^{*}$ \\
\hline Maryland & 0.007 & 0.015 & 0.009 & 0.005 & -0.007 & -0.006 & -0.005 & -0.002 & 0.000 & 0.001 & -0.033 \\
\hline & $(0.002)^{*}$ & $(0.003)^{*}$ & $(0.003)^{*}$ & $(0.003)^{*}$ & $(0.002)^{*}$ & $(0.001)^{*}$ & $(0.002)^{*}$ & $(0.002)$ & $(0.002)$ & $(0.002)$ & $(0.002)^{*}$ \\
\hline Massachusetts & 0.001 & 0.012 & 0.005 & 0.000 & -0.018 & -0.006 & -0.001 & -0.004 & -0.003 & -0.005 & -0.036 \\
\hline & $(0.003)$ & $(0.003)^{*}$ & $(0.003)$ & $(0.003)$ & $(0.003)^{*}$ & $(0.001)^{*}$ & $(0.002)$ & $(0.003)$ & $(0.002)$ & $(0.002)^{*}$ & $(0.002)^{*}$ \\
\hline Michigan & -0.002 & 0.007 & 0.008 & 0.006 & -0.021 & -0.002 & 0.006 & 0.000 & -0.005 & -0.002 & -0.033 \\
\hline & $(0.003)$ & $(0.003)^{*}$ & $(0.004)^{*}$ & $(0.003)^{*}$ & $(0.003)^{*}$ & $(0.002)$ & $(0.003)^{*}$ & $(0.003)$ & $(0.003)^{*}$ & $(0.002)$ & $(0.003)^{*}$ \\
\hline Minnesota & -0.010 & -0.010 & -0.008 & -0.014 & -0.032 & -0.005 & -0.007 & -0.017 & -0.021 & -0.020 & -0.042 \\
\hline & $(0.002)^{*}$ & $(0.002)^{*}$ & $(0.003)^{*}$ & $(0.002)^{*}$ & $(0.002)^{*}$ & $(0.001)^{*}$ & $(0.002)^{*}$ & $(0.002)^{*}$ & $(0.002)^{*}$ & $(0.002)^{*}$ & $(0.002)^{*}$ \\
\hline Mississippi & -0.001 & 0.000 & -0.006 & -0.010 & -0.020 & -0.001 & 0.003 & -0.012 & -0.012 & -0.009 & -0.028 \\
\hline & $(0.003)$ & $(0.003)$ & $(0.003)^{*}$ & $(0.003)^{*}$ & $(0.003)^{*}$ & $(0.001)$ & $(0.002)$ & $(0.003)^{*}$ & $(0.002)^{*}$ & $(0.003)^{*}$ & $(0.002)^{*}$ \\
\hline
\end{tabular}




\section{Table 2.11 Continued}

Equation 2.2 estimates, displayed for MO-WY $\beta_{0}-\beta_{7}$

\begin{tabular}{|c|c|c|c|c|c|c|c|c|}
\hline \multirow[b]{2}{*}{ State } & \multirow[b]{2}{*}{$\beta_{0}$} & \multirow[b]{2}{*}{$\beta_{1}$} & \multicolumn{6}{|c|}{ AR Lags } \\
\hline & & & $\beta_{2}$ & $\beta_{3}$ & $\beta_{4}$ & $\beta_{5}$ & $\beta_{6}$ & $\beta_{7}$ \\
\hline \multirow[t]{2}{*}{ Missouri } & 0.009 & 0.532 & -0.190 & 0.016 & 0.048 & -0.016 & -0.003 & 0.039 \\
\hline & $(0.002)^{*}$ & $(0.080)^{*}$ & $(0.052)^{*}$ & $(0.046)$ & $(0.049)$ & $(0.040)$ & $(0.039)$ & $(0.039)$ \\
\hline \multirow[t]{2}{*}{ Montana } & 0.015 & 0.383 & 0.109 & -0.005 & -0.014 & -0.104 & -0.096 & -0.239 \\
\hline & $(0.003)^{*}$ & $(0.119)^{*}$ & $(0.048)^{*}$ & $(0.046)$ & $(0.055)$ & $(0.045)^{*}$ & $(0.049)^{*}$ & $(0.042)^{*}$ \\
\hline \multirow[t]{2}{*}{ Nebraska } & 0.012 & 0.557 & -0.135 & 0.006 & 0.051 & -0.111 & -0.067 & 0.041 \\
\hline & $(0.002)^{*}$ & $(0.064)^{*}$ & $(0.043)^{*}$ & $(0.039)$ & $(0.043)$ & $(0.043)^{*}$ & $(0.037)^{*}$ & $(0.036)$ \\
\hline \multirow[t]{2}{*}{ Nevada } & 0.025 & 0.278 & 0.389 & 0.214 & -0.055 & -0.105 & -0.222 & 0.047 \\
\hline & $(0.002)^{*}$ & $(0.110)^{*}$ & $(0.048)^{*}$ & $(0.052)^{*}$ & $(0.051)$ & $(0.047)^{*}$ & $(0.046)^{*}$ & $(0.038)$ \\
\hline \multirow[t]{2}{*}{ New Hampshire } & 0.015 & 0.569 & 0.171 & 0.064 & -0.152 & -0.047 & 0.028 & 0.292 \\
\hline & $(0.002)^{*}$ & $(0.102)^{*}$ & $(0.042)^{*}$ & $(0.036)^{*}$ & $(0.044)^{*}$ & $(0.041)$ & $(0.034)$ & $(0.027)^{*}$ \\
\hline \multirow[t]{2}{*}{ New Mexico } & 0.014 & 0.222 & 0.072 & 0.120 & -0.042 & -0.135 & -0.024 & 0.067 \\
\hline & $(0.002)^{*}$ & $(0.081)^{*}$ & $(0.048)$ & $(0.049)^{*}$ & $(0.048)$ & $(0.042)^{*}$ & $(0.044)$ & $(0.038)^{*}$ \\
\hline \multirow[t]{2}{*}{ New York } & 0.007 & 0.290 & -0.097 & 0.099 & 0.102 & -0.139 & 0.075 & 0.084 \\
\hline & $(0.002)^{*}$ & $(0.055)^{*}$ & $(0.055)^{*}$ & $(0.046)^{*}$ & $(0.043)^{*}$ & $(0.041)^{*}$ & $(0.039)^{*}$ & $(0.038)^{*}$ \\
\hline \multirow[t]{2}{*}{ North Carolina } & 0.018 & 0.790 & -0.118 & -0.066 & 0.137 & 0.003 & 0.091 & -0.047 \\
\hline & $(0.002)^{*}$ & $(0.065)^{*}$ & $(0.051)^{*}$ & $(0.042)$ & $(0.045)^{*}$ & $(0.037)$ & $(0.038)^{*}$ & $(0.032)$ \\
\hline \multirow[t]{2}{*}{ North Dakota } & 0.017 & 0.248 & 0.198 & 0.071 & -0.025 & -0.094 & -0.151 & -0.268 \\
\hline & $(0.002)^{*}$ & $(0.083)^{*}$ & $(0.047)^{*}$ & $(0.042)^{*}$ & $(0.045)$ & $(0.041)^{*}$ & $(0.041)^{*}$ & $(0.043)^{*}$ \\
\hline \multirow[t]{2}{*}{ Ohio } & 0.007 & 0.576 & -0.226 & 0.118 & 0.198 & 0.001 & -0.006 & 0.139 \\
\hline & $(0.001)^{*}$ & $(0.074)^{*}$ & $(0.054)^{*}$ & $(0.041)^{*}$ & $(0.037)^{*}$ & $(0.039)$ & $(0.033)$ & $(0.045)^{*}$ \\
\hline \multirow[t]{2}{*}{ Oklahoma } & 0.009 & 0.296 & -0.009 & -0.072 & 0.108 & -0.062 & 0.045 & 0.148 \\
\hline & $(0.002)^{*}$ & $(0.079)^{*}$ & $(0.048)$ & $(0.045)$ & $(0.052)^{*}$ & $(0.044)$ & $(0.036)$ & $(0.036)^{*}$ \\
\hline \multirow[t]{2}{*}{ Oregon } & 0.021 & 0.665 & -0.025 & 0.102 & 0.282 & -0.025 & -0.131 & -0.224 \\
\hline & $(0.002)^{*}$ & $(0.096)^{*}$ & $(0.046)$ & $(0.040)^{*}$ & $(0.036)^{*}$ & $(0.035)$ & $(0.040)^{*}$ & $(0.032)^{*}$ \\
\hline \multirow[t]{2}{*}{ Pennsylvania } & 0.008 & 0.293 & -0.031 & 0.042 & 0.020 & -0.087 & 0.134 & 0.066 \\
\hline & $(0.001)^{*}$ & $(0.065)^{*}$ & $(0.052)$ & $(0.042)$ & $(0.048)$ & $(0.041)^{*}$ & $(0.038)^{*}$ & $(0.034)^{*}$ \\
\hline \multirow[t]{2}{*}{ Rhode Island } & 0.005 & 0.375 & -0.148 & 0.064 & 0.083 & 0.042 & -0.013 & -0.042 \\
\hline & $(0.003)^{*}$ & $(0.094)^{*}$ & $(0.058)^{*}$ & $(0.042)$ & $(0.039)^{*}$ & $(0.040)$ & $(0.040)$ & $(0.032)$ \\
\hline \multirow[t]{2}{*}{ South Carolina } & 0.020 & 0.938 & -0.261 & -0.048 & 0.087 & 0.003 & 0.064 & 0.067 \\
\hline & $(0.002)^{*}$ & $(0.071)^{*}$ & $(0.052)^{*}$ & $(0.040)$ & $(0.047)^{*}$ & $(0.039)$ & $(0.036)^{*}$ & $(0.035)^{*}$ \\
\hline South Dakota & 0.010 & 0.401 & -0.002 & 0.046 & 0.082 & -0.136 & -0.058 & 0.023 \\
\hline & $(0.002)^{*}$ & $(0.070)^{*}$ & $(0.047)$ & $(0.043)$ & $(0.046)^{*}$ & $(0.042)^{*}$ & $(0.036)$ & $(0.037)$ \\
\hline Tennessee & 0.012 & 0.554 & -0.124 & 0.104 & 0.107 & 0.005 & -0.096 & 0.111 \\
\hline & $(0.002)^{*}$ & $(0.082)^{*}$ & $(0.052)^{*}$ & $(0.049)^{*}$ & $(0.042)^{*}$ & $(0.040)$ & $(0.037)^{*}$ & $(0.034)^{*}$ \\
\hline Texas & 0.010 & 0.278 & -0.040 & 0.029 & 0.139 & 0.067 & -0.047 & 0.368 \\
\hline & $(0.001)^{*}$ & $(0.052)^{*}$ & $(0.043)$ & $(0.037)$ & $(0.039)^{*}$ & $(0.037)^{*}$ & $(0.036)$ & $(0.039)^{*}$ \\
\hline Utah & 0.009 & 0.204 & 0.066 & 0.138 & 0.141 & -0.035 & -0.069 & 0.224 \\
\hline & $(0.002)^{*}$ & $(0.068)^{*}$ & $(0.044)$ & $(0.046)^{*}$ & $(0.047)^{*}$ & $(0.043)$ & $(0.045)$ & $(0.043)^{*}$ \\
\hline Vermont & 0.031 & 0.995 & -0.017 & -0.215 & -0.024 & -0.234 & -0.033 & -0.132 \\
\hline & $(0.002)^{*}$ & $(0.093)^{*}$ & $(0.045)$ & $(0.038)^{*}$ & $(0.036)$ & $(0.028)^{*}$ & $(0.029)$ & $(0.027)^{*}$ \\
\hline Virginia & 0.009 & 0.266 & 0.066 & 0.096 & 0.062 & 0.112 & -0.047 & 0.038 \\
\hline & $(0.002)^{*}$ & $(0.067)^{*}$ & $(0.061)$ & $(0.057)^{*}$ & $(0.047)$ & $(0.046)^{*}$ & $(0.049)$ & $(0.041)$ \\
\hline Washington & 0.008 & 0.066 & 0.016 & 0.107 & 0.200 & 0.036 & -0.059 & 0.068 \\
\hline & $(0.002)^{*}$ & $(0.085)$ & $(0.052)$ & $(0.046)^{*}$ & $(0.041)^{*}$ & $(0.044)$ & $(0.037)$ & $(0.044)$ \\
\hline West Virginia & 0.003 & 0.721 & -0.348 & -0.099 & -0.168 & -0.139 & -0.099 & -0.041 \\
\hline & $(0.002)$ & $(0.091)^{*}$ & $(0.030)^{*}$ & $(0.041)^{*}$ & $(0.046)^{*}$ & $(0.032)^{*}$ & $(0.032)^{*}$ & $(0.031)$ \\
\hline Wisconsin & 0.007 & 0.416 & -0.121 & 0.078 & 0.073 & 0.022 & 0.087 & 0.069 \\
\hline & $(0.002)^{*}$ & $(0.068)^{*}$ & $(0.048)^{*}$ & $(0.038)^{*}$ & $(0.044)^{*}$ & $(0.041)$ & $(0.044)^{*}$ & $(0.044)$ \\
\hline Wyoming & 0.010 & 0.161 & 0.315 & 0.018 & -0.056 & -0.080 & -0.100 & -0.153 \\
\hline & $(0.004)^{*}$ & $(0.152)$ & $(0.052)^{*}$ & $(0.051)$ & $(0.050)$ & $(0.044)^{*}$ & $(0.044)^{*}$ & $(0.039)^{*}$ \\
\hline
\end{tabular}




\section{Table 2.11 Continued}

Equation 2.2 estimates, displayed for MO-WY $\beta_{8}-\beta_{18}$

\begin{tabular}{|c|c|c|c|c|c|c|c|c|c|c|c|}
\hline \multirow[b]{2}{*}{ State } & \multicolumn{11}{|c|}{ Seasonal Dummies } \\
\hline & $\beta_{8}$ & $\beta_{9}$ & $\beta_{10}$ & $\beta_{11}$ & $\beta_{12}$ & $\beta_{13}$ & $\beta_{14}$ & $\beta_{15}$ & $\beta_{16}$ & $\beta_{17}$ & $\beta_{18}$ \\
\hline \multirow[t]{2}{*}{ Missouri } & 0.001 & 0.004 & -0.004 & -0.008 & -0.022 & -0.005 & 0.001 & -0.009 & -0.012 & -0.010 & -0.037 \\
\hline & $(0.003)$ & $(0.003)$ & $(0.003)$ & $(0.003)^{*}$ & $(0.002)^{*}$ & $(0.001)^{*}$ & $(0.002)$ & $(0.002)^{*}$ & $(0.002)^{*}$ & $(0.002)^{*}$ & $(0.002)^{*}$ \\
\hline \multirow[t]{2}{*}{ Montana } & -0.007 & -0.005 & -0.006 & -0.002 & -0.031 & 0.000 & -0.009 & -0.015 & -0.019 & -0.016 & -0.049 \\
\hline & $(0.004)^{*}$ & $(0.004)$ & $(0.004)$ & $(0.004)$ & $(0.004)^{*}$ & $(0.003)$ & $(0.004)^{*}$ & $(0.004)^{*}$ & $(0.004)^{*}$ & $(0.004)^{*}$ & $(0.003)^{*}$ \\
\hline \multirow[t]{2}{*}{ Nebraska } & -0.005 & 0.000 & -0.006 & -0.009 & -0.024 & -0.007 & -0.004 & -0.011 & -0.014 & -0.015 & -0.036 \\
\hline & $(0.002)^{*}$ & $(0.003)$ & $(0.003)^{*}$ & $(0.003)^{*}$ & $(0.003)^{*}$ & $(0.001)^{*}$ & $(0.002)^{*}$ & $(0.002)^{*}$ & $(0.002)^{*}$ & $(0.002)^{*}$ & $(0.002)^{*}$ \\
\hline \multirow[t]{2}{*}{ Nevada } & -0.013 & -0.025 & -0.022 & -0.029 & -0.028 & -0.014 & -0.017 & -0.028 & -0.025 & -0.028 & -0.043 \\
\hline & $(0.003)^{*}$ & $(0.003)^{*}$ & $(0.003)^{*}$ & $(0.003)^{*}$ & $(0.003)^{*}$ & $(0.002)^{*}$ & $(0.003)^{*}$ & $(0.003)^{*}$ & $(0.003)^{*}$ & $(0.003)^{*}$ & $(0.003)^{*}$ \\
\hline \multirow[t]{2}{*}{ New Hampshire } & -0.012 & -0.014 & -0.006 & -0.007 & -0.018 & -0.001 & -0.011 & -0.024 & -0.024 & -0.011 & -0.042 \\
\hline & $(0.003)^{*}$ & $(0.003)^{*}$ & $(0.003)^{*}$ & $(0.003)^{*}$ & $(0.003)^{*}$ & $(0.002)$ & $(0.003)^{*}$ & $(0.003)^{*}$ & $(0.003)^{*}$ & $(0.002)^{*}$ & $(0.002)^{*}$ \\
\hline \multirow[t]{2}{*}{ New Mexico } & -0.004 & -0.010 & -0.011 & -0.011 & -0.020 & -0.006 & -0.005 & -0.017 & -0.016 & -0.012 & -0.037 \\
\hline & $(0.003)$ & $(0.003)^{*}$ & $(0.003)^{*}$ & $(0.003)^{*}$ & $(0.003)^{*}$ & $(0.002)^{*}$ & $(0.002)^{*}$ & $(0.003)^{*}$ & $(0.002)^{*}$ & $(0.002)^{*}$ & $(0.002)^{*}$ \\
\hline \multirow[t]{2}{*}{ New York } & 0.003 & 0.000 & -0.006 & 0.001 & -0.015 & -0.007 & -0.007 & -0.002 & -0.007 & -0.006 & -0.040 \\
\hline & $(0.003)$ & $(0.003)$ & $(0.003)^{*}$ & $(0.003)$ & $(0.003)^{*}$ & $(0.002)^{*}$ & $(0.002)^{*}$ & $(0.002)$ & $(0.002)^{*}$ & $(0.002)^{*}$ & $(0.002)^{*}$ \\
\hline \multirow[t]{2}{*}{ North Carolina } & -0.013 & -0.012 & -0.018 & -0.016 & -0.039 & -0.002 & -0.008 & -0.016 & -0.020 & -0.018 & -0.041 \\
\hline & $(0.002)^{*}$ & $(0.003)^{*}$ & $(0.003)^{*}$ & $(0.002)^{*}$ & $(0.002)^{*}$ & $(0.001)^{*}$ & $(0.002)^{*}$ & $(0.002)^{*}$ & $(0.002)^{*}$ & $(0.002)^{*}$ & $(0.002)^{*}$ \\
\hline \multirow[t]{2}{*}{ North Dakota } & -0.004 & -0.004 & -0.006 & -0.022 & -0.039 & -0.009 & 0.004 & -0.008 & -0.020 & -0.022 & -0.048 \\
\hline & $(0.003)$ & $(0.003)$ & $(0.003)^{*}$ & $(0.004)^{*}$ & $(0.003)^{*}$ & $(0.002)^{*}$ & $(0.003)$ & $(0.003)^{*}$ & $(0.003)^{*}$ & $(0.003)^{*}$ & $(0.003)^{*}$ \\
\hline \multirow[t]{2}{*}{ Ohio } & 0.001 & 0.007 & 0.000 & -0.006 & -0.019 & -0.006 & -0.001 & -0.006 & -0.010 & -0.010 & -0.036 \\
\hline & $(0.002)$ & $(0.002)^{*}$ & $(0.002)$ & $(0.002)^{*}$ & $(0.002)^{*}$ & $(0.001)^{*}$ & $(0.002)$ & $(0.002)^{*}$ & $(0.002)^{*}$ & $(0.002)^{*}$ & $(0.002)^{*}$ \\
\hline \multirow[t]{2}{*}{ Oklahoma } & -0.005 & -0.002 & -0.005 & -0.010 & -0.018 & -0.003 & -0.002 & -0.008 & -0.010 & -0.007 & -0.027 \\
\hline & $(0.002)^{*}$ & $(0.003)$ & $(0.003)^{*}$ & $(0.003)^{*}$ & $(0.003)^{*}$ & $(0.002)^{*}$ & $(0.002)$ & $(0.003)^{*}$ & $(0.003)^{*}$ & $(0.002)^{*}$ & $(0.002)^{*}$ \\
\hline \multirow[t]{2}{*}{ Oregon } & -0.010 & -0.009 & -0.020 & -0.019 & -0.046 & -0.009 & -0.012 & -0.015 & -0.026 & -0.027 & -0.053 \\
\hline & $(0.003)^{*}$ & $(0.003)^{*}$ & $(0.004)^{*}$ & $(0.003)^{*}$ & $(0.003)^{*}$ & $(0.002)^{*}$ & $(0.003)^{*}$ & $(0.003)^{*}$ & $(0.003)^{*}$ & $(0.003)^{*}$ & $(0.002)^{*}$ \\
\hline \multirow[t]{2}{*}{ Pennsylvania } & -0.001 & 0.001 & -0.006 & -0.001 & -0.017 & -0.006 & -0.004 & -0.007 & -0.009 & -0.008 & -0.035 \\
\hline & $(0.002)$ & $(0.002)$ & $(0.002)^{*}$ & $(0.002)$ & $(0.002)^{*}$ & $(0.001)^{*}$ & $(0.002)^{*}$ & $(0.002)^{*}$ & $(0.002)^{*}$ & $(0.002)^{*}$ & $(0.002)^{*}$ \\
\hline \multirow[t]{2}{*}{ Rhode Island } & 0.004 & 0.011 & 0.006 & 0.000 & -0.028 & 0.005 & 0.005 & -0.004 & -0.004 & -0.006 & -0.045 \\
\hline & $(0.003)$ & $(0.004)^{*}$ & $(0.004)$ & $(0.004)$ & $(0.004)^{*}$ & $(0.002)^{*}$ & $(0.003)$ & $(0.003)$ & $(0.003)$ & $(0.003)^{*}$ & $(0.003)^{*}$ \\
\hline \multirow[t]{2}{*}{ South Carolina } & -0.014 & -0.012 & -0.019 & -0.021 & -0.037 & -0.011 & -0.014 & -0.022 & -0.022 & -0.018 & -0.040 \\
\hline & $(0.003)^{*}$ & $(0.003)^{*}$ & $(0.003)^{*}$ & $(0.003)^{*}$ & $(0.003)^{*}$ & $(0.002)^{*}$ & $(0.002)^{*}$ & $(0.003)^{*}$ & $(0.002)^{*}$ & $(0.002)^{*}$ & $(0.003)^{*}$ \\
\hline South Dakota & -0.003 & 0.006 & 0.005 & 0.003 & -0.027 & -0.002 & -0.011 & -0.010 & -0.019 & -0.014 & -0.037 \\
\hline & $(0.003)$ & $(0.003)^{*}$ & $(0.003)$ & $(0.003)$ & $(0.003)^{*}$ & $(0.002)$ & $(0.003)^{*}$ & $(0.003)^{*}$ & $(0.003)^{*}$ & $(0.002)^{*}$ & $(0.002)^{*}$ \\
\hline Tennessee & -0.002 & -0.002 & -0.011 & -0.016 & -0.020 & -0.001 & -0.005 & -0.016 & -0.015 & -0.013 & -0.038 \\
\hline & $(0.003)$ & $(0.003)$ & $(0.003)^{*}$ & $(0.003)^{*}$ & $(0.003)^{*}$ & $(0.002)$ & $(0.002)^{*}$ & $(0.002)^{*}$ & $(0.002)^{*}$ & $(0.002)^{*}$ & $(0.002)^{*}$ \\
\hline Texas & -0.006 & -0.005 & -0.008 & -0.012 & -0.011 & -0.007 & -0.007 & -0.010 & -0.009 & -0.008 & -0.026 \\
\hline & $(0.002)^{*}$ & $(0.002)^{*}$ & $(0.002)^{*}$ & $(0.002)^{*}$ & $(0.002)^{*}$ & $(0.001)^{*}$ & $(0.001)^{*}$ & $(0.001)^{*}$ & $(0.002)^{*}$ & $(0.001)^{*}$ & $(0.001)^{*}$ \\
\hline Utah & -0.001 & 0.000 & -0.011 & -0.007 & -0.017 & -0.001 & 0.003 & -0.011 & -0.007 & -0.012 & -0.033 \\
\hline & $(0.002)$ & $(0.003)$ & $(0.002)^{*}$ & $(0.002)^{*}$ & $(0.003)^{*}$ & $(0.001)$ & $(0.002)$ & $(0.002)^{*}$ & $(0.002)^{*}$ & $(0.002)^{*}$ & $(0.002)^{*}$ \\
\hline Vermont & -0.040 & -0.039 & -0.039 & -0.027 & -0.049 & -0.018 & -0.015 & -0.030 & -0.042 & -0.019 & -0.055 \\
\hline & $(0.003)^{*}$ & $(0.003)^{*}$ & $(0.003)^{*}$ & $(0.003)^{*}$ & $(0.003)^{*}$ & $(0.002)^{*}$ & $(0.003)^{*}$ & $(0.004)^{*}$ & $(0.003)^{*}$ & $(0.003)^{*}$ & $(0.003)^{*}$ \\
\hline Virginia & 0.001 & 0.000 & -0.002 & -0.003 & -0.022 & -0.005 & -0.003 & -0.010 & -0.004 & -0.008 & -0.035 \\
\hline & $(0.002)$ & $(0.003)$ & $(0.003)$ & $(0.003)$ & $(0.002)^{*}$ & $(0.001)^{*}$ & $(0.002)$ & $(0.002)^{*}$ & $(0.002)^{*}$ & $(0.002)^{*}$ & $(0.002)^{*}$ \\
\hline Washington & 0.004 & 0.006 & 0.001 & -0.001 & -0.021 & -0.006 & 0.003 & -0.008 & -0.010 & -0.013 & -0.032 \\
\hline & $(0.003)$ & $(0.003)^{*}$ & $(0.003)$ & $(0.003)$ & $(0.003)^{*}$ & $(0.002)^{*}$ & $(0.002)$ & $(0.003)^{*}$ & $(0.002)^{*}$ & $(0.003)^{*}$ & $(0.002)^{*}$ \\
\hline West Virginia & 0.001 & 0.002 & 0.006 & -0.001 & -0.006 & 0.005 & 0.004 & -0.004 & -0.005 & -0.005 & -0.029 \\
\hline & $(0.003)$ & $(0.003)$ & $(0.003)^{*}$ & $(0.003)$ & $(0.003)^{*}$ & $(0.002)^{*}$ & $(0.003)$ & $(0.003)$ & $(0.003)^{*}$ & $(0.003)^{*}$ & $(0.003)^{*}$ \\
\hline Wisconsin & 0.000 & 0.006 & 0.004 & 0.006 & -0.017 & -0.004 & -0.004 & -0.010 & -0.012 & -0.011 & -0.038 \\
\hline & $(0.002)$ & $(0.003)^{*}$ & $(0.003)$ & $(0.003)^{*}$ & $(0.003)^{*}$ & $(0.001)^{*}$ & $(0.002)^{*}$ & $(0.002)^{*}$ & $(0.002)^{*}$ & $(0.002)^{*}$ & $(0.002)^{*}$ \\
\hline Wyoming & -0.003 & -0.006 & 0.012 & 0.017 & -0.037 & 0.001 & -0.005 & -0.021 & -0.013 & -0.002 & -0.040 \\
\hline & $(0.005)$ & $(0.005)$ & $(0.005)^{*}$ & $(0.005)^{*}$ & $(0.005)^{*}$ & $(0.004)$ & $(0.005)$ & $(0.005)^{*}$ & $(0.005)^{*}$ & $(0.005)$ & $(0.005)^{*}$ \\
\hline
\end{tabular}




\section{Chapter 3}

\section{Spatial Approach to Estimating State Employment Volatility}

In Chapter 2, the conditional variance was shown to have an effect on the estimation and prediction of state level employment growth. Here we examine the role of the conditional variance, if any, when accounting for spatial spillover effects. It is well known that interaction and dependences between state economic growth indicators such as employment, personal per capita income, unemployment insurance claims, etc. are highly correlated with neighboring states.

Given the likelihood of spatial presence in state employment growth, this chapter will focus on whether G/ARCH effects are still present when accounting for these effects. If the $\mathrm{G} / \mathrm{ARCH}$ effects disappear in the presence of spatial effects, then they are misclassified spatial spillovers. Conceptually, the volatility cluster as stated by Engle $(1982)$ could be misidentified as dependences between states. The impact of the "Great Moderation" will be examined in conjunction.

Work has been completed on the volatility structure of employment on the national and state-level. The present state of the literature focuses on the change in employment volatility around the 'Great Moderation.' The 'Great Moderation' refers to the reduction in volatility in 1984 due to the U.S. Federal Reserve policy change to concentrate on inflation stability and reduction. The majority of the literature centers on national employment. There are a few key articles that focus on the effects of the 'Great Moderation' on state-level employment: Carlino, DeFina, and Sill (2007), Owyang, Piger, and Wall (2008), and Morgan, Rime, and Strahan (2004). While it is important to keep in mind that current research of reduction in volatility is due to the 'Great Moderation', the prime focus here is to test for autoregressive conditional heteroskedasticity $(\mathrm{ARCH})$ processes at the state-level. 
The literature base for this work is closely tied to Chapter 2. Next, a description of the data and the empirical model is given; followed by results of the model. The chapter concludes with a synopsis of the findings.

\subsection{Review of the Literature}

The relevant literature gives evidence that after 1984 both national and statelevel employment volatility made a statistically significant drop, hence the 'Great Moderation.'

On the national level, Stock and Watson (2002) examined the reasoning behind the 'Great Moderation.' They use a substantial array of macro variables. In testing the hypothesis that a change in policy caused a structural break in the GDP growth, the authors used a structural VAR with a monetary rule similar to Taylor's Rule, a New Keynesian Phillips curve, and an IS equation. The U.S. conditional mean and variance were measured using an autoregressive model in the univariate case and a VAR in the multivariate case. Volatility was measured as the absolute value of the error. The statistically significant changes in volatility were measured using the Quandt likelihood ratio statistic. The results of the study led Stock and Watson (2002) to conclude that better inflation targeting by the Fed accounts for 20 to 30 percent of the reduction in GDP volatility, which began in 1984. Furthermore, the reductions in the magnitude of shocks in productivity and commodities played a role in the decline of GDP volatility. The conclusions also stated that better inventory schedules and the move from manufacturing to services are insignificant in aiding the decline of volatility.

Campbell (2004) took a different approach to measuring the 'Great Moderation,' by using data from the Survey of Professional Forecasters. The data ranges from the first quarter of 1969 to the second quarter of 2003 for the quarterly survey. Data for the annual survey ranged from the first quarter of 1971 to the fourth quarter of 2002. The author defined uncertainty as the expected error variance of output growth regressed on the expected future output growth, which is conditional on the information in the current period, to determine the predictability components of the 'Great Moderation.' The analysis stated that an autoregressive model of order 1 in testing the magnitude of the decline in output volatility inflates the magnitude of the decline; in other words, part of the 'Great Moderation' was due to an increase in predictability.

Owyang, Piger, and Wall (2008) also studied the 'Great Moderation' on the regional level. The data used was total non-farm employment from February 1956 to December 2004. The study used a panel regression with a 
Markov-switching process and structural breaks for state employment growth. The residuals from this panel regression were measured as volatility. They discovered that 38 states saw a reduction in volatility at the same time as the U.S. This article also looks at five possible causes of the decrease in volatility: for example, the deregulation of Regulation Q, improved inventory practices, and improved monetary policy. The authors discovered that of these five theories only the improvement in monetary policy was statistically significant in explaining the decreases in volatility.

When studying the 'Great Moderation' it is important to notice that structural breaks have been included for most of the above articles. However, the assumption of a homoskedastic error has not changed. Given that the structure of volatility has changed over time, so should the structure of the volatility equation. An autoregressive conditional heteroskedastic (ARCH) model would be appropriate for analyzing changes in the conditional variance.

\subsection{Empirical Analysis}

\subsubsection{Data}

This is the same data used in Chapter 2, described in section 2.2.1. For the purpose of uniformity in the spatial weight matrix, all states time-series will range from January 1960 to December 2009. Alaska and Hawaii have been removed from the sample since they have no neighbors in the United States. If the number of neighboring states is zero, then the resulting regression is the same as in Chapter 2. This leaves 49 states with 599 observations per state.

The spatial weight matrix is constructed using queen contiguity, meaning if two states have a common border or vertex they are counted as neighbors. Any column vector, neighbors for a particular state, must sum to one. For simplification, all $n$ neighboring states for state $i$ are given equal weighting, $\frac{1}{n}$.

\subsubsection{Empirical Model}

The structure of the empirical model is analogous the model described in section 2.2 .2 with the addition of the spatial weight matrix. The Ljung-Box Q-statistic is used to test for serial correlation, refer to equation 2.1. The regression specification is as follows: 


$$
\begin{gathered}
y_{i, t}=\beta_{i, 0}+\beta_{i, 1} y_{u s, t-1}+\sum_{a=1}^{6} \beta_{i, a+1} y_{i, t-a}+\sum_{d=1}^{11} \beta_{i, c+d+1} d u m_{d, t} \\
+\sum_{f=1}^{\leq 6} \lambda_{i, f} W y_{i-f}+\epsilon_{i, t} \\
\sigma_{i, t}^{2}=\omega_{i}+\sum_{n=1}^{q=12} \alpha_{i, n} \epsilon_{i, t-n}^{2} \\
\omega>0 \\
\alpha_{n} \geq 0 \forall n, \sum_{n=1}^{q} \alpha_{i, n}<1
\end{gathered}
$$

Where $i=\mathrm{i}^{\text {th }}$ State, $\left\{\epsilon_{i, t} \mid \mathrm{I}_{i, t-1}\right\} \sim \mathcal{N}\left(0, \sigma_{i, t}^{2}\right)$

The additional term of $\sum_{f=1}^{g=6} \lambda_{i, f} W y_{i-f}$ is the weighted average of employment growth for the neighboring state(s) in the previous period. This makes equation 3.1 a variation of a space-time autoregressive model (STAR). 1 It should be noted, that own state employment growth has been set from 1 to 6 , inclusive. This is to keep consistency and continuity equation 2.4 from Chapter 2. Remember, this lag length is when the indication of serial correlation is greatly reduced. Each lag coefficient in the volatility structure is restricted to be positive and the sum of the coefficients on the lags is restricted to be less than one. This is to ensure that the forecast(s) of the employment growth volatility is positive and stationary.

Moreover, the inclusion of the neighboring states' growth will help to identify whether or not the ARCH effects are misclassified intertemporal space-time dependences. Failure to model these space-time dependences, if present, could cause a state's own variance to display time-dependence. That is, if a spatial time-dependencies are not properly modeled, they could appear as own time-dependence in the error distribution.

The standard spatial autoregressive process assumes a iid error, as described in LeSage and Pace (2009). Recall, Engle (1982) states that ARCH ef-

\footnotetext{
${ }^{1}$ The basis of this Chapter, using a STAR implementation of Chapter 2, was suggested by James LeSage PhD. Chapter 2 was rejected from being submitted at a journal. The reject letter included the comment that it would be more powerful if spatial spillover effects were accounted for.
} 


\section{Table 3.1}

\begin{tabular}{lcclcc}
\multicolumn{5}{c}{ Ljung Box Test Q-statistics for all 49 States } \\
\hline \multicolumn{5}{c}{ Using 1 1-Lag of neighboring states } \\
\hline State & 1-Lag & 6-Lag & State & 1-Lag & 6-Lag \\
Q-statistic & Q-statistic & & Q-statistic & Q-statistic \\
Alabama & 0.54 & 1.77 & Nebraska & 0.22 & 2.60 \\
Arizona & 0.81 & $18.45^{*}$ & Nevada & 0.00 & 6.83 \\
Arkansas & 0.36 & 1.53 & New Hampshire & 0.21 & 5.19 \\
California & 0.65 & 4.73 & New Jersey & 1.05 & 3.33 \\
Colorado & 0.00 & 2.86 & New Mexico & 0.00 & 1.13 \\
Connecticut & 0.03 & 4.06 & New York & 2.49 & 3.67 \\
Delaware & 0.17 & 0.33 & North Carolina & 0.42 & 3.92 \\
District of Columbia & 0.00 & 0.92 & North Dakota & $2.92^{*}$ & $34.76^{*}$ \\
Florida & 0.16 & 4.44 & Ohio & 0.11 & 6.15 \\
Georgia & 0.08 & 3.89 & Oklahoma & 0.02 & 5.01 \\
Idaho & 0.68 & 7.96 & Oregon & $5.93^{*}$ & $13.90^{*}$ \\
Illinois & $3.85^{*}$ & 6.43 & Pennsylvania & 0.52 & 4.50 \\
Indiana & 0.02 & 3.50 & Rhode Island & 0.44 & 1.10 \\
Iowa & $3.93^{*}$ & 7.76 & South Carolina & 0.03 & 4.32 \\
Kansas & 0.57 & 3.32 & South Dakota & 1.06 & 3.56 \\
Kentucky & 0.48 & 1.50 & Tennessee & 0.11 & 1.37 \\
Louisiana & 0.15 & 0.71 & Texas & 1.71 & $12.19^{*}$ \\
Maine & 0.55 & $16.60^{*}$ & Utah & 0.20 & $12.62^{*}$ \\
Maryland & 0.05 & 1.79 & Vermont & 0.83 & $16.36^{*}$ \\
Massachusetts & 0.03 & 1.78 & Virginia & 0.04 & 1.64 \\
Michigan & 0.15 & 1.90 & Washington & 0.12 & 3.11 \\
Minnesota & 0.43 & 4.95 & West Virginia & 0.01 & 2.70 \\
Mississippi & 0.12 & 0.60 & Wisconsin & 0.41 & 2.23 \\
Missouri & 0.43 & 3.48 & Wyoming & 0.14 & $20.53^{*}$ \\
Montana & $3.30^{*}$ & $15.28^{*}$ & & & \\
\hline *Statistically Significant at the & $10 \%$ level. & & & \\
\hline
\end{tabular}

fects can approximate real world complexity when structural breaks or omitted variables bias exist. Therefore with the spatial dependences accounted for, if ARCH effects are still present and the neighbor states employment growth effects are significant; then it is clear that the ARCH effects in Chapter 2 are not from omitted variable bias.

\subsection{Results of Empirics}

The results of the Ljung-Box Q-statistic using 1 lag of the neighboring states are displayed in 3.1 .

For simplicity, all states will be evaluated using the same lag length of the spatial weight matrix. As shown in Table 3.2, 44 out of the 49 states show no indication of autocorrelation. The 5 other states will keep the same structure for uniformity. With evidence of the serial correlation reduce, any time-dependences in the variance is not misread as autoregressive lags in the states own growth ${ }^{2}$ Therefore, there is no need to go beyond the first lag of

\footnotetext{
${ }^{2}$ Each shows statistically significant autocorrelation at the $12^{\text {th }}$, suggesting strong sea-
} 


\section{Table 3.2}

\begin{tabular}{lcclcc}
\multicolumn{5}{c}{ ARCH LM test ARCH-statistics for all 49 State } \\
\hline State & 1-Lag & $\mathbf{6 - L a g}$ & State & 1-Lag & 6-Lag \\
ARCH-statistic & ARCH-statistic & & ARCH-statistic & ARCH-statistic \\
Alabama & $2.93^{*}$ & $18.37^{*}$ & Nebraska & 1.08 & 8.41 \\
Arizona & $3.29^{*}$ & 9.23 & Nevada & $37.50^{*}$ & $53.27^{*}$ \\
Arkansas & $5.07^{*}$ & $44.63^{*}$ & New Hampshire & 2.03 & $81.65^{*}$ \\
California & $6.01^{*}$ & $12.02^{*}$ & New Jersey & $4.40^{*}$ & $21.75^{*}$ \\
Colorado & 2.50 & $19.77^{*}$ & New Mexico & 0.22 & 7.65 \\
Connecticut & $6.12^{*}$ & $11.28^{*}$ & New York & $3.22^{*}$ & 7.07 \\
Delaware & $23.05^{*}$ & $42.37^{*}$ & North Carolina & $20.93^{*}$ & $31.43^{*}$ \\
District of Columbia & 2.69 & 6.45 & North Dakota & $15.68^{*}$ & $23.71^{*}$ \\
Florida & $9.86^{*}$ & $41.92^{*}$ & Ohio & $11.66^{*}$ & $47.33^{*}$ \\
Georgia & $28.21^{*}$ & $41.58^{*}$ & Oklahoma & $8.93^{*}$ & $25.49^{*}$ \\
Idaho & 0.53 & 4.96 & Oregon & $7.93^{*}$ & $39.60^{*}$ \\
Illinois & 1.15 & $27.61^{*}$ & Pennsylvania & $5.03^{*}$ & $16.30^{*}$ \\
Indiana & 0.29 & $26.44^{*}$ & Rhode Island & $14.48^{*}$ & $16.06^{*}$ \\
Iowa & $17.12^{*}$ & $20.85^{*}$ & South Carolina & $5.02^{*}$ & $16.32^{*}$ \\
Kansas & $75.09^{*}$ & $89.43^{*}$ & South Dakota & $3.04^{*}$ & $14.64^{*}$ \\
Kentucky & $3.56^{*}$ & $22.67^{*}$ & Tennessee & 0.30 & 9.10 \\
Louisiana & $3.06^{*}$ & 4.58 & Texas & $6.54^{*}$ & $27.03^{*}$ \\
Maine & $22.04^{*}$ & $30.68^{*}$ & Utah & 0.09 & $45.57^{*}$ \\
Maryland & 0.63 & 3.80 & Vermont & $4.76^{*}$ & $44.61^{*}$ \\
Massachusetts & 2.69 & $62.11^{*}$ & Virginia & 0.00 & 7.39 \\
Michigan & $34.11^{*}$ & $79.02^{*}$ & Washington & $7.05^{*}$ & $53.38^{*}$ \\
Minnesota & $18.02^{*}$ & $23.39^{*}$ & West Virginia & 0.15 & $71.57^{*}$ \\
Mississippi & $3.93^{*}$ & $14.95^{*}$ & Wisconsin & $2.86^{*}$ & $48.35^{*}$ \\
Missouri & 1.25 & 6.52 & Wyoming & $5.58^{*}$ & $24.22^{*}$ \\
Montana & 1.05 & $23.88^{*}$ & & & \\
\hline * Statistically Significant & at the $10 \%$ level. & & & \\
\hline & & & & & \\
\hline
\end{tabular}

neighboring state(s) employment growth. The mean equation of 3.1 for each state will be structured as follows.

$$
\begin{aligned}
y_{i, t}=\beta_{i, 0}+\beta_{i, 1} y_{u s, t-1}+\sum_{a=1}^{6} \beta_{i, a+1} y_{i, t-a}+ & \sum_{d=1}^{11} \beta_{i, c+d+1} d u m_{d, t} \\
& +\lambda_{i, 1} W_{y_{i, t-1}}+\epsilon_{i, t}
\end{aligned}
$$

The next step is to test the persistence in the conditional volatility for employment growth, with the ARCH LM test as specified by Engle (1982). The results are displayed in Table $\mathbf{3 . 2}$.

As illustrated in Table $\mathbf{3 . 2}$ at the first lag, the null hypothesis of homoscedasticity is rejected at the $10 \%$ level for 33 of the 49 states For 6-lags, results indicate heteroskedasticity 38 of the 49 states at a $10 \%$ level of significance. Additionally, for one lag 16 states are significant at the $1 \%$ level, while 31 states are statistically significant at the 1\% level when using 6 lags for the volatility structure. These test results indicate that the employment growth sonality. 
rate demonstrates a time-depend volatility even when serial correlation, unit root, and spatial spillovers effect are accounted for.

Evidence suggests that ARCH effects are still present when accounting for spatial spillovers; this is an important discovery for several reasons. First, it supports the hypothesis that volatility cluster occurs in state-level employment growth. The existence of clustering with associated state neighbors, means cross border employment is not the main driver for it. Additionally, this provides additional evidence that volatility clustering should be accounted for measuring the Great Moderation. As discussed earlier Carlino, DeFina, and Sill (2007), and Morgan, Rime, and Strahan (2004), there has been a reduction in state-level employment growth volatility at the end of 1984. However, the effects of time-varying volatility were not accounted for, which means effects of the decline could be overstated. At a minimum, the regression is inefficient and since they are measuring the conditional variance, there is the potential bias.

The Great Moderation's effect on state-level employment. This should also be accounted for when studying the volatility in state-level employment. This effect will be examined by separating the dataset into two and excluding the permanent shock that occurred at the end of 1984, at the outset of the Great Moderation. Omitting this permanent shock is the final step in analyzing the $\mathrm{ARCH}$ effects of state employment growth. If $\mathrm{ARCH}$ effects are still present when excluding the Great Moderation, then it is not the only driver for the time-depended volatility.

The first dataset ranges from January 1960 through December 1983, the second ranges from January 1985 to December 2009. This leaves 287 and 294 observations for the first and second datasets, respectively. The same mean regression will be used to compute the ARCH LM test for these two datasets to keep the results comparable. Tables 3.3 \& 3.4 displays the ARCH LM test results for the pre and post 1984 periods.

Referring to Table $\mathbf{3 . 2}$ when the full sample is included, January 1960 to December 2009, 33 out of the 49 states illustrate ARCH effects. As shown in Table 3.3 at 1-lag length, 16 out of the 49 states exhibit ARCH effects statistically significant at the $10 \%$ level when using the pre-1984 data. This increases to only 18 states when using 6-lags. For post-1984, see Table 3.4, 18 and 22 states are significant at the 1 and 6 lag lengths, respectively.

The separation of the data into pre and post 1984, excluding the year 1984, causes the magnitude of states with ARCH effects to decrease from about two-thirds to about one-third. This steep decline would suggest that the "Great Moderation" caused a single permanent shock, resulting in a need to forecast only the conditional mean equation to predict the state level employment growth for the majority of the states when this period is not 


\section{Table 3.3}

ARCH LM test ARCH-statistics for all 49 States

Time Period: January 1960 through December 1983

\begin{tabular}{lcclcc}
\hline State & $\begin{array}{c}\text { 1-Lag } \\
\text { ARCH-statistic }\end{array}$ & $\begin{array}{c}\text { 6-Lag } \\
\text { ARCH-statistic }\end{array}$ & State & $\begin{array}{c}\text { 1-Lag } \\
\text { ARCH-statistic }\end{array}$ & $\begin{array}{c}\text { 6-Lag } \\
\text { ARCH-statistic }\end{array}$ \\
Alabama & 0.29 & 6.98 & Nebraska & 0.11 & 2.40 \\
Arizona & 0.09 & 2.09 & Nevada & $12.05^{*}$ & $15.98^{*}$ \\
Arkansas & 0.02 & 10.29 & New Hampshire & 0.60 & $15.58^{*}$ \\
California & 0.28 & 1.39 & New Jersey & 0.79 & 9.16 \\
Colorado & 0.00 & 6.02 & New Mexico & $3.93^{*}$ & 10.21 \\
Connecticut & $8.65^{*}$ & 8.47 & New York & 1.62 & 4.59 \\
Delaware & $9.21^{*}$ & $10.91^{*}$ & North Carolina & $4.35^{*}$ & 6.62 \\
District of Columbia & 0.67 & 2.87 & North Dakota & 0.47 & 7.47 \\
Florida & 1.15 & 3.69 & Ohio & 0.01 & $40.43^{*}$ \\
Georgia & $5.66^{*}$ & 9.83 & Oklahoma & $6.29^{*}$ & $15.80^{*}$ \\
Idaho & 0.89 & 3.88 & Oregon & 0.52 & 8.37 \\
Illinois & 0.88 & $12.39^{*}$ & Pennsylvania & 0.19 & $12.68^{*}$ \\
Indiana & 0.36 & $17.45^{*}$ & Rhode Island & $10.08^{*}$ & 10.44 \\
Iowa & $2.73^{*}$ & 6.31 & South Carolina & $3.99^{*}$ & 6.74 \\
Kansas & $30.13^{*}$ & $34.88^{*}$ & South Dakota & 0.44 & 3.50 \\
Kentucky & 0.84 & 7.49 & Tennessee & 0.10 & 3.53 \\
Louisiana & 0.41 & 2.14 & Texas & $6.45^{*}$ & 7.64 \\
Maine & $38.96^{*}$ & $50.21^{*}$ & Utah & 1.46 & $14.24^{*}$ \\
Maryland & 0.02 & 0.99 & Vermont & 0.11 & $11.73^{*}$ \\
Massachusetts & 0.10 & 10.51 & Virginia & 0.04 & 0.49 \\
Michigan & $7.39^{*}$ & $27.77^{*}$ & Washington & 0.01 & 5.28 \\
Minnesota & $17.81^{*}$ & $21.13^{*}$ & West Virginia & 0.13 & $31.27^{*}$ \\
Mississippi & $3.63^{*}$ & $20.29^{*}$ & Wisconsin & 0.00 & $15.19^{*}$ \\
Missouri & 1.59 & 3.92 & Wyoming & 0.20 & 7.06 \\
Montana & 0.38 & $14.27^{*}$ & & & \\
*Statistically Significant & at the $10 \%$ level. & & &
\end{tabular}




\section{Table 3.4}

\begin{tabular}{|c|c|c|c|c|c|}
\hline \multicolumn{6}{|c|}{ Time Period: January 1985 to December 2009} \\
\hline State & 1-Lag & 6-Lag & State & 1-Lag & 6-Lag \\
\hline & ARCH-statistic & ARCH-statistic & & ARCH-statistic & ARCH-statistic \\
\hline Alabama & $5.39^{*}$ & $16.02^{*}$ & Nebraska & 0.44 & $16.40^{*}$ \\
\hline Arizona & 0.24 & 10.64 & Nevada & 0.01 & 3.52 \\
\hline Arkansas & 0.21 & 3.20 & New Hampshire & 2.38 & $12.42^{*}$ \\
\hline California & 1.18 & 8.74 & New Jersey & 0.40 & $13.32^{*}$ \\
\hline Colorado & $3.06^{*}$ & $29.83^{*}$ & New Mexico & 0.11 & 10.29 \\
\hline Connecticut & 0.01 & 5.53 & New York & 0.02 & $20.00^{*}$ \\
\hline Delaware & $21.54^{*}$ & $35.40^{*}$ & North Carolina & 0.25 & 4.47 \\
\hline District of Columbia & $7.86^{*}$ & 9.74 & North Dakota & 1.87 & 10.58 \\
\hline Florida & 0.39 & $18.79^{*}$ & Ohio & 0.33 & $13.12^{*}$ \\
\hline Georgia & $45.48^{*}$ & $50.93^{*}$ & Oklahoma & $14.75^{*}$ & $40.30^{*}$ \\
\hline Idaho & $7.29^{*}$ & 6.99 & Oregon & $3.83^{*}$ & 7.47 \\
\hline Illinois & 0.01 & 6.52 & Pennsylvania & $12.31^{*}$ & $22.15^{*}$ \\
\hline Indiana & 0.50 & 3.74 & Rhode Island & $9.62^{*}$ & $12.78^{*}$ \\
\hline Iowa & 0.02 & 2.82 & South Carolina & 0.01 & 2.66 \\
\hline Kansas & 0.62 & $30.26^{*}$ & South Dakota & $5.39^{*}$ & 8.84 \\
\hline Kentucky & 0.02 & 2.84 & Tennessee & 0.85 & 3.39 \\
\hline Louisiana & 0.09 & 0.35 & Texas & $6.26^{*}$ & $29.66^{*}$ \\
\hline Maine & $4.44^{*}$ & 8.22 & Utah & 1.99 & $13.61^{*}$ \\
\hline Maryland & $9.86^{*}$ & $16.69^{*}$ & Vermont & $3.93^{*}$ & $15.78^{*}$ \\
\hline Massachusetts & $10.07^{*}$ & $19.70^{*}$ & Virginia & $3.71^{*}$ & 7.20 \\
\hline Michigan & 1.64 & 6.62 & Washington & 0.11 & $12.34^{*}$ \\
\hline Minnesota & 0.11 & 7.38 & West Virginia & 0.45 & 4.89 \\
\hline Mississippi & $3.66^{*}$ & 4.52 & Wisconsin & 1.96 & $19.47^{*}$ \\
\hline Missouri & 1.64 & $21.81^{*}$ & Wyoming & 0.47 & 8.33 \\
\hline Montana & 0.35 & 7.92 & & & \\
\hline
\end{tabular}

include. However for the insignificant states and a sample that includes the moderation period, a simultaneous estimation of the conditional mean and variance is needed.

\subsection{Conclusion}

This chapter is aimed at answering whether ARCH effects are present when accounting for spatial spillovers. In Chapter 2, we saw that $92 \%$ of the 51 states demonstrated ARCH effects at the 10\% level according to the Engle (1982) Lagrange Multiplier test. However, one could argue the presence of time-dependent volatility is misclassified by employment movements between the host state and its neighbors.

To test this hypothesis, a STAR model was employed. A single lag of the neighboring state(s) employment was used, with the remainder of the regression being a duplicate of that used in Chapter 2. This setup ensured any reduction in time-dependent volatility is attributed to movements in their neighboring state(s) employment growth. Table 3.2 illustrates that 
the presence of $\mathrm{ARCH}$ effects declines to $67 \%$ of the 49 states, excluding Alaska \& Hawaii.

Furthermore, the effect of the "Great Moderation" is examined by dividing the sample into two separate periods, pre and post 1984. The results, shown in Tables $3.3 \&$ 3.4 are a further decline in the number of states with statistically significant ARCH effects. The pre and post 1984 samples, tested at 1-lag length have $33 \%$ and $37 \%$ of the 49 states with significant ARCH effects.

It would be interesting to study the volatility structure of the remaining 18 states that still display statistically significant ARCH effects in the post 1984 sample. The question would be, does this knowledge improve forecast performance, i.e. decrease MSE, of employment growth? Additionally, does the volatility structure itself tell a story about a particular state's employment growth? 


\section{Final Remarks}

The collaboration of works are amalgamated and summarized. The principle of using non-linear models here was to increase our knowledge of economic forecasting, and reduce the mean squared error (MSE).

The first chapter illustrates the use of neural networks for discovering possible yield curve arbitrage opportunities. There are many theories about the dynamics of the yield curve. Given this heterogeneity, neural networks are a good choice for their adaptability. For each of the 6 different TTMs the ATSM and realized yield curves were through NAR and NARX networks. The difference between these two networks is NAR only includes autoregressive terms, while NARX also includes the use of external inputs. For NARX networks estimated here five macroeconomic variables are used, see Section 1.3.1.

The forecast results of each curve share advantages and disadvantages. For short-term bonds, 1-year or less, only the autoregressive terms are needed for forecasting a 3-month window. Macroeconomic variables aid in forecasting longer terms. Accompanied by comparing the forecast actual and ATSM yield curves, future arbitrage prospects can be surveyed. As shown in Figure 1.4, the three and six months TTM illustrate the greatest profitability. This concludes the first chapter.

The results of Chapter $2 \& 3$ are interlinked. In Chapter 2, the conditional variance for 47 out of the 51 states follow an autoregressive conditional heteroskedasticity $(\mathrm{ARCH})$ process when studying the univariate state-level employment growth. This is according to the Engle (1982) LM test and is displayed in Table 2.2. Given this knowledge the next step was to create forecasts of the volatility structure. The algorithm illustrated in Figures 2.1 $\& 2.2$ was used to determine the optimal ARCH structure for each state. Using a $\operatorname{GARCH}(1,1)$ as the volatility structure proved to provide the best out-of-sample forecast MSE, outperforming the ARCH structure and white noise process.

Chapter 3 arose from a criticism, by James LeSage Ph.D., that the volatility structure seen in Chapter 2 could be misclassified as spatial spillover ef- 
fects. The basis of this theory was tested using a STAR model. All this required was to add a spatial lag to the mean regression, which is shown in equation 3.1. The results, shown in Table 3.2, displayed a sharp decline in the number of the states with ARCH effects. At 1-lag length, 33 of the 49 states were statistically significant.

As an extension, the effects of the 'Great Moderation' were examined. This was done by splitting the dataset into before and after 1984. The pre1984 dataset only had 16 states with statistically significant ARCH effects, while post-1984 slightly increased to 18 states. This decline demonstrates that the 'Great Moderation' was a permanent shock on state-level employment growth. This shock should be properly accounted for in state employment growth forecast to ensure an unbiased MSE. 


\section{Bibliography}

(2011): Product HelpThe MathWorks, Inc., matlab r2011b edn., Neural Network Toolbox.

Amilon, H. (2003): "A Neural Network Versus Black-Scholes: A Comparison of Pricing and Hedging Performances," Journal of Forecasting, 22, $317-335$.

Anders, U., O. Korn, and C. Schmitt (1998): "Improving the Pricing of Options: A Neural Networks Approach," Journal of Forecasting, 17, 369-388.

At-Sahalia, Y., and R. Kimmel (2010): "Estimating Affine Multifactor Term Structure Model Using Closed-Form Likelihood Expansions," Journal of Financial Economics, 98, 113-144.

Blanchard, O., and J. Simon (2001): "The Long and Large Decline in U.S. Output Volatility," .

Bliss, R. R. (1997): "Testing term structure estimation methods," Advance in Futures and Options, 9, 197-231.

Bollerslev, T. (1986): "Generalized Autoregressive Conditional Heteroskedasticity," Journal of Econometrics, pp. 307-327.

Campbell, S. (2004): "Macroeconomic Volatility, Predictability and Uncertainty in the Great Moderation: Evidence From the Survey of Professional Forecasters," Finance and Economics Discussion Series, pp. 1-38.

Carlino, G., R. DeFina, and K. Sill (2007): "The Long and Large Decline in State Employment Growth Volatility," Working paper NO. 0711.

Dai, Q., And K. Singleton (2000): "Specification Analysis of Affine Term Structure Models," Journal of Finance, 55, 769-809. 
Duarte, J., F. A. Longstaff, and F. Yu (2007): "Risk and Return in Fixed-Income Arbitrage: Nickels in Front of a Steamroller?," The Review of Financial Studies, 20(3), 769-809.

Duffee, G. (2002): "Term Premia and Interest Rate Forecasts in Affine Models," Journal of Finance, 57, 405-443.

Enders, W. (2010): Applied Econometric Time Series. Wiley.

Engle, R. (1982): "Autoregressive Conditional Heteroscedasticity with Estimates of the Variance of United Kingdom Inflation," Econometrica, 50(4), 987-1007.

Engle, R., And D. KARFT (1983): "Multiperiod forecast error variances of inflation estimated from ARCH models," Applied time series analysis of economic data (Bureau of the Census, Washington, DC), pp. 293-302, in: A. Zellner, ed.

Fausett, L. (1993): Fundamentals of Neural Neural Networks: architectures, algorithms, and applications. Pearson.

LeSage, J., and R. K. PaCe (2009): Introduction to Spatial Econometrics. CRC Press.

McCulloch, J. H. (1975): "The Tax-Adjusted Yield Curve," J, 30, 811830.

(1990): Handbook of Monetary Economics, vol. 1. North Holland.

Mculloch, J. H., ANd H.-C. Kwon (1993): "U.S. term structure data," Ohio State University Working Paper \# 93-6.

Morgan, D., B. Rime, and P. Strahan (2004): "Bank Integration and State Business Cycles," Quarterly Journal of Economics, 119, 1555-1584.

Owyang, M., J. Piger, and H. Wall (2008): "A State-Level Analysis of the Great Moderation," Regional Science and Urban Economics, 38, $578-589$.

Stock, J., And M. Watson (2002): "Has the Business Cycle Changed and Why?," NBER Working Paper Series, 17.

VAsiceK, O. (1977): "An Equilibrium Characterization of the term structure," Journal of Financial Economics, 5, 177-188. 